\title{
Sovereign Risk, Currency Risk, and Corporate Balance Sheets*
}

\author{
Wenxin Du \\ Federal Reserve Board \\ Jesse Schreger ${ }^{\dagger}$ \\ Harvard University
}

May 22, 2015

\begin{abstract}
We examine the question of why a government would default on debt denominated in its own currency. Using a newly constructed dataset of 14 emerging markets, we document that the private sector continues to borrow from abroad in foreign currency while sovereigns increasingly borrow from foreigners in local currency. Because depreciation can be very costly for a corporate sector with a currency mismatch due to foreign currency liabilities, emerging market sovereigns may still prefer to default on local currency sovereign debt rather than inflate the debt away. Using our crosscountry dataset, we show that a higher reliance on external foreign currency corporate financing is associated with a higher default risk on sovereign debt. We quantify the effects of corporate balance sheet mismatch on sovereign credit risk by introducing local currency sovereign debt and private currency mismatch into a standard sovereign debt model. The model demonstrates how the currency composition of corporate borrowing affects the sovereign's incentive to inflate or default in times of fiscal stress. Reductions in the share of private external debt in foreign currency can lead to significant reductions in sovereign default risk. A calibration of the model generates the empirical patterns of currency and credit risk in local currency sovereign debt documented in Du and Schreger (2015).
\end{abstract}

\footnotetext{
${ }^{*}$ We are especially grateful to Gita Gopinath, Ken Rogoff, John Campbell, Jeff Frieden and Jeff Frankel for their invaluable advice and guidance. We thank Serkan Arslanalp, David Baqaee, Carol Bertaut, Laura Blattner, Luigi Bocola, Max Eber, Emmanuel Farhi, Herman Kamil, Ricardo Hausmann, Illenin Kondo, Marcio Garcia, Matteo Maggiori, Andrea Raffo, Romain Raniciere, Carmen Reinhart, John Rogers, Jeremy Stein, Alexandra Tabova, Adrien Verdelhan, Vivian Yue, and seminar participants at various institutions for comments and suggestions. We thank Lina Beatriz Gómez Castillo, Joao Henrique Freitas, Emmanuel Kohlscheen, and Renzo Jiménez Sotelo for assistance in acquiring and interpreting various data sources. Conor Howells provided excellent research assistance. The views in this paper are solely the responsibility of the authors and should not be interpreted as reflecting the views of the Board of Governors of the Federal Reserve System or any other person associated with the Federal Reserve System. All errors are our own.

${ }^{\dagger}$ Schreger (Corresponding author): Department of Economics, Harvard University, Littauer Center, Cambridge, MA 02138. Email: schreger@fas.harvard.edu. Cell: 914-645-9519. Du: Federal Reserve Board, 20th and C Street NW, Washington, D.C. 20551. Email: wenxin.du@frb.gov.
} 


\section{Introduction}

During the 1980s, 1990s, and early 2000s, a number of sovereign debt crises engulfed emerging markets. While the details of each sovereign debt crisis were different, the broader story remained the same: the government borrowed from foreign investors in foreign currency (FC) during good times only to later default on their external debt as economic conditions deteriorated. In response to these crises, emerging market governments curtailed their FC borrowing and moved towards borrowing in their local currency (LC). Using a newly constructed comprehensive dataset on the currency composition of sovereign and corporate external debt, we find that over the last decade major emerging market sovereigns went from having around $85 \%$ of their external debt in FC to borrowing more than half of their external sovereign debt in their own currency. By contrast, even as governments were dramatically changing the way they finance themselves, the private sector continued to borrow from foreigners almost entirely in FC.

Despite their shift towards LC debt, emerging market (EM) sovereigns continue to be charged a positive credit spread when they borrow in their own currency. In our previous work (Du and Schreger, 2015), we calculate a measure of the default-free LC interest rate using cross-currency swaps and show that emerging market sovereigns borrow at a significant credit spread above the risk-free rate in their own currency. These positive LC credit spreads suggest that nominal LC sovereign bonds are not default-free. Furthermore, LC credit spreads remain positive even for countries where the sovereign external liabilities are almost exclusively denominated in LC, such as Thailand, Malaysia and South Korea. This raises the question of why a sovereign would default on debt denominated in its own currency when it could instead inflate the debt away. The simplest answer is that it would default if it were less painful to do so than to experience inflation high enough to restore fiscal solvency.

In this paper, we argue that the private sector's continuing reliance on external FC debt raises the cost of inflating away sovereign debt and explains why sovereign default risk remains even though governments increasingly borrow in their own currency. If the private sector earns revenues in LC but has borrowed extensively in FC, a depreciation could adversely affect firm net worth, which in turn could reduce aggregate output in the presence of firm financial constraints. The idea that corporate balance sheet mismatch could make depreciations contractionary was studied extensively following the Asian Financial Crisis. ${ }^{1}$ The theoretical contribution of this paper is to demonstrate how these contractionary effects working through corporate balance sheets can be a source of default risk on LC sovereign debt.

We begin by documenting the dramatic contrast between the currency denomination of sovereign and corporate external portfolios in 14 major emerging markets. We find that sovereigns are increasingly borrowing in LC from foreign investors, while corporate external liabilities still remain largely in FC. Since 2003, we find that the average fraction of external sovereign debt in LC increased from around $15 \%$ to almost $60 \%$. However, during this same period, the share of external

\footnotetext{
${ }^{1}$ See, for instance, Krugman (1999), Céspedes et al. (2004), Gertler et al. (2007), and Aghion et al. (2000, 2001, 2004). Korinek (2010) explores the effects of the private sector borrowing in foreign currency.
} 
private sector debt in LC only increased from $7 \%$ to $10 \%$. Figure 1 documents the sharp rise of foreign participation in LC sovereign debt markets and shows that foreign holdings now account for approximately one-third of all outstanding local currency sovereign debt.

We then demonstrate the relevance of the balance sheet channel by showing that Brazilian and Mexican firms that are more indebted in FC are more adversely affected by a currency depreciation than other firms. We do so by showing that firms with more of their liabilities in FC are more sensitive to changes in the exchange rate, measured through changes in credit spreads and excess equity returns.

The composition of corporate balance sheets has significant implications for sovereign credit risk. We use our cross-country dataset on the currency composition of external liabilities to show that a higher reliance on external FC corporate financing is associated with a higher default risk on sovereign debt. In a panel regression, conditional on the variables the literature has shown to explain sovereign credit spreads, we find that an increase in the ratio of private FC debt-to-GDP of $10 \%$ is associated with an approximately 30 basis point increase in the sovereign LC credit spread.

Motivated by the dramatic changes in emerging market borrowing and the empirical evidence on the importance of private FC debt for sovereign risk, we introduce LC sovereign debt and an entrepreneurial sector with FC external liabilities and LC revenues into the canonical Eaton and Gersovitz (1981) sovereign default model, as formulated in a quantitative framework by Aguiar and Gopinath (2006) and Arellano (2008). The model demonstrates that the borrowing patterns of the private sector can have large effects on the nature of sovereign risk. When the private sector is highly mismatched, meaning private debt is overwhelmingly in FC but revenues are in LC, the sovereign is reluctant to allow an exchange rate depreciation to reduce the real value of its debt, generating a "Fear of Floating" as in Calvo and Reinhart (2002). In this case, when the government considers whether to default or use inflation to reduce the fiscal burden of sovereign debt repayments, it is relatively more inclined to explicitly default than to inflate away the debt because of the effect of depreciation on the private sector.

When the sovereign is forward-looking but cannot commit to state-contingent policies, the sovereign's inability to commit not to inflate or default generates a debt Laffer curve, where the market value of outstanding sovereign debt initially increases with the face value of debt before reaching the peak of the curve. In equilibrium, the sovereign borrows on the good side of the debt Laffer curve, where revenue is increasing with the face value of the debt. If the temptation to inflate away the debt occurs at lower borrowing levels than the temptation to default, then a government that internalizes the effect of the amount it borrows on the interest rate it is charged may never borrow enough to potentially default. We demonstrate that this is the case when the corporate sector is not overly reliant on FC external financing, meaning that sovereign debt can be free from default risk in equilibrium when there are low levels of corporate currency mismatch.

A calibration of the dynamic model to the average share of corporate debt in our panel of emerging markets produces simulated moments of currency and credit risk very similar to the crosscountry mean empirical moments documented in our previous work (Du and Schreger (2015)). The 
model suggests that relatively small reductions in the share of private external borrowing in FC could significantly reduce the probability of a sovereign default. The model's prediction on the rate at which sovereign credit risk declines with the share of LC corporate debt finds strong support in the data.

This paper makes two primary contributions. First, we provide a comprehensive account of the currency composition of external liabilities by sector in emerging markets. This contributes to the work on "Original Sin," beginning with Eichengreen and Hausmann (1999), and the evolution of the currency composition of external liabilities documented in Lane and Shambaugh (2010). A series of recent papers document the rapid growth in foreign participation in domestic LC sovereign debt markets, for example, Burger and Warnock (2007), Burger et al. (2012), Burger et al. (2014) and Arslanalp and Tsuda (2014). We combine data on foreign participation in domestic sovereign debt markets with data on international debt securities and cross border loans and demonstrate how including foreign ownership of domestic debt in calculations of external debt significantly changes the aggregate currency composition of sovereign external liabilities. Vulnerabilities in the emerging market corporate sector coming from external foreign currency borrowing have recently been highlighted by the BIS in Avdjiev et al. (2014) and Chui et al. (2014). We argue that these vulnerabilities in the corporate sector are a source of sovereign risk. The second major contribution of the paper is that we offer a new explanation for why nominal sovereign debt may not be default free. The history of sovereign default on domestic debt is addressed in detail in Reinhart and Rogoff $(2008,2011)$. We contribute to the large literature on the determinants of sovereign credit risk by demonstrating how the borrowing patterns of the private sector affect sovereign risk. ${ }^{2}$ The theoretical section contributes to the international finance literature on sovereign default by introducing LC sovereign debt and a mismatched corporate sector into the Aguiar and Gopinath (2006) and Arellano (2008) formulation of the Eaton and Gersovitz (1981) model. We build on recent papers that introduce long-term bonds into this framework, such as Hatchondo and Martinez (2009), Arellano and Ramanarayanan (2012), and Chatterjee and Eyigungor (2012). Our corporate sector builds on Céspedes et al. (2004) and Gertler et al. (2007), who study a Bernanke et al. (1999) financial accelerator in the open economy when firms potentially borrow in foreign currency. Our contribution is to integrate a simplified version of this channel into a sovereign default framework to examine how the cost of depreciation arising from this balance sheet channel can affect sovereign risk. We contribute to a growing literature on the default risk on nominal debt, including recent work by Aguiar et al. (2013), Corsetti and Dedola (2013), Araujo et al. (2013) and Sunder-Plassmann (2013), by exploring a channel through which differences in private borrowing behavior explain why the risk of sovereign default on nominal debt varies across countries.

Our paper is organized as follows. In Section 2, we review the evidence of credit risk on LC denominated debt documented in our earlier work (Du and Schreger, 2015). Section 3 constructs measures of the currency composition of external sovereign and corporate portfolios and examines

\footnotetext{
${ }^{2}$ See, for instance, Edwards (1984), Eichengreen and Mody (1998), Hilscher and Nosbusch (2010), Longstaff et al. (2011) and Uribe and Yue (2006).
} 
the contrasting behavior of sovereign and corporate external borrowing. Section 4 provides empirical evidence on the effect of corporate FC liabilities on the vulnerability of firms to exchange rate depreciation and the relationship between private FC debt and sovereign default risk. Sections 5 and 6 present a new sovereign default model featuring LC sovereign debt and FC corporate financing. Section 7 concludes.

\section{Measuring Credit Risk on LC Sovereign Debt}

The first challenge in examining the default risk on LC sovereign debt is to measure it separately from currency risk. When a country borrows in a foreign currency, for instance the US dollar, the credit spread is measured as the difference between the yield a borrowing government pays and the yield on a U.S. Treasury bond of the same duration. However, when a government borrows in its own currency, the difference in the yield it pays versus what the U.S. government pays to borrow in dollars might be compensating investors for the risk that the local currency depreciates ("currency risk") as well as the risk that the sovereign explicitly defaults on the debt ("credit risk"). In our previous work, Du and Schreger (2015), we propose a way to measure the credit risk on LC sovereign debt in emerging markets that separates the credit risk from the currency risk. We define the LC credit spread $\left(s_{t}^{L C C S}\right)$ as the gap between an emerging market sovereign bond yield $\left(y_{t}^{L C}\right)$ and the LC risk-free rate implied by the U.S. Treasury bond yield $\left(y_{t}^{*}\right)$ and the fixed-for-fixed LC/USD cross currency swap rate $\left(\rho_{t}\right)$,

$$
s_{t}^{L C C S}=y_{t}^{L C}-\left(y_{t}^{*}+\rho_{t}\right),
$$

The way to understand the LC risk-free rate $\left(y_{t}^{*}+\rho_{t}\right)$ is to think of it as the nominal interest rate that the US government (assumed to be default-free) would pay if it issued a bond in an emerging market currency. The fixed-for-fixed LC/USD cross currency swap rate $\rho_{t}$ is the interest rate differential an investor receives when converting fixed dollar cash flows into fixed LC cash flows. When dealing with zero-coupon bonds, $\rho_{t}$ is simply the long-horizon forward premium. By using cross currency swaps to convert the fixed dollar cash flows from a US Treasury into fixed LC cash flows, we construct a synthetic LC instrument that is free from sovereign default risk. The LC credit spread measures how much an emerging market sovereign pays to borrow relative to this default-free benchmark in its own currency. In other words, the LC credit spread measures the deviation from long-term covered interest rate parity between a nominal sovereign bond and a US Treasury.

If emerging market sovereign debt were free from credit risk, the LC credit spread should equal zero in the absence of arbitrage. However, when we look at emerging markets, we see that they borrow at a significant credit spread even in their own currency. From 2005-2012, for 13 emerging markets, ${ }^{3}$ the mean LC credit spread is 128 basis points for five-year zero-coupon bonds. This is in

\footnotetext{
${ }^{3}$ The included countries are Brazil, Colombia, Hungary, Indonesia, Israel, South Korea, Malaysia, Mexico, Peru, Poland, South Africa, Thailand and Turkey. Russia is excluded as the local currency debt market was not investable for foreigners during much of the period. See Du and Schreger (2015) for details on the segmentation of Russia's domestic debt market.
} 
stark contrast to a developed economy like the United Kingdom, where the mean LC credit spread is under 10 basis points on average over the same time period.

Throughout the paper, we refer to $s^{L C C S}$ as the credit risk of an LC bond and $\rho$ as the currency risk component of the bond. Using the LC credit spread definition given in Equation 1, we can decompose the nominal yield differential between an emerging market sovereign LC bond and a U.S Treasury $\left(s^{L C / U S}\right)$ into a credit and a currency component:

$$
s_{t}^{L C / U S}=s_{t}^{L C C S}+\rho_{t} .
$$

In Figure 2, we plot the cross-country average of the nominal spread $s^{L C / U S}$, credit risk $s^{L C C S}$ and currency risk $\rho$ on nominal LC sovereign debt. This broad pattern, with around $75 \%$ of the nominal spread composed of currency risk and the remaining $25 \%$ composed of credit risk, will be the key moment of interest in the dynamic model. In appendix Table A1, we report summary statistics for currency and credit risk in each of our sample countries.

In this paper, we do not consider selective defaults across LC and FC sovereign debt and abstract from the effects various capital market frictions in affecting sovereign credit spread measures. ${ }^{4}$ In Figure 3, we plot a time series of the cross-country mean LC credit spread and the spread on FC debt (implied from credit default swaps (CDS)) for our sample countries. LC and FC credit spreads are strongly correlated, and have even recently converged to the same level on average. Because LC credit spreads measure default risk on LC debt and CDS spreads measure default risk on FC debt, the convergence of the credit spreads on the two type of debt suggests a market expectation for simultaneous default and restructuring. Indeed, between 1996-2012 Jeanneret and Souissi (2014) document 31 defaults on LC debt, 27 defaults on FC debt, with 15 of these instances being simultaneous default on both types of debt.

\section{The Changing Composition of Emerging Market External Port- folios}

In this section, we combine various national and international data sources to construct measures of the currency composition of the external liabilities of the sovereign and corporate sectors in 14 major emerging markets. We document that emerging market sovereigns have shifted away from borrowing externally in foreign currency to borrowing primarily in LC. However, the external liabilities of the corporate sector remain heavily dollarized.

\subsection{Dataset Construction and Definitions}

The goal of this section is to construct a measure of the currency composition of emerging market external debt by the government and corporate sector. We define "external debt" as any public

\footnotetext{
${ }^{4}$ We address the effects of factors such as capital controls, liquidity in the currency swap market, counterparty risk, and incomplete integration between domestic and external debt markets in detail in Du and Schreger (2015).
} 
or private debt issued by emerging market entities and owed to nonresidents, regardless of the market of issuance. We can then classify external debt along three dimensions: currency, market of issuance, and sector. First, in terms of the currency classification, LC refers to debt for which the principal and coupons are denominated in the currency of the country of issuance and foreign currency debt is debt for which the principal and coupons are denominated in another country's currency. Second, in terms of the market of issuance classification, international debt is defined as debt issued under foreign law in international markets and domestic debt is debt issued in domestic markets under domestic law. Finally, in terms of the sector classification, government debt is debt issued by central and local governments and social security funds and corporate debt is debt issued by the private sector of the economy. Table 1 illustrates the relationship between currency, market and sector classifications of emerging market external debt.

In the rest of this subsection, we discuss the construction of different components of external debt by currency and sector for debt securities and cross-border loans and deposits. We restrict our analysis to private lending to emerging markets, excluding official loans made by bilateral and multilateral organizations.

\subsubsection{Debt Securities}

In this section, we discuss the construction of the amount of external debt securities outstanding by currency. We start with international debt. We assume that all international debt securities are held by nonresidents and thus count toward external debt. We obtain the amount of international debt securities outstanding for the sovereign and corporate sectors from the BIS debt securities statistics. The BIS does not report the currency composition of international debt securities at the country level. We address this data gap as follows. Only a few countries (Brazil, Colombia, Mexico, Peru and Russia) have ever issued LC denominated bonds in the international market. We construct amounts outstanding for these individual LC issuances and treat the rest of BIS sovereign international debt securities as FC. We obtain currency shares of corporate international debt securities by aggregating the entire universe of individual corporate bonds recorded in the Thomson One bond database for our sample countries. ${ }^{5}$

Second, in terms of non-resident holdings of domestic debt by currency, we assume that nonresident holdings of $\mathrm{FC}$ domestic debt are equal to zero. This assumption is reasonable because the outstanding amount of FC domestic debt is negligible. ${ }^{6}$ The dataset of nonresident holdings of domestic LC sovereign debt for our 14 emerging markets comes from individual central banks, finance ministries, and the Asian Development Bank. The detailed data sources are given in the appendix. In simultaneous work, Arslanalp and Tsuda (2014) compiled a dataset of foreign holdings

\footnotetext{
${ }^{5}$ The dataset includes all major characteristics of a bond deal, including issuance and maturity dates, currency of denomination and the market of issuance, etc. For each sample country, we aggregate net issuance of corporate bonds by currency (LC and FC) and by market (onshore and offshore) since 1998 to estimate outstanding amounts in each category.

${ }^{6}$ For the countries with data available, we see that nonresident holdings of indexed and FC domestic debt are very small relative to nonresident holdings of LC domestic debt.
} 
of domestic debt from similar sources, focusing on how this change affected emerging market vulnerability to funding shocks. There is no comparable national data available on foreign holdings of domestic corporate debt. Our estimation is based on our data on non-resident holdings of domestic LC sovereign debt and the U.S. Treasury International Capital (TIC) data. The TIC data measures U.S. investor holdings of corporate and sovereign debt and is the only ownership source of corporate debt we have by currency. ${ }^{7}$ To approximate foreign holdings of domestic LC corporate debt, we make the assumption that U.S. investors compose an equal share of foreign investors in domestic corporate and domestic sovereign debt. For example, if U.S. investors account for 25 percent of total nonresident holdings of domestic LC sovereign debt for a given country, and hold $\$ 250$ million of LC corporate debt, we estimate that total foreign holdings of domestic LC corporate debt are equal to $\$ 1$ billion. ${ }^{8}$

\subsubsection{External Loans and Deposits}

In addition to debt securities, we also consider cross-border loans and deposits as part of external debt. The data on total external loans and deposits come from the BIS Locational Banking Statistics (LBS). ${ }^{9}$ The level of external loans for country $i$ is given by the total claims of all BIS reporting countries against counterparty country $i$. Most developed and large developing countries are BIS reporting countries, and thus aggregate lending of BIS reporting countries to country $i$ represents the majority of private sector cross-border loans from the rest of the world to country $i$. These portions of the data are publicly available.

To estimate the currency composition of these external loans, we use the restricted BIS Locational Banking Statistics, which classifies the currency of cross-border loans and deposits into reporting countries' home currencies, dollar, euro, yen, British pound, Swiss francs and residual currencies. From an emerging market country $i$ 's perspective, the amount of loans and deposits denominated in the residual currencies of the reporting countries gives a very good proxy of the level of loans and deposits denominated in the LC of country $i$. To obtain the sectoral breakdown of cross-border loans, we construct the sovereign/corporate share by aggregating the entire universe of cross-border loans outstanding in the Thomson loan database. ${ }^{10}$

\subsection{Comparison between Sovereign and Corporate Currency Portfolios}

By combining these various sources, we find that the share of LC sovereign debt in the external portfolio increased from 15 percent to 60 percent over the past decade. Figure 4 plots the crosscountry mean of the share of sovereign, corporate and total debt in LC from 2003-2012. However, EM sovereigns are not issuing debt in their own currency in international markets. Instead, foreign

\footnotetext{
${ }^{7}$ We use the currency shares of corporate and sovereign debt calculated by Bertaut and Tabova (2014), which provides longer time series than the data published by the U.S. Treasury.

${ }^{8}$ More details on the TIC data and estimation of non-resident holdings of LC corporate debt securities can be found in Appendix A.2.3.

${ }^{9}$ More details on the LBS dataset can be found in Appendix A.2.4.

${ }^{10}$ We define the loan deal cross-border if at least one bookrunner of the deal is a foreign bank.
} 
investors are buying sovereign debt issued under domestic law. While the share of FC is shrinking dramatically for sovereign external liabilities, external emerging market corporate debt remains primarily in FC. The shares of LC in corporate debt and private external bank loans have increased at a much slower pace, reaching about 10 percent in 2012. These aggregate numbers mask a substantial degree of cross-country heterogeneity, as can be seen in Table 2 and Appendix Figure A1. For instance, by 2012 over $90 \%$ of Thailand's external sovereign debt to private creditors was in LC, but less than $15 \%$ of Colombia's external sovereign debt was in LC. Despite this cross-country heterogeneity, in all of our sample countries, the sovereign borrows more in LC as a share of total external debt than does the private sector.

In Figure 5, we plot the cross-country mean LC/GDP and FC/GDP ratios by year. While we see in the right panel that the FC/GDP ratios are stable across time, the LC/GDP ratio has nearly quintupled for sovereigns over the last decade. However, even as the growth of sovereign external LC borrowing has dramatically increased, corporate external LC borrowing has stayed very low. At the end of 2012 for our 14 sample countries, of the roughly $\$ 1$ trillion of EM external sovereign debt outstanding, $60 \%$ is in LC and $40 \%$ is in foreign currency. Foreign holdings of domestic LC sovereign debt account for 95 percent of sovereign external LC liabilities. Of the roughly $\$ 1.9$ trillion in external EM corporate debt outstanding, approximately $90 \%$ is denominated in foreign currency. In contrast to the sovereign, 90 percent of corporate external LC liabilities take the form of direct issuance of LC corporate international debt and cross-border loans, as opposed to foreign investment in local currency debt markets.

\section{Firm-Level and Macro Effects of Corporate FC Liabilities}

Having documented the changing external borrowing patterns in emerging markets, we now provide evidence that this currency composition matters. We will examine the importance of FC corporate debt at the firm-level and at the country-level. Using Brazilian and Mexican firm-level data, we show that firms more heavily indebted in foreign currency are more vulnerable to depreciation. At the country level, we provide evidence on the linkage between corporate balance sheets and sovereign credit risk. We first present cross-country evidence that countries with a higher reliance on FC corporate financing tend to have higher sovereign credit risk. We then show in a panel regression with country fixed effects that an increase in the corporate FC debt-to-GDP ratio is associated with an increase in the sovereign credit spread.

\subsection{Firm-Level Evidence}

The dollarization of external liabilities for the corporate sector poses a particular concern if it is not matched by FC assets, FC revenues, or FX derivative hedging. Firms may have FC revenues

and hence issue FC debt to hedge the currency risk of their revenues. ${ }^{11}$ In addition to operational

\footnotetext{
${ }^{11}$ Michaux (2012) presents evidence of such firm-level hedging for Mexico.
} 
hedging, firms can enter into FX derivative contracts to hedge their currency exposure. ${ }^{12}$ Despite rapid growth of FX derivatives markets over the past decade, in Appendix Section A.4, we use data from the Depository Trust and Clearing Corporation (DTCC) to argue that these currency derivative markets are currently much smaller than the amount of FC debt outstanding in most of emerging markets, making it very unlikely these liabilities are fully hedged. Despite operational and derivative hedging possibilities, we use firm-level data from Brazil and Mexico and document that reliance on FC liabilities remains a significant explanatory variable for cross-sectional variations in firm vulnerability to exchange rate depreciation.

We show the values of firms with more FC liabilities are more sensitive to exchange rate movements. In particular, firms with more FC liabilities experience larger increases in credit spreads and lower equity returns in response to currency depreciation. While we make no claim that the currency composition of firm liabilities is exogenous or is necessarily sub-optimal from a private perspective, the goal is to show that the corporate sector does not perfectly hedge its currency exposure and so firms that borrow more in dollars load more heavily on the exchange rate. If the debt composition were chosen only with the goal of hedging operations and assets, then we would not expect to see any differential loading of firms with more FC debt on the exchange rate.

The question of which firms are more sensitive to exchange rate movements is one that has been addressed in the macroeconomics and development literature with a focus on investment. A number of past studies, such as Aguiar (2005), Cowan et al. (2011), and papers surveyed in Galindo et al. (2003) and Frankel $(2005,2010)$ find support for the idea that mismatched firms invest less following a depreciation. Kim et al. (2012) present evidence for South Korea during the Asian Financial Crisis that smaller, non-exporting firms with foreign currency debt were particularly affected through the balance sheet channel. However, some counterexamples exist, such as Bleakley and Cowan (2008). In the finance literature, a large literature has examined equity market exposure to currency risk without directly focusing on the cross-sectional relationship between foreign currency liabilities and the sensitivity of firm value to exchange rate depreciation (See, for instance, Adler and Dumas (1984), Bartram et al. (2010), Bodnar and Wong (2003), Griffin and Stulz (2001), Dominguez and Tesar (2006), Chue and Cook (2008), and Kedia and Mozumdar (2003)).

We focus on Brazil and Mexico because firms in these two countries report the currency composition of their liabilities in their quarterly accounting statements. We obtain fixed-coupon dollar corporate bond yields and equity returns at the firm-level and match them to corporate balance sheet data. All data are from Bloomberg and more details on the firm-level data can be found in Appendix A.3. Rather than examining real variables like output and investment, we look instead at market-based measures of changes in the firm value, stock returns and changes in credit spreads. The advantage of using asset prices over slow-moving output and investment variables is that we are able to focus on asset price and exchange rate movements for the exact same horizon. To measure the firm's reliance of FC financing, we construct two versions of our key balance sheet variable, the

\footnotetext{
${ }^{12}$ See, for instance, Kamil (2009) on firm incentives to hedge currency risk under difference exchange rate regimes.
} 
FC Liability Ratio $(F C L R)$

$$
\begin{aligned}
F C L R^{L i a b} & =\frac{\text { Foreign Currency Liabilities }}{\text { Total Liabilities }} \\
F C L R^{\text {Asset }} & =\frac{\text { Foreign Currency Liabilities }}{\text { Total Assets }}
\end{aligned}
$$

We normalize the amount of FC liabilities by both total assets and total liabilities to measure firm reliance on $\mathrm{FC}$ debt that is comparable across firms. We measure the quarterly exchange rate depreciation

$$
\Delta e_{t+1}=\log \left(\mathcal{E}_{t+1}\right)-\log \left(\mathcal{E}_{t}\right)
$$

where $\Delta e_{t+1}>0$ corresponds to a depreciation of the LC.

\subsubsection{Corporate Debt and Equity Returns}

For every publicly traded Brazilian and Mexican company, we collect all available equity return data and secondary market bond prices from 2000 to the present. For bonds, the primary object we work with is the bond's yield to maturity, which we will denote $y_{t}^{C o r p}$. For every date with bond pricing data, we match the bond to a zero-coupon Treasury with the same remaining maturity. We use the Nelson-Siegel-Svennson coefficients estimated by Gurkaynak et al. (2007) to calculate the yield to maturity on a U.S. Treasury bond, defined as $y_{t}^{U S}$. We then calculate the credit spread between the corporate bond and a US Treasury as

$$
s_{i, j, t}^{C o r p / U S}=y_{i, j, t}^{C o r p}-y_{t}^{U S}
$$

where $i$ indicates the firm and $j$ indicates in the individual corporate bond, and $t$ indicates the quarter of the observation.

The change in the credit spread is given by

$$
\Delta s_{i, j, t+1}^{C o r p / U S}=s_{i, j, t+1}^{C o r p / U S}-s_{t}^{C o r p / U S}
$$

Because equity returns are calculated in LC, we calculate the excess return as the return over the local risk-free rate, using the 3-month deposit rate from Global Financial Data as the short-term local risk-free rate. We denote the excess holding period return over the risk-free rate as $R_{i, t+1}$.

We examine the change in the credit spread and the excess equity return over a quarterly holding period using non-overlapping quarters. The key specification we run is

$$
\begin{aligned}
Y_{i, j, t+1} & =\alpha+\beta_{0} \Delta e_{t+1}+\beta_{1}\left(\Delta e_{t+1} \cdot F C L R_{i, t}\right) \\
& +\delta_{0} W_{t+1}+\delta_{1}\left(W_{t+1} \cdot F C L R_{i, t}\right)+\gamma\left(\Delta e_{t+1} \cdot Z_{i, t}\right)+\epsilon_{i, j, t+1}
\end{aligned}
$$


where $Y_{i, j, t+1}$ is either the change in the corporate credit spread $\Delta s_{i, j, t+1}^{\text {Corp } / U S}$ or the excess holding period equity return $R_{i, t+1}, W_{t+1}$ is a common country level factor, such as the equity market return or the change in the sovereign bond index. $Z_{i, t}$ is a vector of corporate observables such firm size (log of market capitalization) or Market/Book value. As indicated by the timing subscripts, we use contemporary values of balance sheet variables and characteristics to look at changes in next period's credit spreads and equity returns.

The key coefficient is $\beta_{1}$, the coefficient on the interaction between the change in the exchange rate and the FCLR. If firms that borrow in dollars are not hedged, and so corporate dollar borrowing indicates a balance sheet mismatch, we would expect firms with more FC debt to perform worse following a depreciation. When our dependent variable is equity returns, this means that we would expect $\beta_{1}<0$ so that firms with a higher fraction of their liabilities in FC have lower equity returns when the exchange rate depreciates $(\Delta e>0)$. When our dependent variable is corporate credit spreads, we would expect $\beta_{1}>0$ so that firms with a higher fraction of their liabilities in FC see their credit spreads increase more when the exchange rate depreciates $(\Delta e>0)$. In all regressions, we exclude financial firms and utilities, include industry and country fixed effects, and estimate two-way clustered standard errors by firm and quarter.

In Table 3, we run this regression for equity returns for our two measures of the FCLR, using $F C L R^{A s s e t}$ in the first six columns and $F C L R^{L i a b}$ in the second six. In columns 1 and 7, where we only include $\Delta e_{t+1}$, we find that the coefficient on $\Delta e_{t+1} X F C L R$ is large and negative, indicating that if the exchange rate depreciates by $1 \%$, firms with an $F C L R^{A s s e t}$ of $50 \%$ underperform by 78 basis points and firms with an FCLR $R^{\text {Liab }}$ of $50 \%$ underperform by 43 basis points, relative to a firm with no FC liabilities. In columns 2 and 8, we interact FCLR with other factors, firm size and the Market/Book ratio, and find that the differential loading of firms with more FC debt on the exchange rate remains unchanged. In columns 3 and 9, we control directly for the $F C L R$ and see that the key interaction coefficient is essentially unchanged. In columns 4 and 10, we control for market returns and find that our estimated coefficient is roughly halved in each specification, with $\beta_{1}$ losing statistical significance in the $F C L R^{L i a b}$ specification. In columns 5 and 11 , we introduce an interaction between the market return and the FCLR ratio, and find that this interaction is strongly positive, indicating that firms with more FC debt load more heavily on the market. The exchange rate interaction coefficient remains negative, but becomes insignificant. However, as shown in Brusa et al. (2014), the exchange rate is an important factor in pricing equity returns, and the differential loading of firms with more FC debt on the market rather than the exchange rate directly is not inconsistent with these firms being more vulnerable to depreciation. In fact, it may explain why these firms load more heavily on the market as the exchange rate and market returns are highly correlated. ${ }^{13}$ To account for this, in columns 6 and 12, we orthogonalize the market return on the exchange rate, assigning the common variation to the exchange rate. Once again, the coefficient on

\footnotetext{
${ }^{13}$ Since 1998 , the quarterly correlation between the stock market index return and the change in the exchange rate is $49 \%$ in Mexico and $41 \%$ in Brazil.
} 
the $\Delta e_{t+1} X F C L R^{A s s e t}$ is strongly significant while the version for $F C L R^{L i a b}$ remains negative, but insignificant.

In Table 2, we examine the change in credit spreads. Rather than conditioning on the market return for equities, we use changes in country-level spreads of the JP Morgan Emerging Market Bond Index (EMBI). The EMBI serves as a proxy for the aggregate credit conditions at the country level. ${ }^{14}$ Since secondary bond market prices are much sparser than equity returns and not all listed firms have issued dollar debt securities, we reduce our sample from 334 firms to 56. However, the results are more consistent for the bond regressions than for the equity regressions. Across all 10 regression specifications for the two types of balance sheet measures, the interaction coefficient between the FCLR and FX changes remains statistically significant and fairly stable. In our preferred specification, with the EMBI is orthogonalized on the exchange rate (columns 5 and 10), conditional on a host of controls, we find that a firm with an FCLR $R^{\text {Asset }}$ of $50 \%$ would see its credit spread rise 20 basis points more than a firm with no FC debt following a $1 \%$ depreciation of the exchange rate. In the version of the regression using the FCLR ${ }^{L i a b}$, and a firm a 50\% FCLR would be see its credit spread rise 16 basis points more than a firm with no FC debt.

\subsection{Sovereign Risk and Corporate Balance Sheets}

While the previous subsection provided evidence that firms with more FC debt are more vulnerable to depreciations, we now examine the question of whether more FC corporate debt at the country level is associated with a higher level of sovereign default risk. To do so, we will examine the relationship between the sovereign LC credit and the FC credit spread (from CDS markets) and the country's debt composition. At the country level we find evidence that a higher reliance on external FC corporate debt is associated with a higher risk of sovereign default.

\subsubsection{Unconditional Correlation}

We first look at the unconditional cross-country correlation between corporate reliance on FC external financing and the sovereign credit spread. In order to measure the corporate sector's reliance on external finance, we construct the "Corporate External Finance Ratio", which we define as

$$
\text { Corporate External Finance Ratio }=\frac{\text { Corporate External FC Borrowing }}{\text { Total Corporate Borrowing }}
$$

where "Total Corporate Borrowing" is the sum of corporate domestic debt securities from BIS Securities Statistics, World Bank domestic bank lending to the domestic private sector, and external borrowing. By normalizing the level of corporate external FC borrowing by total corporate borrowing, we are able to control for the cross-country heterogeneity in the depth of domestic financial market and uncover the importance of external FC financing in the overall corporate financing for each sample country.

\footnotetext{
${ }^{14}$ We do not use the Corporate EMBI because the time series is too short. However, this measure also has its drawbacks as it it is commonly used as a measure of sovereign credit risk.
} 
In Figure 6, we plot the mean credit spread from 2005-2012 against the mean Corporate External Finance Ratio. In the left panel, we use the sovereign FC credit spread as the measure of sovereign credit risk, and in the right hand panel we use the sovereign LC credit spread. In both panels, we see a strong positive relationship between corporate external borrowing and sovereign credit spreads. The cross-sectional correlation between the mean Corporate External Finance Ratio and sovereign LC credit spread is $67.3 \%$, and the correlation is $83.6 \%$ between the mean Corporate External Finance Ratio and sovereign FC credit spread. While just a correlation, these figures present suggestive evidence on the relationship between corporate borrowing and sovereign risk across countries.

\subsubsection{Panel Regression Evidence}

In Table 5, we use a panel regression framework to examine whether a higher reliance on FC external corporate debt is associated with more sovereign default risk. Here, we focus on within country variation, examining whether increases in FC sovereign debt/GDP, LC sovereign debt/GDP and FC private debt/GDP are associated with higher sovereign default spreads. We estimate the following regression at the quarterly frequency:

$$
\text { Spread }_{i, t+1}=\alpha+\beta_{1}\left(\frac{F C G o v}{G D P}\right)_{t}+\beta_{2}\left(\frac{L C G o v}{G D P}\right)_{t}+\beta_{3}\left(\frac{F C \text { Private }}{G D P}\right)_{t}+\gamma X_{i, t}+\delta_{i}+\epsilon_{i, t}
$$

where $\delta_{i}$ is a country fixed effect and $X_{i, t}$ is a vector of time-varying country level or global variable. As an alternative to global variables, we also introduce quarter fixed effects. For common global variables, we follow Hilscher and Nosbusch (2010) in including four time series to proxy for such factors as global risk aversion, world interest rates, and liquidity. Those variables are the VIX index, the BBB-Treasury Spread, the 10-Year Treasury Yield, and the TED Spread. In addition, we follow the recent IMF paper by Csonto and Ivaschenko (2013) and include the US Federal Funds Rate. ${ }^{15}$ Standard errors are calculated following Driscoll and Kraay (1998) with 4-quarter lags to account for within-country serial correlation and clustering by quarter to correct for spatial correlation across countries. $^{16}$

We run the regression for two types of spreads, sovereign LC credit spreads and sovereign FC credit spreads derived from CDS markets, at a quarterly and annual frequency. ${ }^{17}$ We include country fixed effects in each regression and examine changes within countries. Because we only have annual data for the external debt composition of South Africa, we exclude the country from the quarterly regressions. In columns 1 and 2, our dependent variable is the sovereign LC credit spread at a quarterly frequency, where column 1 includes quarter fixed effects and column 2 instead controls directly for global factors. At a quarterly frequency, we find that a $1 \%$ of GDP increase in the sovereign FC debt/GDP ratio is associated with a 12.5 basis point increase in the LC credit

\footnotetext{
${ }^{15}$ All global variables are from FRED, Federal Reserve Economic Data, from the Federal Reserve Bank of St. Louis.

${ }^{16}$ When time fixed effects are included, we follow Vogelsang (2012).

${ }^{17}$ The reason for using CDS instead of the underlying bonds is because FC debt markets have shrunk so much in some countries, such as Thailand, that it is becoming difficult to estimate a consistent FC yield curve.
} 
spread. By contrast, a 1\% of GDP increase in the LC sovereign debt-to-GDP ratio is associated with a 7-9 basis point increase. Furthermore, we find that increases in the amount of corporate FC debt are associated with higher sovereign credits spreads. We find that a $1 \%$ point increase in the FC corporate debt-to-GDP ratio is associated with a 2.2-2.7 basis point increase in the LC credit spread. Because the FC corporate debt-to-GDP ratio is more volatile within countries than sovereign debt, this actually explains an important share of the variation. For the estimates in column 1, a one standard deviation increase in the sovereign FC debt-to-GDP ratio is associated with a 57 basis point increase in the LC credit spread, and a one standard deviation increase in the private FC debt-to-GDP ratio is associated with a 28 basis point increase in the LC credit spread.

In Columns 3 and 4, we run the same regressions as in the first two columns, replacing the sovereign LC credit spread with the sovereign FC credit spread as our dependent variable. While default on sovereign FC debt is not the concern of this paper, if countries were to default on the two types of debt simultaneously, we should expect the regressions to be similar when we use the LC or FC credit spread as our dependent variable. We find that this is indeed the case, as a $1 \%$ point increase in the FC corporate debt/GDP ratio is associated with a 2.2-4.1 basis point increase in the FC credit spread.

In columns 5-8, we run the same regressions at an annual frequency and find the results for the importance of private FC debt are further strengthened. Because only annual data is available for the currency composition of South Africa's external sovereign debt, the country is excluded from our quarterly regressions. However, when we look at annual data in columns 5-8, we are able to include South Africa in our analysis. In these regressions, the global controls are year averages. At an annual frequency, we find that a $1 \%$ increase in the private FC debt/GDP ratio is associated with a 4 basis point increase in the LC credit spread and a 5 basis point increase in the FC credit spread. ${ }^{18}$

\section{A Model of Sovereign Risk and Corporate Balance Sheets}

Motivated by these empirical findings, we now formally examine the interplay between sovereign risk and corporate balance sheets. Our main empirical motivations for the model are as follows. First, sovereigns are increasingly borrowing in LC and firms borrow overwhelmingly in FC. However, a positive credit spread on LC sovereign debt remains. Second, firms with more FC debt are vulnerable to exchange rate movements, evidence that the corporate sector does not completely hedge currency risk. Third, higher levels of FC corporate debt are associated with a higher risk of default on sovereign LC debt. We argue that a mismatched corporate sector is one reason why a sovereign would choose to explicitly default on LC sovereign debt rather than inflating it away. In this section, we introduce LC sovereign debt and a mismatched corporate sector into the standard model of sovereign debt, and demonstrate how corporate currency mismatch generates sovereign default risk.

\footnotetext{
${ }^{18}$ In Appendix Table A3, we include additional country-specific variables found to price sovereign risk in the previous literature and show that the main results are largely unchanged.
} 
We microfound the mismatched corporate sector by introducing a class of agents that we call "entrepreneurs." These entrepreneurs are the only agents in the economy capable of producing an intermediate input used for the production of tradable goods. These entrepreneurs borrow from foreign lenders to make a fixed investment at the start of the period, produce a non-stochastic amount of the tradable good, and use the proceeds from the sale of these goods to repay their foreign loans. They then invest to produce intermediate goods that are used to produce more of the tradable output. The key financial friction in the model is that entrepreneurs' investment in intermediate goods is limited by their net worth. In order to keep the model simple while modeling currency mismatch, this entrepreneurial net worth comes from the profits entrepreneurs make from selling their tradable output every period. The key mismatch in the model arises because entrepreneurs are committed to sell a fraction of their tradable endowment in fixed LC prices. This means that inflation reduces the real value of their sales without commensurately reducing the real value of their liabilities. Inflation, therefore, reduces the real value of these firms' profits and thereby reduces the amount they can invest in the production of intermediate inputs. This, in turn, reduces aggregate tradable output.

\subsection{Setup}

A large literature following Arellano (2008) and Aguiar and Gopinath (2006) has examined sovereign default on foreign currency debt in a quantitative Eaton and Gersovitz (1981) framework. As in this class of literature, we assume that the government borrows from risk-neutral foreign investors in order to smooth and/or front-load household consumption. The key friction in the model is that the government cannot commit, and instead decides each period whether or not to repay and how much to borrow. We will make two main changes relative to the existing literature. First, we introduce LC sovereign debt and give the sovereign another policy tool, the inflation rate, with which to reduce real repayments on the debt. Second, rather than working with an endowment economy, we introduce a production economy and treat aggregate productivity as the exogenous state variable. We will begin by discussing how we introduce these two new features. We will then discuss our microfoundation of the production economy that causes currency depreciation to reduce output. After solving for the sovereign's policy functions and the bond price schedule, we will present the intuition for why reducing corporate currency mismatch can eliminate sovereign default risk in equilibrium by examining the equilibrium price schedules, policy functions and debt Laffer curve. We demonstrate that a calibrated version of the model can generate the simulated moments of currency and credit risk similar to that observed in the data. Finally, we examine the model's predictions on the effect of reducing corporate currency mismatch on equilibrium sovereign default risk.

\subsubsection{Setup}

As in the existing literature examining FC debt, we assume that the sovereign's objective is to maximize the discounted utility stream of consumption for the representative agent: 


$$
\max _{b^{\prime}, \zeta, D} E\left[\sum_{t=0}^{\infty} \beta^{t} u\left(C_{t}\right)\right] .
$$

The sovereign maximizes this objective function by choosing how much to borrow $\left(b^{\prime}\right)$, whether to default on the outstanding debt $(D)$, and, now, how much of the existing debt to inflate away $\zeta$. In order to tractably introduce LC sovereign debt, we assume that the sovereign borrows with exponentially decaying nominal LC perpetuities with promised LC cash flows:

$$
P_{t} \kappa\left[1, \delta, \delta^{2}, \ldots\right]
$$

where $P_{t}$ indicates today's price level. Because PPP will hold in our model, a foreign lender values this stream of coupons by dividing through by the LC price level at the time the coupons are paid to calculate their value in $\mathrm{FC}$ :

$$
\kappa\left[\frac{P_{t}}{P_{t+1}}, \delta \frac{P_{t}}{P_{t+2}}, \delta^{2} \frac{P_{t}}{P_{t+3}}, \ldots\right]
$$

Defining $\frac{P_{t+1}}{P_{t}}=1+\pi_{t+1}$, with $\pi$ being the net inflation rate, we can define the inflation tax $\zeta_{t+1}=\frac{\pi_{t+1}}{1+\pi_{t+1}}$. Working with the inflation tax rather than the inflation rate is simply a matter of convenience. The real (FC) value of the coupons can then be written compactly as

$$
\kappa\left[\left(1-\zeta_{t+1}\right), \delta \prod_{s=1}^{2}\left(1-\zeta_{t+s}\right), \delta^{2} \prod_{s=1}^{3}\left(1-\zeta_{t+s}\right), \ldots\right],
$$

The bond price is equal to the discounted expected value of all future cash flows:

$$
\begin{aligned}
q_{t}^{L C} & =E_{t}\left[\frac{\kappa \cdot\left(1-D_{t+1}\right)\left(1-\zeta_{t+1}\right)}{1+r^{*}}+\frac{\delta \kappa \cdot\left(1-D_{t+1}\right)\left(1-D_{t+2}\right)\left(1-\zeta_{t+1}\right)\left(1-\zeta_{t+2}\right)}{\left(1+r^{*}\right)^{2}}+\ldots\right] \\
& =\frac{E_{t}\left[\left(1-D_{t+1}\right)\left(1-\zeta_{t+1}\right)\left(\kappa+\delta q_{t+1}^{L C}\right)\right]}{1+r^{*}}
\end{aligned}
$$

The details of this bond pricing can be found in Appendix Section B.1. The bond price is a function of today's exogenous state $A$ and amount of debt issued $b^{\prime}$.

$$
q^{L C}\left(A, b^{\prime}\right)=\frac{E\left[\left(1-D\left(A^{\prime}, b^{\prime}\right)\right)\left(1-\zeta\left(A^{\prime}, b^{\prime}\right)\right)\left(\kappa+\delta q^{L C}\left(A^{\prime}, b^{\prime \prime}\left(A^{\prime}, b^{\prime}\right)\right)\right) \mid A, b^{\prime}\right]}{1+r^{*}} .
$$

This expectation is taken after the state $A$ and borrowing $b^{\prime}$ have been realized, but tomorrow's state $A^{\prime}$ and tomorrow's borrowing level $b^{\prime \prime}$ are not yet known. $D\left(A^{\prime}, b^{\prime}\right)$ is an indicator variable for default. In the event of default, $D=1$, and the holder of the bond receives nothing. In repayment states, $D=0$, and the expectation is taken over losses from inflation $\zeta$, which are a function of tomorrow's state $A^{\prime}$ and the debt level $b^{\prime}$. If the bonds were only one period, then this would be sufficient. However, because these are long-term bonds, lenders must account for future inflation 
and default risk reducing the value of future repayments. The recursive pricing structure makes this calculation feasible, because rather than calculating expected future inflation and default over all future periods, investors only need to form an expectation over inflation, default, and the price of the bond tomorrow. The bond price next period is dependent not just on the aggregate state $A^{\prime}$, but also on the level of debt the sovereign will issue next period. This feature makes long-term debt more computationally demanding than using short-term debt but generates more interesting and realistic dynamics. If we were to restrict inflation to be zero, this bond pricing equation would be equivalent to that presented for FC debt in Hatchondo and Martinez (2009).

The second change we make is that we introduce a production economy where output is a Cobb-Douglas function of intermediate goods $(X)$ and labor $(L)$

$$
y=A X(\zeta)^{\gamma} L^{1-\gamma}
$$

The output costs of inflation and depreciation will come through reduced intermediate good provision and will be discussed in detail in the next subsection. For now, we simply write $X$ as a function of $\zeta$. Consumption in repayment is given by:

$$
\begin{aligned}
& C^{R}=A_{t} X(\zeta)^{\gamma} L^{1-\gamma}-(1-\zeta) \kappa b+q^{L C}\left(A, b^{\prime}\right)\left[b^{\prime}-(1-\zeta) \delta b\right] . \\
& \text { Output Coupon Payments Net revenue from bond issuance }
\end{aligned}
$$

The term $(1-\zeta) \kappa b$ gives the real value of coupon payments this period. Therefore, the real amount paid (measured in tradables) is the coupon per bond $\kappa$, scaled by the number of bonds outstanding $b$, times the real value of the local currency, which is $(1-\zeta)$. The next term $q^{L C}\left(A, b^{\prime}\right)\left[b^{\prime}-(1-\zeta) \delta b\right]$ is the net revenue raised from bond issuance. Net issuances are just the gross issuance $b^{\prime}$ minus the equivalent number of today's bonds from the previous period, $(1-\zeta) \delta b .(1-\zeta)$ denotes the measure of existing bonds not inflated away, $\delta$ the speed with which coupon payments decay, and $b$ is the number of these perpetuities the government issued last period. If $b^{\prime}-(1-\zeta) \delta b>0$, then the sovereign has positive net issuance, and if $b^{\prime}-(1-\zeta) \delta b<0$ then the sovereign is repaying the outstanding debt.

In order to determine the sovereign's optimal policy, we need to know how output varies with the chosen inflation rate. Our microfoundation for $X(\zeta)$ is the focus of the next subsection.

\subsubsection{Entrepreneurs' Problem}

We assume there is a continuum of identical households and, similar to the microfoundation of Gertler and Karadi (2011), we assume that within each household there are two types of agents. While Gertler and Karadi (2011) assume the household is made up of workers and bankers, we assume that a fraction $1-\gamma$ of household members are "workers" and $\gamma$ are "entrepreneurs."

At the beginning of the period entrepreneurs have access to projects that require a fixed investment to return a fixed amount $\omega$ of the tradable good. To finance the investment in the project, entrepreneurs borrow intra-period from foreign lenders. The key assumption is that conditional on 
producing, entrepreneurs are committed to sell a share of their output at a fixed LC per-unit price. Because they have set their prices in LC but have to repay a real amount, inflation (depreciation) reduces the real value of their profits. Therefore, we are assuming that goods prices are sticky for a longer period than it takes entrepreneurs to borrow and invest. While the entrepreneurs are constrained to sell a fraction of their output in fixed LC prices, the single consumption good is also traded internationally with flexible prices. This implies that purchasing power parity holds, and changes in the domestic price level are equal to changes in the nominal exchange rate. This will allow us to talk about inflation and depreciation interchangeably. Entrepreneurs' profits from the sale of the tradable good in the first stage of the period constitute their net worth when they want to invest in intermediate good production in the second stage. We assume that no external finance can be used for the production of intermediate goods, and so changes in net worth will determine the amount of intermediate goods entrepreneurs can produce. This in turn will determine aggregate production.

The closest paper in the literature to our entrepreneurial sector is Céspedes et al. (2004), who study a Bernanke et al. (1999) financial accelerator in an open economy environment. Céspedes et al. (2004) demonstrate that depreciations are less expansionary, and potentially contractionary, when entrepreneurs are indebted in FC but earn revenues in sticky LC prices. In their model, informational frictions create an external finance premium that is falling in net worth. A lower net worth that leads to a higher premium on external borrowing thereby reduces aggregate investment. While we are after a similar channel, we make a starker assumption. In particular, we assume that entrepreneur net worth comes only from their profits from the sale of their output in the first stage, net of external debt repayment. We then assume that only this net worth can be used to finance intermediate good production, and no external financing can be used in the second stage when they invest in intermediate good production. By making these simplifications, we can solve the entrepreneurs' subproblem in closed form, avoiding the need for local approximation methods. This facilitates the introduction of the mismatched entrepreneurial sector into the inherently non-linear sovereign default problem. ${ }^{19}$

At the beginning of the period, entrepreneurs borrow a fixed amount from foreign lenders with a share $\alpha_{P}$ in LC. Entrepreneur's borrow significantly less than they will produce $\omega$, so we do not consider them defaulting on their debt. ${ }^{20}$ However, their profit $\Pi$ is a function of the inflation rate. The amount produced per project is denoted by $\omega$ and the face value of promised repayments is given by $Z$. A share $\alpha_{P}$ of the face value of the debt is denominated in LC and $\left(1-\alpha_{P}\right)$ is denominated in FC. We assume that entrepreneurs are committed to sell a share $\mu$ of their output at a fixed LC price $P_{t-1}$ and may set the price of the remaining $(1-\mu)$ optimally. We can write the real value of entrepreneurial profits as:

\footnotetext{
${ }^{19}$ Here, we assume that the firms with sticky prices are intermediate good producers while it is more common to think consumer goods prices are sticky. This assumption is made for tractability.

${ }^{20}$ When we turn to the sovereign's problem, we will see that an optimizing sovereign would not choose a level of inflation in equilibrium that leaves entrepreneurs unable to repay their debt.
} 


$$
\Pi=\gamma\left(\frac{P_{t-1}}{P_{t}}\left(\mu \omega-\alpha_{P} Z\right)+(1-\mu) \omega-\left(1-\alpha_{P}\right) Z\right),
$$

where $P_{t-1}$ is the price level entering the period and $P_{t}$ is the price level that the sovereign sets after the realization of aggregate productivity. This expression for their profits captures the fact that only the value of LC repayments are affected by inflation. Using our earlier definition of the inflation $\operatorname{tax} \zeta$, we can rewrite this equation as:

$$
\Pi=\gamma\left(\left(1-\zeta_{t}\right)\left(\mu \omega-\alpha_{P} Z\right)+(1-\mu) \omega-\left(1-\alpha_{P}\right) Z\right) .
$$

Because the tradable good is the numeraire, the profit per entrepreneur represents their net worth measured in tradable goods. We assume that entrepreneurs have access to a linear production technology that allows them to invest to produce intermediate goods $X$,

$$
X=\xi I
$$

where $\xi$ is the productivity of the intermediate good production technology and $I$ denotes the units of tradable goods invested. The key financial friction is that we assume entrepreneurs cannot access external finance to invest in intermediate good provision, so we must have that investment is less than net worth:

$$
I \leq \Pi
$$

We will consider the case where this constraint binds in every state, and so entrepreneurs will invest the maximum amount possible and we have $I=\Pi$. We can therefore write the amount of intermediates produced in equilibrium as:

$$
X(\zeta)=\xi \gamma\left((1-\zeta)\left(\mu \omega-\alpha_{P} Z\right)+(1-\mu) \omega-\left(1-\alpha_{P}\right) Z\right)
$$

In default states, inflation $\zeta=0$, and so if we have $X_{D}=\xi I_{D}$ and $I_{D} \leq \Pi_{D}$, equilibrium intermediate good provision in default states will be given by:

$$
X_{D}=\xi \gamma(\omega-Z)
$$

\subsubsection{Introducing Entrepreneurs into the Model}

Having presented the relationship between the sovereign choice of inflation and intermediate good provision $X(\zeta)$, we can introduce the production economy into the model. After entrepreneurs produce the intermediate goods, they rejoin their household. Each household has access to a production technology that combines intermediate goods from the entrepreneurs and labor from the workers to produce a final good. As discussed previously, this production technology is Cobb-Douglas in 
intermediates and (inelastically-supplied) labor. This delivers consumption in repayment states of

$$
\begin{aligned}
C^{R} & =A X(\zeta)^{\gamma} L^{1-\gamma}-(1-\zeta) \kappa b+q^{L C}\left(A, b^{\prime}\right)\left[b^{\prime}-(1-\zeta) \delta b\right] \\
\text { where } X(\zeta) & =\xi \gamma\left((1-\zeta)\left(\mu \omega-\alpha_{P} Z\right)+(1-\mu) \omega-\left(1-\alpha_{P}\right) Z\right)
\end{aligned}
$$

Before we can determine when the sovereign finds it optimal to default, we first need to calculate the best the sovereign can do by repaying and choosing the optimal inflation rate. This problem is kept tractable because our microfoundation of the entrepreneurs' problem delivers a simple closed form expression for the inflation policy function, conditional on any choice of borrowing tomorrow and the bond price schedule. Conditional on the choice of borrowing being $b^{\prime}$, the sovereign chooses inflation to maximize static consumption (equation 6). Taking the FOC of consumption in repayment states with respect to inflation delivers an inflation policy function:

$$
\zeta\left(A, b, b^{\prime}\right)=\max \left[\frac{\omega-Z-\left(\gamma\left(\mu \omega-\alpha_{P} Z\right)\left(\frac{A(\xi \gamma)^{\gamma}}{b\left(\kappa+\delta q^{L C}\left(A, b^{\prime}\right)\right)}\right)\right)^{1 /(1-\gamma)}}{\left(\mu \omega-\alpha_{P} Z\right)}, 0\right] .
$$

This captures the tradeoffs the sovereign faces in choosing the optimal inflation rate. First, inflation is countercyclical, as a lower aggregate productivity makes it more tempting to inflate away the debt. Second, the larger today's debt service, $\kappa b$, the higher the optimal inflation rate. Third, the term $\delta b q^{L C}\left(A, b^{\prime}\right)$ captures the present value of outstanding long-term debt than can be inflated away. Because the expression for inflation is for a fixed amount of debt to be issued $b^{\prime}$, net revenue raised $q^{L C}\left(A, b^{\prime}\right)\left(b^{\prime}-(1-\zeta) \delta b\right)$ is increasing with the amount of debt inflated away. Therefore, the higher the price a sovereign will receive for new bond issuances, the more tempting it is to inflate away the existing debt. Of course, this temptation will be captured by the bond price schedule in equilibrium.

While the inflation choice can thus be reduced to a static optimization problem, the choice of the debt level is inherently dynamic as this debt level is the endogenous state variable in the next period. Before turning to this problem, we need to briefly discuss how the economy operates during a sovereign default as the optimal amount to borrow depends critically on how costly default is. Consumption in default is simply output in default, and from the entrepreneurs' problem, we have

$$
\begin{aligned}
C_{D} & =A_{D}(A) X_{D}^{\gamma} L^{1-\gamma} \\
X_{D} & =\xi \gamma(\omega-Z) \\
A_{D}(A) & =A-\phi(A)
\end{aligned}
$$

where $\phi(A)$ is a non-negative function capturing how much aggregate productivity drops in default. This is the production economy equivalent of the loss of output $\phi(y)$ discussed in models of FC borrowing. Follow the existing literature discussed in the FC sovereign debt section, we can write 
the government's problem recursively as

$$
\begin{aligned}
V^{R}(A, b) & =\max _{b^{\prime}} u\left(C_{R}\left(A, b, b^{\prime}\right)\right)+\beta E V\left(A^{\prime}, b^{\prime}\right) \\
V^{D}(A) & =u\left(C_{D}(A)\right)+\beta\left(\lambda E V^{R}\left(A^{\prime}, 0\right)+(1-\lambda) E V^{D}\left(A^{\prime}\right)\right) \\
V(A, b) & =\max _{D \in\{0,1\}}(1-D) V^{R}(A, b)+D V^{D}(A)
\end{aligned}
$$

where

$$
\begin{aligned}
C_{R}\left(A, b, b^{\prime}\right) & =A X\left(\zeta\left(A, b, b^{\prime}\right)\right)^{\gamma}-\kappa b \cdot\left(1-\zeta\left(A, b, b^{\prime}\right)\right)+q^{L C}\left(A, b^{\prime}\right)\left[b^{\prime}-\left(1-\zeta\left(A, b, b^{\prime}\right)\right) \delta b\right] \\
C_{D}(A) & =A_{D}(A) X_{D}^{\gamma} \\
X\left(A, b, b^{\prime}\right) & =\xi \gamma\left[\left(1-\zeta\left(A, b, b^{\prime}\right)\right)(\mu \omega-\alpha Z)+(1-\mu) \omega-(1-\alpha) Z\right] \\
X_{D} & =\xi \gamma(\omega-Z) \\
\zeta\left(A, b, b^{\prime}\right) & =\max \left[\frac{\omega-Z-\left(\gamma\left(\mu \omega-\alpha_{P} Z\right)\left(\frac{A(\xi \gamma)^{\gamma}}{b\left(\kappa+\delta q^{L C}\left(A, b^{\prime}\right)\right)}\right)\right)^{1 /(1-\gamma)}}{\left(\mu \omega-\alpha_{P} Z\right)}, 0\right] \\
q^{L C}\left(A, b^{\prime}\right) & =\frac{E\left[\left(1-D\left(A^{\prime}, b^{\prime}\right)\right)\left(1-\zeta\left(A^{\prime}, b^{\prime}\right)\right)\left(\kappa+\delta q^{L C}\left(A^{\prime}, b^{\prime \prime}\left(A^{\prime}, b^{\prime}\right)\right)\right) \mid A, b^{\prime}\right]}{1+r^{*}} \\
A_{D}(A) & =A-\phi(A) .
\end{aligned}
$$

The value function in repayment states $V^{R}$ is today's flow utility and the expectation of tomorrow's value function. In the event a country defaults or remains in bad credit history, there are no choices to be made and the country's period utility is just $u\left(C_{D}(A)\right)$. Finally, the value function today is the upper envelope of the two: the sovereign remains in $V^{R}$ if it prefers to repay the debt rather than explicitly default, and if it prefers to default, the relevant value function is $V^{D}$. In addition, it captures the fact that conditional on a choice of $b^{\prime}$, the optimal inflation policy function is pinned down analytically, conditional on the equilibrium bond price schedule $q\left(A, b^{\prime}\right)$.

One of the primary benefits of the way in which we introduce LC debt and the entrepreneurial sector into the canonical model is that our model is a generalization of the existing FC literature. If we were to restrict inflation to always be zero, then this setup collapses exactly to a model with FC debt, particularly the version with long-term debt studied by Hatchondo and Martinez (2009). If we also restricted the sovereign to borrowing with one-period debt $(\delta=0)$, then this would be equivalent to the model studied by Arellano (2008) and Aguiar and Gopinath (2006). With no inflation, we would $X=X_{D}=\bar{X}$, and so output would be equivalent to an endowment economy, with changes in the endowment proportional to changes in productivity $A$. Because of this, we will be able follow the existing literature in our numerical solution of the model. 


\subsubsection{Equilibrium Definition}

We study the Recursive Markov Equilibrium for this economy where all decision rules are functions only of the state variables $A$ and $b$. An equilibrium is a set of policy functions for consumption $\tilde{c}(A, b)$, debt issuance $\tilde{b}(A, b)$, default $\tilde{D}(A, b)$ and inflation $\tilde{\zeta}(A, b)$, and a price function for debt $q\left(A, b^{\prime}\right)$ such that:

1. Taking as given the government policy functions, household consumption satisfies the resource constraint

2. Taking the bond price function $q\left(A, b^{\prime}\right)$ as given, the government's policy functions satisfy the sovereign's optimization problem

3. The bond price function satisfies the risk-neutral foreign lenders' zero-profit condition.

The government's lack of commitment is captured by the fact that equilibrium policy functions are restricted to be functions of today's state variables $A$ and $b$, and cannot be history dependent. Instead, the government policy functions must satisfy the government's optimization problem period-by-period.

\subsection{Bond Pricing, Currency Risk and Credit Risk}

Just as we are able to measure the currency and credit risk on local currency sovereign debt in the data by pricing a synthetic default-free local currency bond, in the model our decomposition of currency and credit risk will rely on pricing an instrument in zero net supply. Even though the only debt actually issued by the government is a defaultable local currency bond, we can still price a default-free local currency bond. This will be the theoretical counterpart to our empirical version of combining a US Treasury with a cross-currency swap to approximate the interest rate at which a risk-free entity would borrow if it issued a single unit of debt in an EM currency. To do so, we simply have to calculate what price global investors would pay for the default-free sequence of LC cash flows in equation 4 . The price is the discounted risk-neutral expected value of the cash flows, conditional on the time $t$ information set,

$$
\begin{aligned}
q_{t}^{* L C} & =E_{t}\left[\frac{\kappa \cdot\left(1-\zeta_{t+1}\right)}{1+r^{*}}+\frac{\delta \kappa \cdot\left(1-\zeta_{t+1}\right)\left(1-\zeta_{t+2}\right)}{\left(1+r^{*}\right)^{2}}+\ldots\right] \\
& =\frac{E_{t}\left[\left(1-\zeta_{t+1}\right)\left(\kappa+\delta q_{t+1}^{* L C}\right)\right]}{1+r^{*}}
\end{aligned}
$$

and so once again the bond has a simple recursive representation. ${ }^{21}$ Just as is the case for the defaultable LC bond price $q_{t}^{L C}$, the default-free LC bond price is a function of today's exogenous productivity level $A$ and the amount of defaultable debt issued $b^{\prime}$. It is important to note that the payoff on this bond is a function of the sovereign's inflation choice, and therefore its payoffs

\footnotetext{
${ }^{21}$ Additional details can be found in Appendix Section B.1.
} 
are a function of government policy just like the defaultable debt. The key difference is that this default-free debt is not issued by the sovereign and therefore cannot be defaulted on. However, by suppressing the state variables, equation 10 hides the complications in pricing this debt. To solve for default-free LC bond price schedule, we need to account for the payoff a creditor receives from owning this bond in sovereign default states. Although this is not a concern for defaultable bonds, as once the government defaults the value of the debt goes to zero, we need to consider these periods for default-free debt. To see this, it is easiest to write the bond price schedule for default-free LC debt when the sovereign is in default and when it is not in default, with subscript $D$ indicating default states and $R$ indicating repayment states.

$$
\begin{aligned}
q_{R}^{* L C}\left(A, b^{\prime}\right) & =\frac{E\left[\left(1-\zeta\left(A^{\prime}, b^{\prime}\right)\right)\left(\kappa+\delta\left(\left(1-D\left(A^{\prime}, b^{\prime}\right)\right)\left(q_{R}^{* L C}\left(A^{\prime}, b^{\prime \prime}\left(A^{\prime}, b^{\prime}\right)\right)\right)+D\left(A^{\prime}, b^{\prime}\right) q_{D}^{* L C}\left(A^{\prime}\right)\right)\right) \mid A, b^{\prime}\right]}{1+r^{*}} \\
q_{D}^{* L C}(A) & =\frac{\kappa+\delta E\left[\lambda q_{R}^{* L C}\left(A^{\prime}, 0\right)+(1-\lambda) q_{D}^{* L C}\left(A^{\prime}\right) \mid A, b^{\prime}\right]}{1+r^{*}}
\end{aligned}
$$

This makes clear that the default-free bond price does still depend on the government's default policy function through its effect on the government's incentive to inflate in the future. ${ }^{22}$ In other words, the expectation of next period's bond price differs depending on whether the country is currently in good or bad financial standing:

$$
\begin{aligned}
& E_{t}\left(q_{t+1}^{* L C} \mid D_{t}=0\right)=E_{t}\left[\left(1-D\left(A^{\prime}, b^{\prime}\right)\right) q_{R}^{* L C}\left(A^{\prime}, b^{\prime \prime}\left(A^{\prime}, b^{\prime}\right)\right)+D\left(A^{\prime}, b^{\prime}\right) q_{D}^{* L C}\left(A^{\prime}\right)\right] \\
& E_{t}\left(q_{t+1}^{* L C} \mid D_{t}=1\right)=E_{t}\left[\lambda q_{R}^{* L C}\left(A^{\prime}, 0\right)+(1-\lambda) q_{D}^{* L C}\left(A^{\prime}\right)\right]
\end{aligned}
$$

where $D=0$ means the country is in good standing and $D=1$ means the country is in bad standing. Because this default-free debt is not issued by the sovereign, and the payoff on this debt in no way affects the decisions of the sovereign, its price can simply be computed by solving the above fixed point problem while taking the equilibrium sovereign policy functions as given. While the price of default-free LC debt during periods of sovereign default is an important element in pricing the debt, we will focus on comparing the default-free LC bond price to the defaultable LC bond price in non-default states, as the latter price is not defined when the sovereign is locked out of international debt markets.

In order to connect the bond prices to the empirical currency and credit spread decomposition discussed in Section 2, we need to convert these bond prices to yields. To do so, we can define the yield-to-maturity (YTM) of bond type $j$ at time $t$ as $r_{t}^{j}$, as the rate of return that equates the present value of the bond's promised cash flows to its price:

$$
q_{t}^{j}=\sum_{s=1}^{N} \frac{C F_{t+s}}{\left(1+r_{t}^{j}\right)^{s}}
$$

\footnotetext{
${ }^{22} \mathrm{Na}$ et al. (2014) demonstrate that in the presence of downward rigid nominal wages, a government might find it optimal to devalue following a sovereign default. We abstract from this feature that would generate inflation upon default and there is no incentive to inflate after default here.
} 
where $C F_{t+s}$ is the promised cash flow of the bond at time $t+s$. Because the bonds we are looking at have an exponentially declining coupon structure, this calculation is particularly simple and becomes:

$$
r_{t}^{j}=\frac{\kappa}{q_{t}^{j}}-(1-\delta)
$$

This allows us to calculate the credit risk (LC credit spread, equation 1), currency risk (crosscurrency swap rate), and to decompose the nominal yield into currency and credit risk:

$$
\begin{aligned}
\rho_{t} & =r_{t}^{* L C}-r^{*} \\
s_{t}^{L C C S} & =r_{t}^{L C}-r_{t}^{* L C} \\
s_{t}^{L C / U S} & =r_{t}^{L C}-r^{*} \\
& =s_{t}^{L C C S}+\rho_{t}
\end{aligned}
$$

where $r_{t}^{L C}$ is the YTM on a defaultable LC sovereign bond, $r_{t}^{* L C}$ is the YTM on the (zero net supply) default-free LC bond, and $r^{*}$ is the FC risk-free rate, which we assume to be constant. By calculating these three spreads in the model, we will be able to compare the model-implied moments to their empirical counterparts.

\section{Quantitative Results}

\subsection{Calibration and Numerical Solution}

In this section, we will outline the functional form assumptions, parameter calibrations and solution method used to solve the model numerically. We assume a CRRA utility function with a coefficient of relative risk aversion $\sigma$ and we will assume that log productivity follows an $\operatorname{AR}(1)$ process

$$
\begin{aligned}
u(c) & =\frac{c^{1-\sigma}-1}{1-\sigma} \\
\ln A_{t} & =\mu_{z}\left(1-\rho_{z}\right)+\rho_{z} \ln A_{t-1}+\epsilon_{t}, 0<\rho_{z}<1 \text { and } \epsilon_{t} \sim N\left(0, \sigma_{\epsilon}^{2}\right) .
\end{aligned}
$$

We follow Chatterjee and Eyigungor (2012) and use the flexible form for default costs

$$
\begin{array}{r}
A_{D}=A-\phi(A) \\
\phi(A)=\max \left\{0, d_{0} A+d_{1} A^{2}\right\}, d_{1} \geq 0
\end{array}
$$

If $d_{1}=0$ and $d_{0}>1$, this is simply the proportional default costs used in Aguiar and Gopinath (2006). If $d_{1} \geq 0$ and $d_{0}<0$, then the default costs become closer to the Arellano (2008) costs because when $A \leq-\frac{d_{0}}{d_{1}}$, the default costs are zero but when $A$ is above that threshold the default costs are convex in $A$. However, because here we have $A_{D}$ increasing with $A$ rather than staying constant, the default costs are less kinked than in Arellano (2008). 
We calibrate the model to a quarterly frequency. The parameter values are documented in Table 6. We set the intermediate good share $\gamma$ to $1 / 3$ so that the labor share is $2 / 3$. We set the amount of foreign currency external corporate financing $Z$ to .51, so that in the absence of inflation the mean debt/output ratio is equal to $17 \%$, the mean private external debt/GDP ratio documented in Section 3. We calibrate mean entrepreneur output and the efficiency of the intermediate good production technology $\xi$ so that in the absence of inflation, $X=1$ and the model collapses to the endowment economy with FC sovereign debt discussed earlier. This requires $\xi=1 / \gamma(\omega-Z)$, meaning that the choice of $\xi$ and $\omega$ only involves setting one parameter. We set $\xi$ and $\omega$ to match the average inflation differential between the $13 \mathrm{EMs}$ and the United States from 2000-2012. This delivers $\xi=3.025$ and $\omega=1.5017$. We set the default costs to match the historical average credit spread on foreign currency debt (from CDS) over the last decade of $2 \%$ when we solve a version of the model with only FC debt. The implied default costs correspond to an aggregate productivity loss of $3 \%$ in the worst state and $3.75 \%$ in the best state. This is within the range used in the literature, as in Aguiar and Gopinath (2006) the proportional cost is equal to 3\%, in Hatchondo and Martinez (2009) it is equal to $10 \%$, and in Arellano (2008), in the low states it is $0 \%$ and in high states it can exceed $20 \%$. We can then set $\alpha_{P}$ to $10 \%$ to match the mean share of LC corporate debt in total external corporate debt in the data. We set the quarterly discount factor $\beta=.95$, a standard value in this literature with long-term debt. In order to generate default in equilibrium, the sovereign has to be less patient than international investors. This leads the sovereign try to front-load consumption, generating default risk in equilibrium. This low discount factor can be understood as capturing a government that is more impatient than individuals for political economy reasons. ${ }^{23}$

To calibrate the productivity process, we follow Aguiar and Gopinath (2006), setting the autocorrelation $\rho_{z}=0.9$ and $\sigma_{z}=0.034$. We follow Tauchen (1986) to discretize the productivity process. We set $\delta=.9595$ to set the risk-free duration of the LC bonds to 5 years when the quarterly risk-free rate is $1 \% .{ }^{24}$ This duration is close to the cross-country average calculated in appendix Table A2. For the probability of re-entry into credit markets, we follow Aguiar and Gopinath (2006) and set the probability of re-entry $\lambda$ to $10 \%$, consistent with the evidence in Gelos et al. (2011). ${ }^{25}$ The share of sticky price goods $\mu$ is set to .75 , a common calibration parameter for Calvo pricing.

To solve the model, we use value function iteration over a discretized state space. Because our recursive representation is identical to the model studied in Hatchondo and Martinez (2009),

\footnotetext{
${ }^{23}$ See Cuadra and Sapriza (2008) for a model that explicitly models political economy frictions in an Eaton and Gersovitz (1981) sovereign debt model.

${ }^{24}$ The risk free Macaulay duration of bond is given by $D=\sum_{n=1}^{\infty} n \frac{C_{n}\left(1+r^{*}\right)^{-n}}{q}$, where $C_{n}$ is the coupon payment due in period $n$. In our framework with exponentially declining coupons, $D=\frac{1+r^{*}}{1+r^{*}-\delta}$.

${ }^{25}$ This implies that on average sovereigns are excluded from financial markets for 2.5 years. Other authors, such as Benjamin and Wright (2013), find a longer exclusion period. Cruces and Trebesch (2013) calculate the mean time to for market re-access following is 5.1 years and the median is 3 years, so our calibration of $\lambda$ implies a shorter period of exclusion. However, the parameter for market re-access $\lambda$ also determines the length that the country suffers the output costs of default. Estimates of the output cost of default, as in Borensztein and Panizza (2009) and Yeyati and Panizza (2011), imply a much shorter duration. Therefore, we are inclined to follow Aguiar and Gopinath (2006), setting $\lambda=10 \%$, for a relatively short punishment period.
} 
Chatterjee and Eyigungor (2012), and a one-bond version of Arellano and Ramanarayanan (2012), with one additional constraint on the policymaker (equation 8), we can simply follow the solution methods used in the FC sovereign debt literature. The state space for productivity shocks is discretized to a 25 state grid. The state space for bonds is discretized into 451 grid points. A finer grid is used for the endogenous state variable to keep the discretization from impacting the sovereign's choices. Following the recommendations in Hatchondo et al. (2010), we iterate backwards from the solution of the final period of the finite-horizon model so that we select the equilibrium bond price of the finite horizon model. To improve the convergence properties of the solution, we follow Chatterjee and Eyigungor (2012) and introduce a small i.i.d. component to the productivity process. Chatterjee and Eyigungor (2012) show that in sovereign debt models with long-term bonds large changes in the bond issuance policy function can achieve roughly the same welfare level, so that small changes in the bond price can lead the bond issuance policy function to change significantly. These discontinuities arise from the non-convexity of the budget set. The introduction of a small i.i.d. component to the productivity process acts to convexify the budget set and improve convergence without significantly affecting the business cycle properties of the model. In the event of default, we set this i.i.d. component to its lowest value, slightly increasing the cost of default. ${ }^{26}$

After solving for the equilibrium policy functions and the defaultable LC bond price, we price the synthetic default-free LC bond as in section 5.2. With our policy functions and bond price schedules in hand, we can calculate the model-implied moments by simulating the model 20 times for 3000 quarters per simulation. We discard the first 500 periods of each simulation.

\subsection{Quantitative Results and Key Mechanisms}

In this section, we will discuss the quantitative results and the model's key mechanisms. First, we will compare the model's simulated moments to their empirical counterparts. Second, we will explore the mechanisms at work in the model, focusing on why a higher share of LC corporate debt reduces sovereign default risk in equilibrium. We will demonstrate how the sovereign's equilibrium inflation and default policy functions vary with the share of LC corporate debt and how these policy functions generate different bond price schedules for the government. We will then examine how the sovereign optimally responds to these bond price schedules and its own future default and inflation incentives when deciding how much to borrow. We will use the debt Laffer curve, the equilibrium schedule of the market value of sovereign debt $q \cdot b^{\prime}$, to provide intuition for why there is no sovereign default risk in equilibrium when the corporate sector is less mismatched.

\subsubsection{Quantitative Results}

In Table 7, we report the key moments for 8 different calibrations of $\alpha_{P}$, as well as a version of the model with only FC sovereign debt, where the corporate debt composition is irrelevant. In the first row, we report the sample average local currency credit spread $\left(s^{L C C S}\right)$, nominal spread $\left(s^{L C / U S}\right)$,

\footnotetext{
${ }^{26}$ As in Chatterjee and Eyigungor (2012), we set a bounded support of this i.i.d. shock at .006 and find it is sufficient to achieve faster convergence for our calibration.
} 
and the share of credit risk in the nominal spread $\left(s^{L C C S} / s^{L C / U S}\right)$. These are the average of currency and credit spreads for 13 countries from 2005-2012 $2^{27}$ calculated following the methodology discussed in Section 2. Each country receives equal weight in computing the sample average. The final column, external sovereign debt-to-GDP, is again just the simple cross-country average, with the external debt/GDP ratio calculated using our data discussed in Section 3. The remaining rows of the table report the simulated moments for the five alternative calibrations of the model, with the baseline calibration in blue with $\alpha_{P}$ set to its sample average of $10 \%$. In our baseline calibration, we come quite close to matching the average cross-country empirical moments, with an average local currency credit spread of $1.10 \%$ as compared to $1.28 \%$ in the data, and a nominal spread of $3.33 \%$ as compared to a mean of $4.77 \%$ in the data. In addition, in the baseline calibration we generate a ratio of external sovereign debt to annual GDP of $8.7 \%$, very close to the $9 \%$ found in the data. By changing $\alpha_{P}$ from $10 \%$ to $50 \%$, we see that credit risk disappears completely for the reasons discussed in the previous section. One key finding of the quantitative model, is that there is a fairly narrow region of the parameter space where both inflation and default are observed in equilibrium. Therefore relatively small changes to the corporate debt composition may have large effects on the risk of sovereign default. In this calibration, we find that the nominal spread on LC sovereign debt does not dramatically increase with the share of LC corporate debt. The mechanisms behind these results are the focus of the next subsection.

\subsubsection{Equilibrium Policy Functions and Bond Prices}

In order to better understand the mechanisms at work in the model, we will begin by looking at the sovereign's policy functions for two different levels of currency mismatch, $\alpha_{P}=10 \%$ (baseline) and $\alpha_{P}=50 \%$ (low mismatch). In Figure 7, we plot the sovereign's equilibrium default and inflation policy functions for different levels of debt outstanding and aggregate productivity. The legend on the right side of each figure indicates the level of inflation, where warmer colors mean higher inflation and crimson indicates explicit default. In the left panel, we plot the baseline case where $10 \%$ of corporate debt is in LC and we see that there is only a small range of low positive inflation before the sovereign chooses to explicitly default on its debt. This is in sharp contrast to the right panel of Figure 7, where half of corporate debt is in LC. Here, we see a wider range of positive inflation before the sovereign actually chooses to default on the debt.

Because lenders recognize the incentives facing the sovereign, these policy functions are embodied in the bond price schedules that ensure that foreign lenders break even in expectation. In Figure 8 , we plot the bond price schedule the sovereign faces in good and bad states for two levels of corporate mismatch. The thick blue lines plot the case where $10 \%$ of private sector debt is in LC and the thin red lines plot the case where $50 \%$ of private sector debt is in LC, with the dashed lines indicating the high productivity state. With only $10 \%$ of debt in LC, the narrow band of positive inflation from the policy function is reflected in the bond price schedule as the government borrows at a relatively high price (low spread) at lower levels of debt before the bond price sharply declines.

\footnotetext{
${ }^{27}$ Russia is excluded because its LC debt was not investable for much of the period.
} 
This reflects the fact that the default threshold is very steep in the amount of debt outstanding. Therefore, there is only a small region of the bond price schedule where the sovereign significantly compensates the lender for currency risk and, as the amount of debt issued increases, the bond price very sharply declines as the sovereign approaches the default threshold. By contrast, when half of corporate debt is in LC, we initially see a more gradual decline in the bond price as the sovereign compensates the lender for the increasing currency risk, and then a sharper decline as default risk becomes more prevalent.

\subsubsection{Debt Laffer Curve}

While these policy functions and bond price schedules are useful for seeing the options facing the sovereign, to understand the difference in equilibrium currency and credit risk in these two economies we have to examine how the sovereign actually borrows when facing these different incentives. In particular, we have to look at the equilibrium bond issuance policy function $\tilde{b}(A, b)$. We will find it particularly useful to focus on the amount of debt the sovereign chooses to issue relative to the amount of debt that would maximize the market value of the debt. In order to do so, we define the gross revenue curve (the market value of the debt), as the quantity of debt times its price $q\left(A, b^{\prime}\right) \cdot b^{\prime} .^{28}$

In the left panel of Figure 9, we plot the gross revenue curve for $\alpha_{P}=10 \%$ and $\alpha_{P}=50 \%$ when aggregate productivity $A$ is at its mean. We see that in both cases the sovereign faces a debt Laffer curve: revenue initially increases with the quantity of debt and then declines as the bond price sharply falls with amount of debt issued. The dotted vertical lines indicate the peak of the debt Laffer curves for the two parameterizations. Because the cost of default is assumed to be independent of the stock of debt, as the face value of debt increases, the sovereign chooses to default in more states. Eventually the bond price goes to zero, as the debt level is high enough that the sovereign will default in the next period regardless of how productive the economy is. As the bond price goes to zero, the market value of outstanding debt $q \cdot b^{\prime}$, also goes to zero. In the right panel of Figure 9, we plot the share of credit risk in the nominal spread for the two parameterizations for each level of borrowing $b^{\prime}$. Using the notation from Section 2, we define the credit share as $\left(s^{L C C S} / s^{L C / U S}\right)$, the LC credit spread divided by the nominal spread. This credit share tells us what fraction of the spread a government pays over the risk-free rate is compensation for the risk that it may default on its debt. The vertical dotted lines are plotted at the peak of the debt Laffer curve, as in the left panel. This plot shows that when $\alpha_{P}=10 \%$, the credit share is positive for all levels of borrowing, increasing slightly as the government approaches the peak of the debt Laffer curve, and then going to $100 \%$ at borrowing levels slightly above the peak. By contrast, when $\alpha_{p}=50 \%$, the credit share is 0 for all borrowing levels below the peak of the debt Laffer curve, and it only becomes positive at debt levels well above the peak of the debt Laffer curve. In other words, debt issued when $\alpha_{P}=10 \%$ always contains credit risk, but when $\alpha_{P}=50 \%$, the debt is free

\footnotetext{
${ }^{28}$ The net revenue raised is only the amount raised from net issuances, $q\left(b^{\prime}, A\right) \cdot\left(b^{\prime}-(1-\zeta) \delta b\right)$. Of course, in the case of one period debt, $\delta=0$ and so gross and net revenue from total bond issuance $b^{\prime}$ coincide.
} 
from default risk unless the sovereign borrows far onto the declining side of the debt Laffer curve. However, if in equilibrium the sovereign issued past the peak of the debt Laffer curve in the region with positive credit risk, then there would be credit risk on debt issued below the peak of the debt Laffer curve. This is because with long-term debt, the bond price today reflects the probability of default in all future periods.

In Figure 10, we plot the share of credit risk in the nominal spread at the peak of the Laffer curve for different levels of $\alpha_{P}$. We see that the credit share gradually falls with the share of private debt in LC. We plot this share for two levels of aggregate productivity, the highest realization and the lowest realization. We see that for each level of productivity, there is a higher share of credit risk when all private debt is in FC than when more private debt is LC. As the share of debt in LC increases, the share of credit risk in the nominal sovereign spread converges to zero for all productivity levels, meaning that the debt Laffer curve peaks because of currency risk alone. ${ }^{29}$ In other words, the total amount of resources that can be raised from lenders is not at all constrained by the risk of a sovereign default and is solely constrained by the temptation to inflate away the debt. In parameterizations of the model that do not generate credit risk at the peak of the debt Laffer curve, we observe no default risk in equilibrium.

In theory, the sovereign may actually choose to borrow past the peak of the debt Laffer curve. This is because if the sovereign borrows using long-term debt, it may be able to raise additional net revenue by borrowing on the declining side of the debt Laffer curve. Despite this possibility, we will show this rarely happens in our calibrated model. It is more convenient to discuss this issue using the terminology of Lorenzoni and Werning (2013), and define our debt Laffer curve as the "stock Laffer curve" and define another object called the "issuance Laffer curve." The stock Laffer curve, $q\left(A, b^{\prime}\right) \cdot b^{\prime}$, is the total market value of outstanding debt as a function of gross issuance $b^{\prime}$ ("stock" because it refers to the total stock of outstanding debt). The issuance Laffer curve $q\left(A, b^{\prime}\right) \cdot\left(b^{\prime}-(1-\zeta) \delta b\right)$ captures the change in new revenue the sovereign raises with new net issuance. Because existing creditors bear the debt dilution losses (the change in the value of outstanding debt $\delta q\left(A, b^{\prime}\right) b$ as the sovereign increases $\left.b^{\prime}\right)$, the issuance Laffer curve can still be increasing even after the sovereign has issued debt past the peak of the stock Laffer curve. This difference between the two Laffer curves could theoretically lead the sovereign to borrow on the declining side of the stock Laffer curve. This is more likely to happen the larger is the sovereign's inherited debt stock $b$ and the smaller the slope of the bond price schedule with respect to $b^{\prime}$. In

\footnotetext{
${ }^{29}$ It may at first seem surprising that the share of credit risk in the nominal spread is a higher share in good states than in bad states, but it is important to remember that this does not imply that in equilibrium we will see more defaults in good states than bad states. Instead, this reflects the fact that default is generally caused by an unexpected deterioration in the aggregate state. Because we have assumed a bounded productivity distribution, in the lowest state, there can be no unexpected drop in productivity. This means that when the government borrows in the worst state, the probability of defaulting in the next period has to be zero: the worst shock possible is to remain in the same state. Because, conditional on debt outstanding, the sovereign defaults when aggregate productivity is below a given threshold, if the sovereign defaulted in this state, it would default in all states and the bond price would be zero. The credit risk in the nominal spread instead represents the probability of future default, that the economy exits the worst state and then experiences a negative shock, leading to default in the future. Therefore, if the sovereign only had access to one-period debt, conditional on being in the lowest state, there can be no credit risk on sovereign debt.
} 
Figure 11, however, we plot the equilibrium bond issuance functions, $\tilde{b}(\bar{A}, b)$ for $\alpha_{P}=10 \%$ and $\alpha_{P}=50 \%$. The dashed lines are the bond issuance levels denoting the peak of the stock Laffer curves for each parameterization of the model. In both cases, as long as the sovereign began the period on the increasing side of the stock Laffer curve, it will not find it optimal to issue on the declining side of the curve. ${ }^{30}$ This explains why when there is no credit risk at the peak of the stock Laffer curve, we observe no sovereign default in equilibrium.

\subsubsection{Theory and Data}

The results in Table 7 show that the model predicts that sovereign credit risk declines very sharply with the share of private LC debt. In order to assess the empirical relevance of this theoretical prediction, we need to examine the relationship between the share of external corporate debt in LC and sovereign default risk on nominal debt. To do so, we regress the LC credit spread on the empirical counterpart of $\alpha_{P}$, the share of external corporate debt in LC, the share of external sovereign debt in LC (which we denote $\alpha_{G}$ ), and the external sovereign and corporate debt-to-GDP ratios. In addition, while we have assumed risk-neutral pricing in the theory, a number of papers, such as Longstaff et al. (2011) and Hilscher and Nosbusch (2010) demonstrate the importance of global factors in determining sovereign spreads. Therefore, we alternately control for the global covariates discussed in Section 4.2 or use time fixed effects.

In Table 8, we estimate a panel regression of the form:

$$
\operatorname{Spread}_{i, t}=\beta_{0}+\beta_{1} \cdot \alpha_{P}+\beta_{2} \cdot \alpha_{G}+\beta_{3}\left(\frac{\text { Ext.Sov.Debt }}{G D P}\right)+\beta_{4}\left(\frac{\text { Ext.Corp.Debt }}{G D P}\right)+\delta X_{t}+\epsilon_{i, t}
$$

where $X_{t}$ is a vector of time-varying global variables. ${ }^{31}$ In Columns 1-4, we estimate the regression at a quarterly frequency, forcing us to drop South Africa from the sample. In Columns 5-8, we estimate the regression at an annual frequency. Because Brazil's LC credit spread is significantly higher than other countries', in columns 3, 4, 7 and 8 we exclude Brazil. When we estimate the quarterly or annual specifications including Brazil, we find that a $1 \%$ increase in the share of external LC corporate debt is associated with a 6-8 basis point reduction in the local currency credit spread. In addition, a $1 \%$ of GDP increase in the total amount of sovereign debt outstanding is associated with an increase in the LC credit spread between 3 and 6 basis points. When we exclude Brazil from the sample, we find that a $1 \%$ increase in the share of external LC corporate debt is associated with a 3-4 basis point reduction in the local currency credit spread, roughly half the size as when Brazil is included.

\footnotetext{
${ }^{30}$ We further explore difference between stock and issuance Laffer curves Appendix B.1.1. In Appendix Figure A3, we examine the difference between the stock and issuance Laffer curves. In Appendix Figure A4, we show that the equilibrium bond issuance function stays weakly below the issuance level at the peak of stock Laffer peak and well below the peak of the issuance Laffer curve.

${ }^{31}$ Although the model only includes LC sovereign debt, the FC sovereign debt share might have been an important omitted variable and so it is included here. However, the results are largely unchanged when this control is omitted.
} 
In Figure 12, we plot two binned scatterplots of the local currency credit spread against the share of corporate debt in LC, after orthogonalizing the LC credit spread on the covariates used columns 5 and 7 of Table 8. We can then regress the residuals on $\alpha_{P}$ and plot the estimated local currency credit spread, averaged across 20 quantiles. These data points are in red, as is the dashed linear fit connecting them. The left panel includes all countries for which we could compute the LC credit spread and the right panel excludes Brazil. We also the plot the mean model-implied LCCS against each level of $\alpha_{P}$, with the model-implied moments in blue along with a linear fit. Here, we restrict $\alpha_{P}$ to be less than the maximum observed country average, which is $30 \%$ for South Africa. In a univariate regression of the orthogonalized LC credit spread on a constant and $\alpha_{P}$, the model implied constant is 189.8 and the slope coefficient on $\alpha_{P}$ is -7.065. Using the orthogonalized LC credit spread for the binned scatter plot, the empirical estimates are an intercept of 198.7 basis points and a slope of -6.15 , neither of which is significantly different that the model-implied slope and intercept. However, the right panel of Figure 12 indicates that Brazil is an important driver of the remarkable equivalence of the empirical and model-implied slope. Because Brazil's LC credit spread may be driven more by capital control risk than credit risk, ${ }^{32}$ we also run the regressions excluding Brazil. When we exclude Brazil, the fit is worsened, but the patterns in the data and model remain quite similar. In both cases, we continue to find support for the model's prediction that relatively small reductions in the share of FC corporate debt lead to large reduction in sovereign credit risk.

\section{Conclusion}

This paper examines why a country would default on its sovereign debt when the government could instead inflate it away. We argue that a government is more inclined to default than inflate when the currency mismatch of the corporate sector implies large adverse balance sheet effects from a currency depreciation. In making this argument, we use a new dataset on the currency composition of emerging market external borrowing to show that the corporate sector remains reliant on external FC debt even as sovereigns have swiftly moved towards borrowing in their own currency. We provide evidence that firms with more FC liabilities are more vulnerable to depreciation. We then show that a higher level of external FC corporate debt is associated with higher sovereign credit risk. Motivated by these empirical findings, we provide an explanation for why sovereign default risk remains on LC debt by presenting a model where mismatched corporate balance sheets increase the cost of inflating away sovereign debt and make default relatively more appealing. We embed a corporate balance sheet channel in the canonical Eaton and Gersovitz (1981) sovereign debt model and demonstrate how higher shares of LC private debt can reduce the default risk on LC sovereign debt in equilibrium by affecting the cost of inflation relative to default and the sovereign's endogenous issuance decision. A calibration of the model matches the patterns of currency and credit risk on LC sovereign debt documented in Du and Schreger (2015). The model implies that

\footnotetext{
${ }^{32}$ We discuss this issue in detail in Du and Schreger (2015).
} 
reductions in the share of FC external debt would significantly reduce sovereign default risk on LC debt.

\section{References}

Adler, M. And B. Dumas (1984): "Exposure to currency risk: definition and measurement," Financial management, 41-50.

Aghion, P., P. Bacchetta, And A. Banerjee (2000): "A simple model of monetary policy and currency crises," European Economic Review, 44, 728-738.

- (2001): "Currency crises and monetary policy in an economy with credit constraints," European Economic Review, 45, 1121-1150.

(2004): "A corporate balance-sheet approach to currency crises," Journal of Economic Theory, 119, 6-30.

Aguiar, M. (2005): "Investment, devaluation, and foreign currency exposure: The case of Mexico," Journal of Development Economics, 78, 95-113.

Aguiar, M., M. Amador, E. Farhi, and G. Gopinath (2013): "Crisis and commitment: Inflation credibility and the vulnerability to sovereign debt crises," Working Paper.

Aguiar, M. And G. Gopinath (2006): "Defaultable debt, interest rates and the current account," Journal of International Economics, 69, 64-83.

Araujo, A., M. Leon, And R. Santos (2013): "Welfare analysis of currency regimes with defaultable debts," Journal of International Economics, 89, 143-153.

Arellano, C. (2008): "Default risk and income fluctuations in emerging economies," American Economic Review, 98, 690-712.

Arellano, C. And A. Ramanarayanan (2012): "Default and the maturity structure in sovereign bonds," Journal of Political Economy, 120, 187-232.

Arslanalp, S. And T. Tsuda (2014): "Tracking global demand for emerging market sovereign debt," IMF Working Paper.

Avdjiev, S., M. K. Chui, And H. S. Shin (2014): "Non-Financial Corporations from Emerging Market Economies and Capital Flows," BIS Quarterly Review December.

Bartram, S. M., G. W. Brown, and B. A. Minton (2010): "Resolving the exposure puzzle: The many facets of exchange rate exposure," Journal of Financial Economics, 95, 148-173.

Benjamin, D. And M. L. Wright (2013): "Recovery before redemption: A theory of delays in sovereign debt renegotiations," Working Paper. 
Bernanke, B. S., M. Gertler, and S. Gilchrist (1999): "The financial accelerator in a quantitative business cycle framework," Handbook of Macroeconomics, 1341-1393.

Bleakley, H. And K. Cowan (2008): "Corporate Dollar Debt and Depreciations: Much ado about Nothing?" Review of Economics and Statistics, 90, 612-626.

Bodnar, G. M. And M. F. Wong (2003): "Estimating exchange rate exposures: issues in model structure," Financial Management, 35-67.

Borensztein, E. And U. Panizza (2009): "The Costs of Sovereign Default," IMF Staff Papers, $56,683-741$.

Brusa, F., T. Ramadorai, And A. Verdelhan (2014): "The International CAPM redux," Available at SSRN 2462843.

Burger, J. D., R. Sengupta, F. E. Warnock, and V. C. Warnock (2014): "US investment in global bonds: As the Fed pushes, some EMEs pull," Tech. rep., National Bureau of Economic Research.

Burger, J. D. And F. E. WARnock (2007): "Foreign participation in local currency bond markets," Review of Financial Economics, 16, 291-304.

Burger, J. D., F. E. Warnock, and V. C. Warnock (2012): "Emerging local currency bond markets," Financial Analysts Journal, 68.

Calvo, G. A. And C. M. Reinhart (2002): "Fear of floating," The Quarterly Journal of Economics, 117, 379-408.

Céspedes, L. F., R. Chang, and A. Velasco (2004): "Balance Sheets and Exchange Rate Policy," American Economic Review, 94, 1183-1193.

Chatterjee, S. And B. Eyigungor (2012): "Maturity, indebtedness, and default risk," American Economic Review, 102, 2674-2699.

Chue, T. K. And D. Cook (2008): "Emerging market exchange rate exposure," Journal of Banking and Finance, 32, 1349-1362.

Chui, M. K., I. Fender, And V. Sushko (2014): "Risks related to EME corporate balance sheets: the role of leverage and currency mismatch," BIS Quarterly Review September.

Corsetti, G. And L. Dedola (2013): "The mystery of the printing press: Self-fulfilling debt crises and monetary sovereignty," Working Paper.

Cowan, K., E. Hansen, And L. Herrera (2011): "Currency mismatches, balance-sheet effects and hedging in Chilean non-financial corporations," IDB Working Paper. 
Cruces, J. J. And C. Trebesch (2013): "Sovereign defaults: The price of haircuts," American Economic Journal: Macroeconomics, 5, 85-117.

Csonto, B. And V. Ivaschenko (2013): "Determinants of Sovereign Bond Spreads in Emerging Markets: Local Fundamentals and Global Factors vs. Ever-Changing Misalignments," International Monetary Fund Working Paper no. 13-164.

Cuadra, G. And H. SAPriza (2008): "Sovereign default, interest rates and political uncertainty in emerging markets," Journal of International Economics, 76, 78-88.

Dominguez, K. M. And L. L. Tesar (2006): "Exchange rate exposure," Journal of International Economics, 68, 188-218.

Driscoll, J. C. AND A. KraAy (1998): "Consistent covariance matrix estimation with spatially dependent panel data," Review of Economics and Statistics, 80, 549-560.

Du, W. And J. Schreger (2015): "Local Currency Sovereign Risk," Working Paper, Harvard University.

Eaton, J. And M. Gersovitz (1981): "Debt with potential repudiation: Theoretical and empirical analysis," Review of Economic Studies, 48, 289-309.

EDWARDS, S. (1984): "LDC foreign borrowing and default risk: An empirical investigation, 197680," The American Economic Review, 726-734.

Eichengreen, B. And R. Hausmann (1999): "Exchange Rates and Financial Fragility," in New Challenges for Monetary Policy, Federal Reserve Bank of Kansas City, 329-68.

Eichengreen, B. And A. Mody (1998): "What explains changing spreads on emerging-market debt: fundamentals or market sentiment?" .

FrAnkel, J. A. (2005): "Contractionary currency crashes in developing countries," Tech. rep., National Bureau of Economic Research.

- (2010): "Monetary policy in emerging markets: A survey," in Handbook of Monetary Economics, ed. by B. Friedman and M. Woodford, vol. 3B, 14-39.

Galindo, A., U. Panizza, and F. Schiantarelli (2003): "Debt composition and balance sheet effects of currency depreciation: a summary of the micro evidence," Emerging Markets Review, 4, 330-339.

Gelos, R. G., R. Sahay, and G. Sandleris (2011): "Sovereign borrowing by developing countries: What determines market access?" Journal of International Economics, 83, 243-254.

Gertler, M., S. Gilchrist, And F. M. NAtalucci (2007): "External constraints on monetary policy and the financial accelerator," Journal of Money, Credit and Banking, 39, 295-330. 
Gertler, M. And P. Karadi (2011): "A model of unconventional monetary policy," Journal of monetary Economics, 58, 17-34.

Griffin, J. M. And R. M. Stulz (2001): "International competition and exchange rate shocks: a cross-country industry analysis of stock returns," Review of Financial Studies, 14, 215-241.

Gurkaynak, R. S., B. Sack, and J. H. Wright (2007): "The U.S. Treasury Yield Curve: 1961 to the Present," Journal of Monetary Economics, 54, 2291-2304.

Hatchondo, J. C. And L. Martinez (2009): "Long-duration bonds and sovereign defaults," Journal of International Economics, 79, 117-125.

Hatchondo, J. C., L. Martinez, And H. Sapriza (2010): "Quantitative properties of sovereign default models: solution methods matter," Review of Economic Dynamics, 13, 919-933.

Hilscher, J. And Y. Nosbusch (2010): "Determinants of sovereign risk: Macroeconomic fundamentals and the pricing of sovereign debt," Review of Finance, 235-262.

Jeanneret, A. And S. Souissi (2014): "Sovereign Defaults by Currency Denomination," Working Paper.

KAmiL, H. (2009): "How do exchange rate regimes affect firms' incentives to hedge currency risk in emerging markets?" International Monetary Fund Working Paper.

Kedia, S. And A. Mozumdar (2003): "Foreign currency-denominated debt: An empirical examination," The Journal of Business, 76, 521-546.

Kim, Y. J., L. Tesar, And J. Zhang (2012): "The Impact of Foreign Liabilities on Small Firms: Firm-Level Evidence from the Korean Crisis," National Bureau of Economic Research.

Korinek, A. (2010): "Excessive dollar borrowing in emerging markets: Balance sheet effects and macroeconomic externalities," Available at SSRN 967524.

Krugman, P. (1999): "Balance Sheets, the Transfer Problem, and Financial Crises," International Tax and Public Finance, 6, 459-472.

Lane, P. R. And J. C. Shambaugh (2010): "Financial exchange rates and international currency exposures," The American Economic Review, 518-540.

Longstaff, F. A., J. Pan, L. H. Pedersen, and K. J. Singleton (2011): "How Sovereign is Sovieregn Credit Risk?" American Economic Journal: Macroeconomics, 3, 75-103.

Lorenzoni, G. And I. Werning (2013): "Slow Moving Debt Crises," NBER Working Paper.

Michaux, M. (2012): "Trade, Exchange Rate Exposure, and the Currency Composition of Debt," AFA Denver Meetings Paper. 
Na, S., S. Schmitt-Grohé, M. Uribe, and V. Z. Yue (2014): "A Model of the Twin Ds: Optimal Default and Devaluation," Tech. rep., National Bureau of Economic Research.

Reinhart, C. M. And K. S. Rogoff (2008): This time is different: Eight centuries of financial folly, Princeton University Press.

_ (2011): "The forgotten history of domestic debt," The Economic Journal, 121, 319-350.

Sunder-Plassmann, L. (2013): "Inflation, default, and the denomination of sovereign debt," Working Paper.

Tauchen, G. (1986): "Finite state markov-chain approximations to univariate and vector autoregressions," Economics letters, 20, 177-181.

URIBE, M. AND V. Z. Yue (2006): "Country spreads and emerging countries: Who drives whom?" Journal of international Economics, 69, 6-36.

Vogelsang, T. J. (2012): "Heteroskedasticity, autocorrelation, and spatial correlation robust inference in linear panel models with fixed-effects," Journal of Econometrics, 166, 303-319.

Yeyati, E. L. And U. PAnizza (2011): "The elusive costs of sovereign defaults," Journal of Development Economics, 94, 95-105. 


\section{Figures}

Figure 1: Share of Foreign Ownership of Outstanding Domestic LC Sovereign Debt Securities

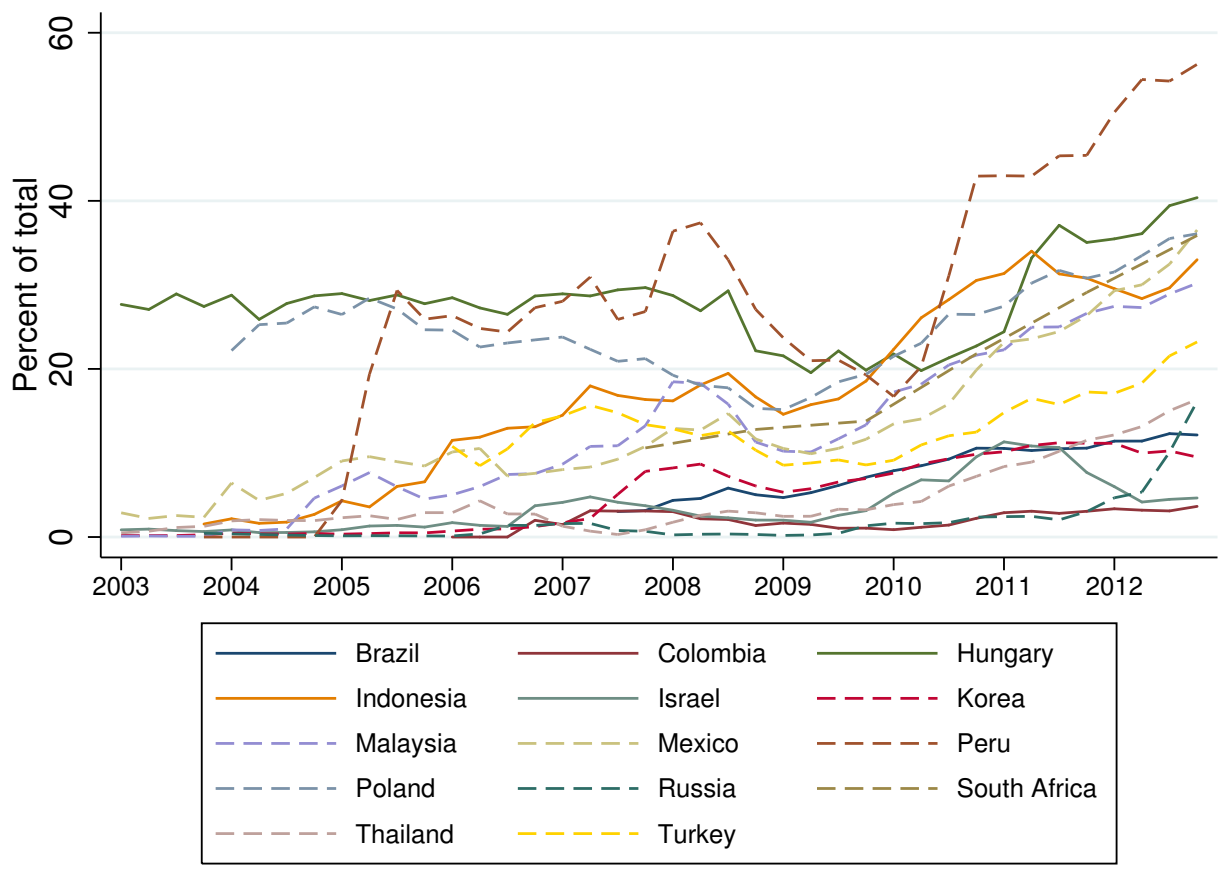

Notes: Share of foreign ownership of domestic sovereign debt in 14 emerging markets. Data are from national sources or the Asian Development Bank, with details in the appendix. 
Figure 2: Currency Risk, Credit Risk and the Nominal Spread on LC Sovereign Debt: Cross-Country Average

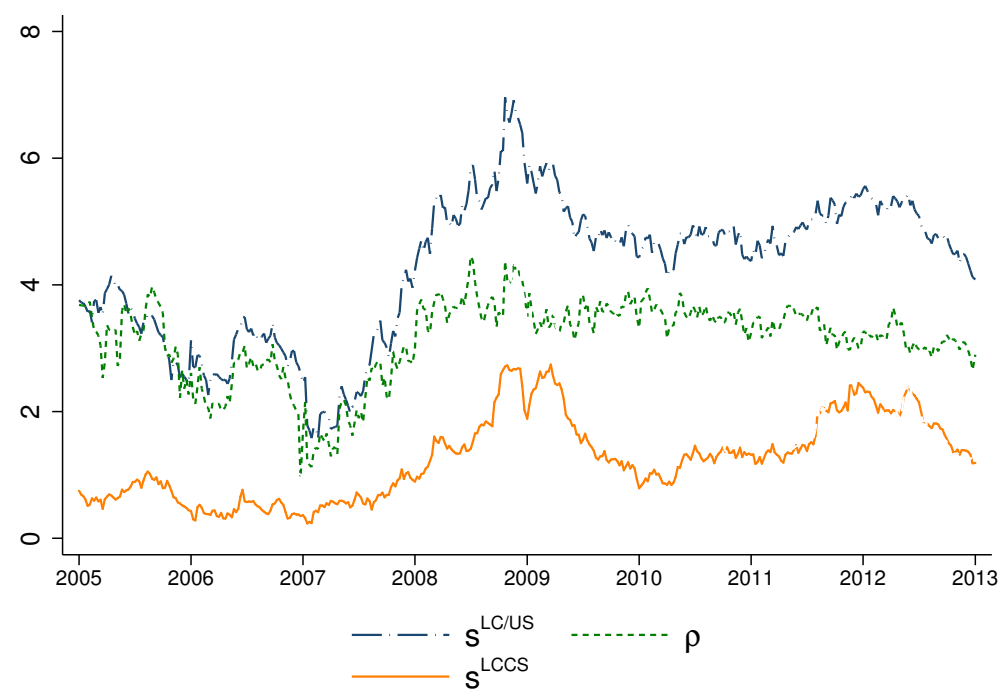

Notes: $s^{L C / U S}$ is the nominal spread between a 5 year LC sovereign bond a 5 year US Treasury. $\rho$ is the fixed-forfixed 5-year zero coupon cross-country swap rate. $s^{L C C S}$ is the local currency credit spread, the difference between $s^{L C / U S}$ and $\rho$. The countries included are Brazil, Colombia, Hungary, Israel, South Korea, Mexico, Malaysia, Peru, Philippines, Poland, Thailand, Turkey and South Africa. All data are from Bloomberg.

Figure 3: Credit Risk on LC and FC Sovereign Debt: Cross-Country Average

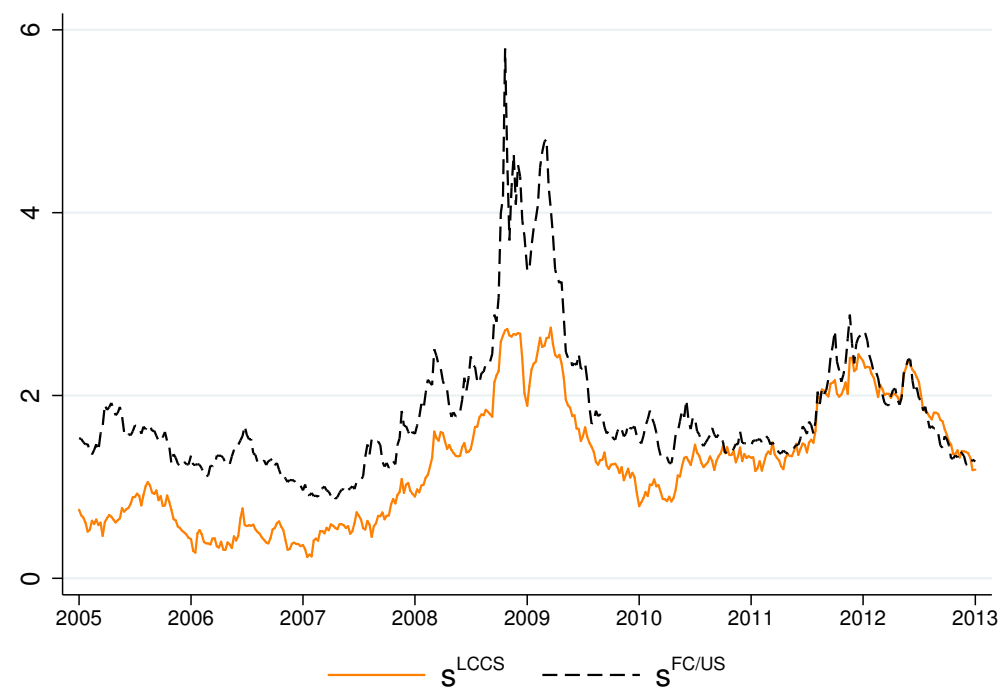

Notes: $s^{L C C S}$ is the local currency credit spread, the difference between $s^{L C / U S}$ and $\rho . s^{F C / U S}$ is the foreign currency credit spread derived from credit default swaps. The countries includes are Brazil, Colombia, Hungary, Israel, South Korea, Mexico, Malaysia, Peru, Philippines, Poland, Thailand, Turkey and South Africa. CDS data are from Markit and LC nominal yields and cross currency swap rates from Bloomberg. 
Figure 4: Share of External Debt in LC (Mean of 14 sample countries)

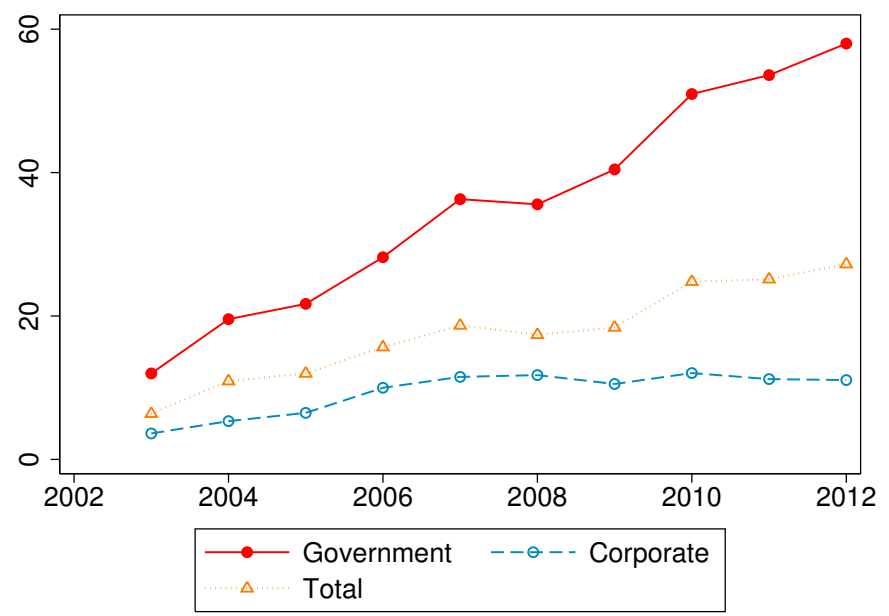

Notes: This figure plots the cross-country mean of the share of external debt by sector in LC. The cross-country mean gives each country in the sample an equal weight. Within each country, the share of total debt in LC is the weighted average of the share of sovereign and corporate debt in LC, weighted by the amount of each type of debt outstanding. The countries included in the sample are Brazil, Colombia, Hungary, Indonesia, Israel, South Korea, Malaysia, Mexico, Peru, Poland, Russia, South Africa, Thailand and Turkey.

\section{Figure 5: External Debt/GDP by Currency and Sector}
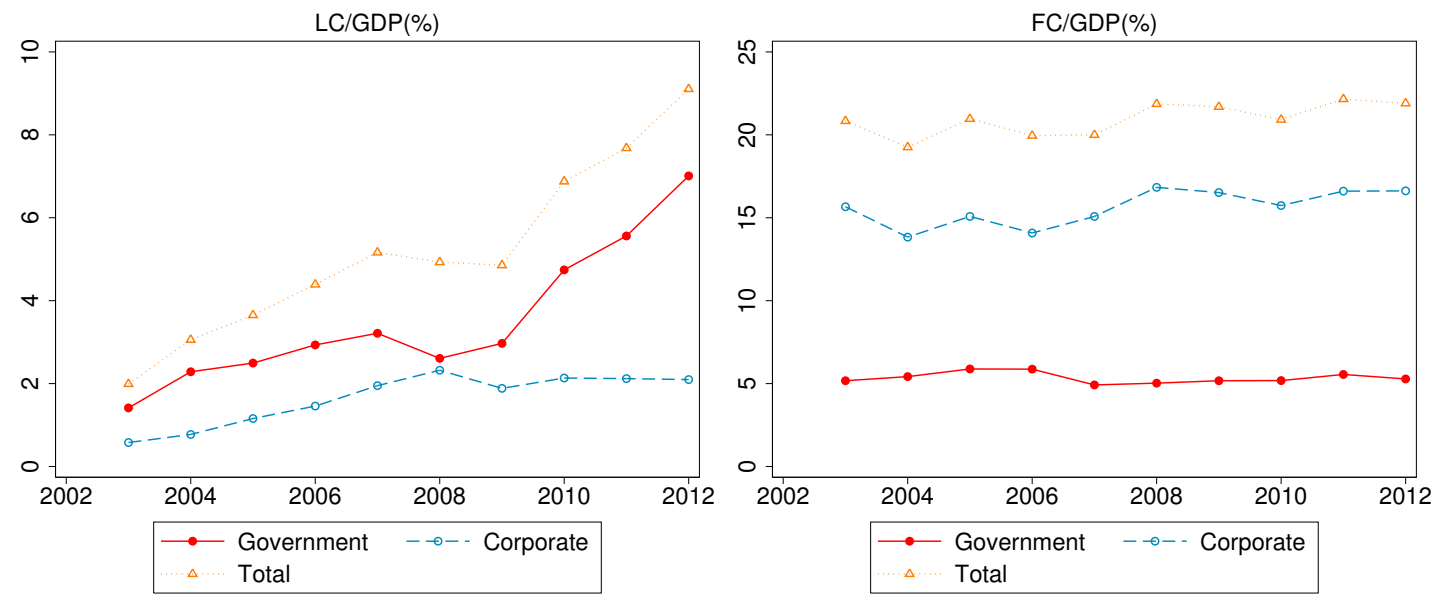

Notes: The left panel plots the cross-country mean of amount of external LC debt outstanding, as a share of GDP, for the government, private sector, and the sum of the two. The right panel plots the cross-country mean of amount of external FC debt outstanding for the same three categories. The cross-country mean equally weights all countries in the sample. The countries in the sample are Brazil, Colombia, Hungary, Indonesia, Israel, South Korea, Malaysia, Mexico, Peru, Poland, Russia, South Africa, Thailand and Turkey. 
Figure 6: Corporate External Borrowing and Sovereign Default Risk, 2005-2012
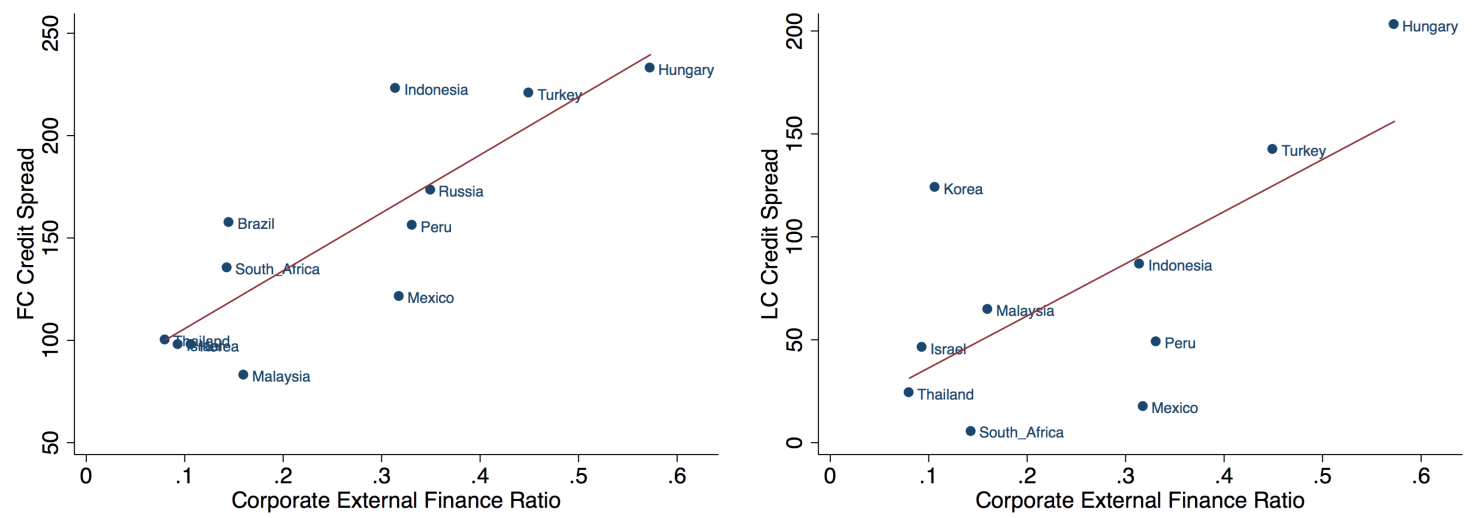

Notes: Left panel plots the mean sovereign FC credit spread derived from CDS markets (y-axis) against the mean corporate external finance ratio (x-axis). Right panel plots the mean sovereign LC credit spread (y-axis) against the mean corporate external finance ratio on the (x-axis). Each observation is the mean of year-end observations in each country from 2005-12. Russia and Brazil are included in the FC figure but are excluded from LC figure. As discussed in detail in Du and Schreger (2015), capital controls are the dominant factor in the Brazilian LC credit spread and the Russian LC bond market is not investable during this period.

Figure 7: Inflation Policy Function and Default Region: $\alpha_{P}=10 \%$ (Left), $\alpha_{P}=50 \%$ (Right)
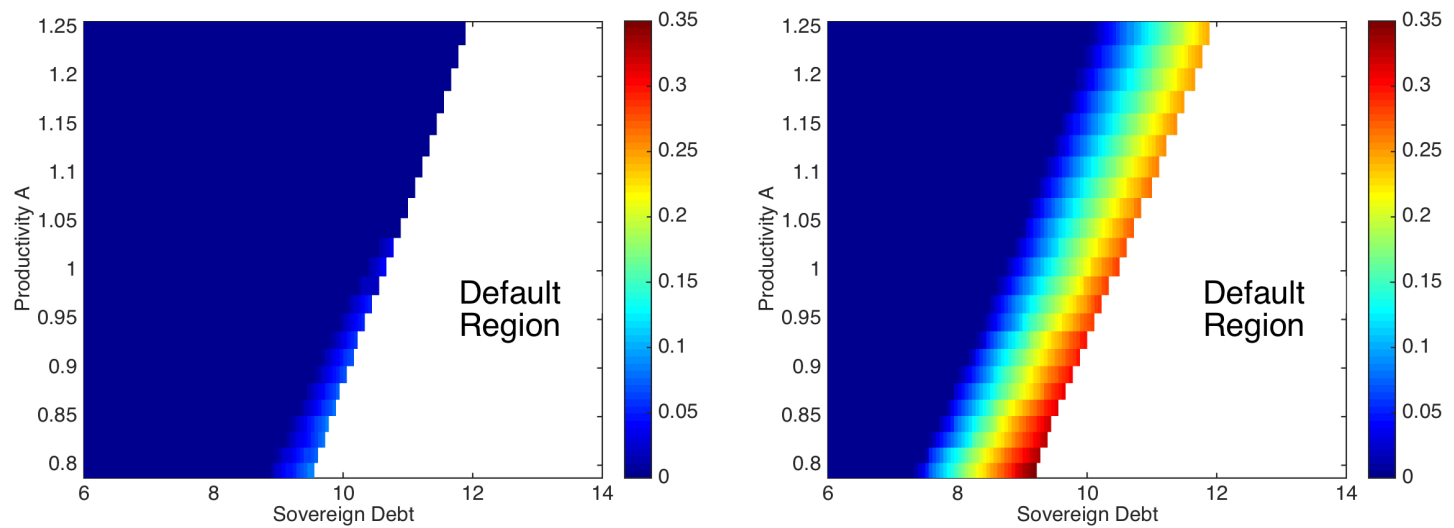

Notes: This figure plots the inflation policy function and the default set for two calibrations of the dynamic model. The left panel sets the share of LC private debt $\alpha_{P}=10 \%$ and the right panel sets $\alpha_{P}=50 \%$. The coloring of the figure indicates the equilibrium inflation rate the sovereign chooses for a given amount of inherited debt and productivity level. The white region in the lower right hand corner denotes the region where the sovereign explicitly defaults and the dark blue in the upper left hand corner denotes repayment and zero inflation. In between, as the colors get warmer, the inflation rate is rising. The inflation rate corresponding to each color is given by the bar to the right of each figure. 
Figure 8: Bond Price Schedule

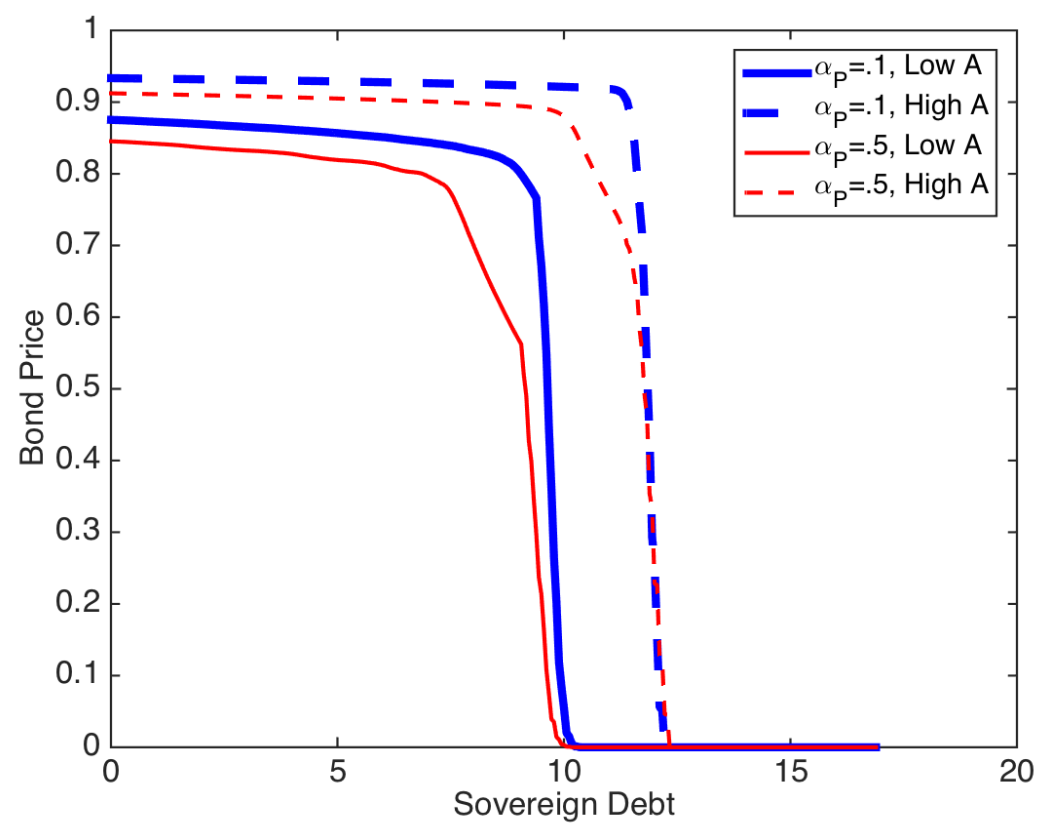

Notes: This figure plots the bond price schedule $q\left(A, b^{\prime}\right)$ for two calibrations of the model. The x-axis denotes the amount of sovereign bonds a government can issue $b^{\prime}$ and the $\mathrm{y}$-axis the bond price $q$. The thick blue lines refer to the baseline calibration of the model when the share of corporate debt in LC $\alpha_{P}=10 \%$ and the thin red lines refer to the calibration of the model when $\alpha_{P}=50 \%$. The dashed lines refer to the case when aggregate productivity $A$ is at its highest value and the solid lines refer to the case when aggregate productivity is at its lowest value.

Figure 9: The Debt Laffer Curve (Left) and the Share of Credit Risk (Right)
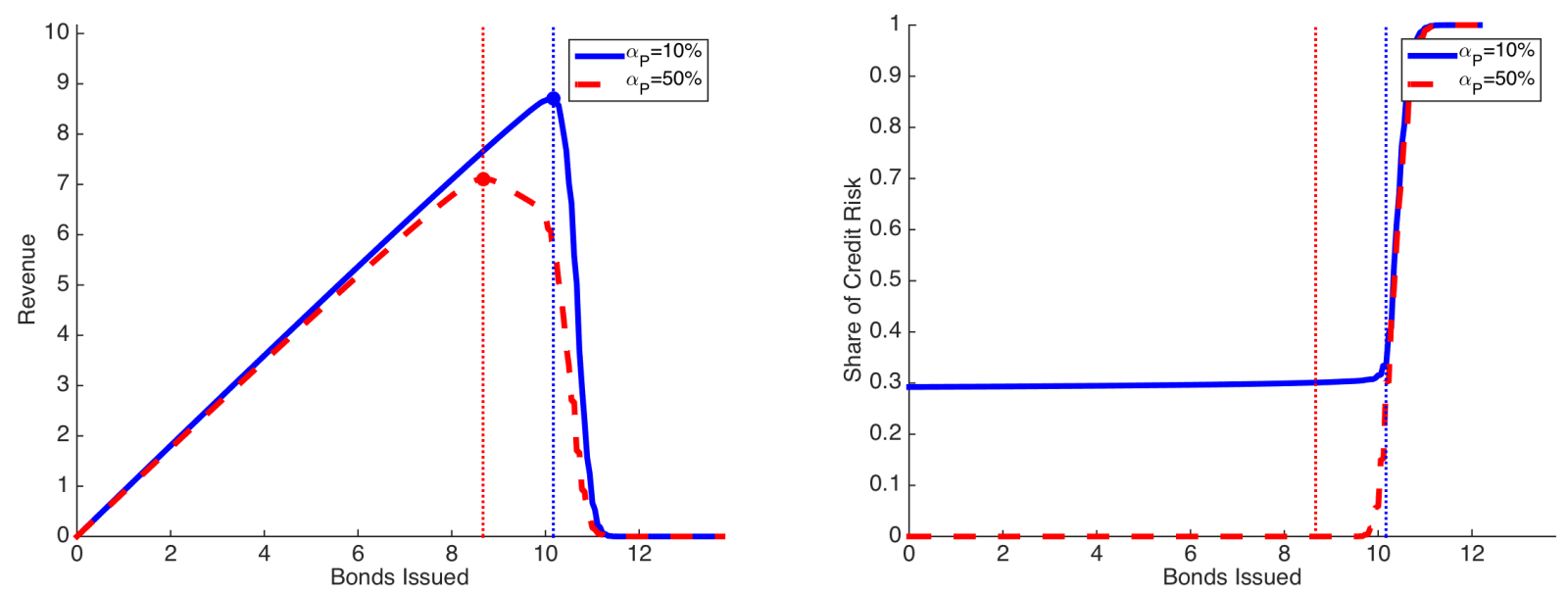

Notes: The left panel of the figure plots the Revenue curve $\left(q \cdot b^{\prime}\right)$ against the bond issuance curve $\left(b^{\prime}\right)$ for the case when $\alpha_{P}=.1$ and $\alpha_{P}=.5$. The blue curve plots the case where $\alpha_{P}=.1$ and the red curve plots the case where $\alpha_{P}=.5$. All figures are plotted for when $A=\bar{A}$. The vertical dashed lines are plotted at the peak of the two debt Laffer curves. In the right panel, the two curves plot the share of credit risk in the nominal spread $\frac{s^{L C C S}}{s^{L C / U S}}$ for each level of borrowing $b^{\prime}$. The vertical lines are the same as in the left panel, denoting the peak of the debt Laffer curve. The credit share plot is plotted in dashed lines after the peak of the debt Laffer curve. 
Figure 10: Share of Credit Risk at Peak of Laffer Curve

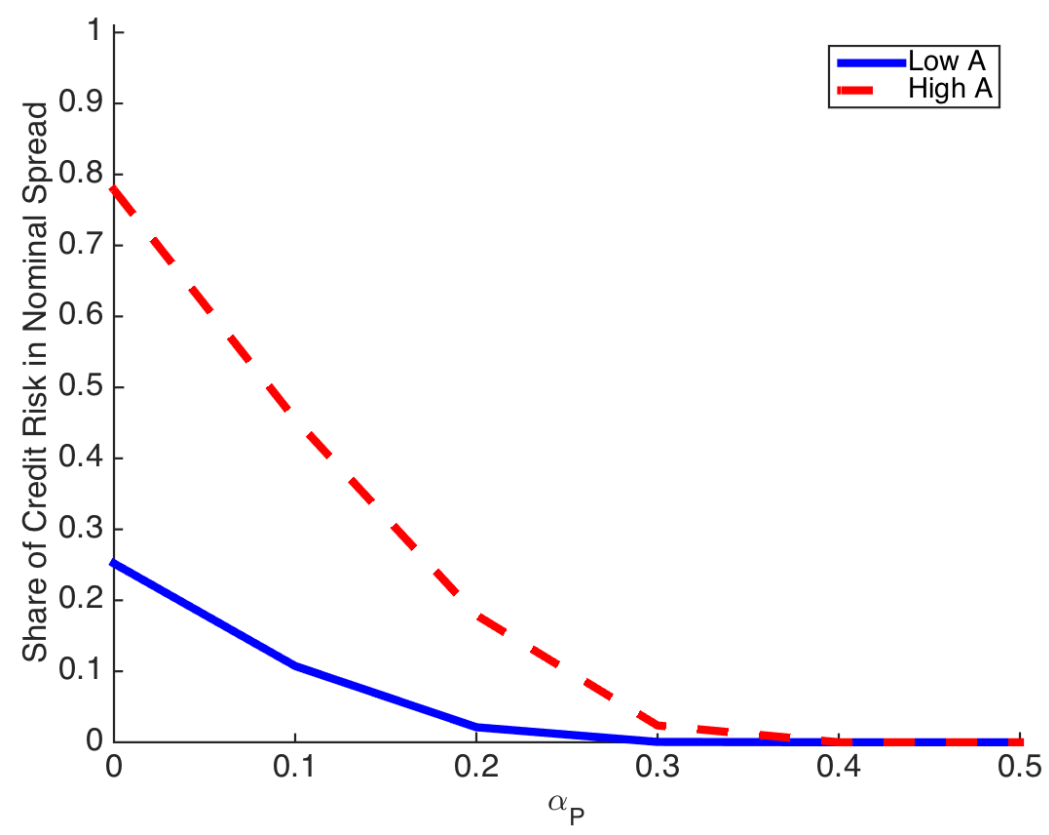

Notes: This figure plots the share of credit risk in the nominal spread $\left(s^{L C C S} / s^{L C U S}\right)$ at the peak of the debt Laffer curve for different levels of $\alpha_{P}$, the share of corporate debt in LC. The dashed red line plots the case when aggregate productivity $A$ is at its peak and the blue line plots the case when aggregate productivity $A$ is at its trough. 
Figure 11: Debt Laffer Curve and Debt Issuance Policy

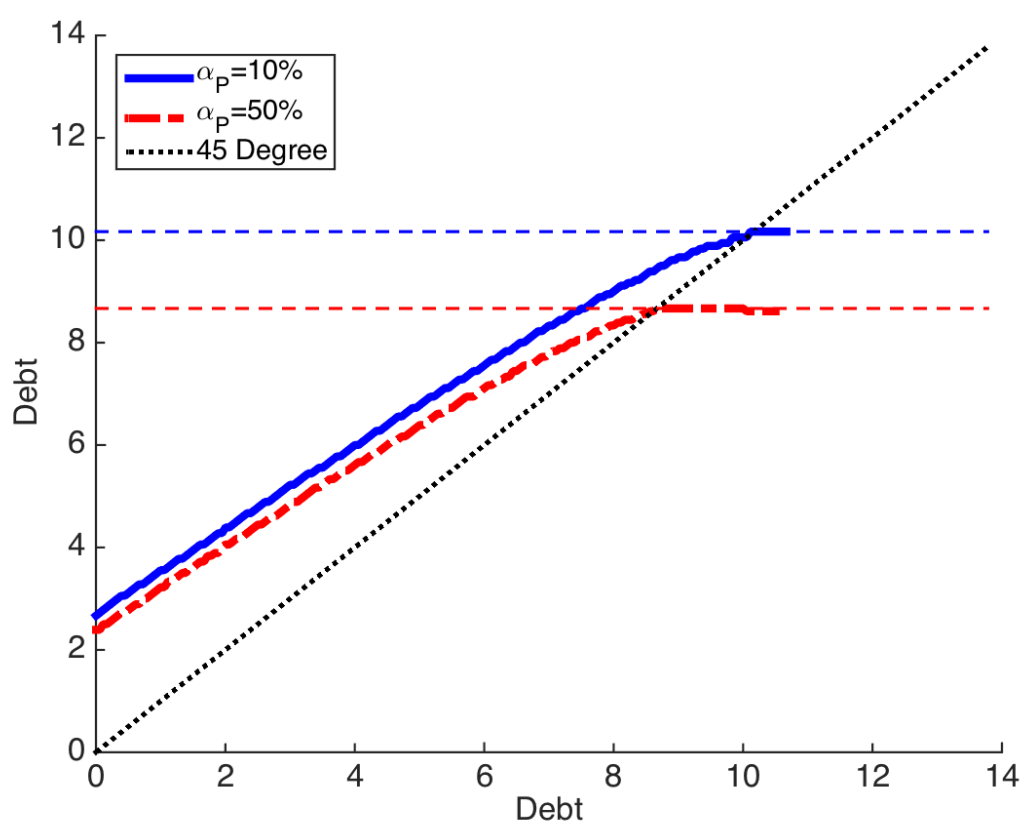

Notes: This figure plots the bond issuance policy function $\tilde{b}(\bar{A}, b)$ for average productivity $\bar{A}$ when $\alpha_{P}=10 \%$ (thick solid blue) and $50 \%$ (thin dashed red). Last period's debt issuance $b$ is on the x-axis and this period's issuance $b^{\prime}$ is on the y-axis. The thin dashed red and blue lines are plotted at the level at which the debt Laffer curve $q\left(\bar{A}, b^{\prime}\right) b^{\prime}$ is maximized for $\alpha_{P}=10 \%$ and $50 \%$, respectively. The dotted black line is the 45 degree line, so that when the bond issuance policy functions are above the dotted black line $\tilde{b}(\bar{A}, b)>b$.

Figure 12: LC Credit Spread and the Share of Private Debt in LC
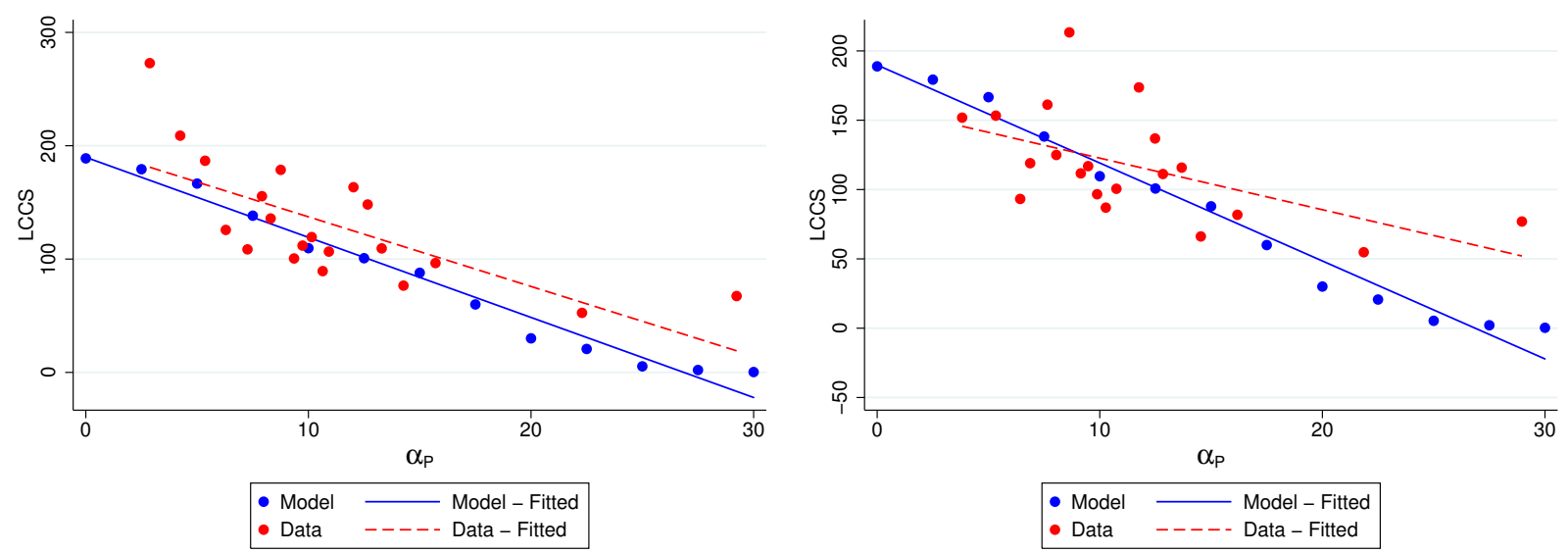

Notes: The figures plots the empirical and model generated relationship between the LC credit spread and the share of corporate debt in LC, $\alpha_{P}$. The empirical plots (dashed red, and red dots) are derived by orthogonalizing the LC credit spread on the variables in column 5 and 7 in Table 8 and then plotting them as a binned scatterplot. The left panel includes all countries and the right panel excludes Brazil. The model observations (solid blue, and blue dots) are generated by solving the model for different values of $\alpha_{P}$ and calculating the simulated mean LC credit spread, as in Table 7. 


\section{Tables}

Table 1: Currency, Market and Sector Classification of External Debt

\begin{tabular}{|c|c|c|c|c|c|}
\hline \multicolumn{3}{|c|}{ Government Debt } & \multicolumn{3}{|c|}{ Corporate Debt } \\
\hline \multirow{3}{*}{$\begin{array}{c}\text { Domestic } \\
\text { International }\end{array}$} & LC & $\mathrm{FC}$ & \multirow{3}{*}{$\begin{array}{c}\text { Domestic } \\
\text { International }\end{array}$} & LC & $\mathrm{FC}$ \\
\hline & LC Dom & FC Dom & & LC Dom & FC Dom \\
\hline & LC Int & FC Int & & LC Int & FC Int \\
\hline
\end{tabular}

Notes: "LC Dom" refers to local currency domestic debt; "FC Dom" refers to foreign currency domestic debt; "LC Int" refers to local currency international debt; and "FC Int" refers to foreign currency international debt.

Table 2: Share of External Borrowing in Local Currency

\begin{tabular}{|c|c|c|c|c|}
\hline & \multicolumn{2}{|c|}{ Sovereign } & \multicolumn{2}{|c|}{ Corporate } \\
\hline & 2004 & 2012 & 2004 & 2012 \\
\hline Brazil^^ & 34.8 & 66.8 & 4.2 & 5.3 \\
\hline Colombia^ $^{\wedge}$ & 12.2 & 15.1 & 16.2 & 7.7 \\
\hline Hungary & 50.9 & 48.2 & 6.5 & 10.6 \\
\hline Indonesia & 25.3 & 46.0 & 5.5 & 8.4 \\
\hline Israel & 5.8 & 37.6 & 1.4 & 6.4 \\
\hline Korea & 8.1 & 83.1 & 3.1 & 4.2 \\
\hline Malaysia & 22.9 & 89.2 & 5.6 & 9.3 \\
\hline Mexico & 12.6 & 71.3 & 4.6 & 11.7 \\
\hline Peru & 0.0 & 46.4 & 0.3 & 6.7 \\
\hline Poland & 53.0 & 46.3 & 19.5 & 19.8 \\
\hline Russia & 0.1 & 37.7 & 0.8 & 11.2 \\
\hline South Africa^^ & 42.8 & 77.0 & 26.4 & 32.6 \\
\hline Thailand & 17.0 & 97.9 & 6.1 & 9.0 \\
\hline Turkey^ & 38.9 & 49.3 & 9.0 & 12.0 \\
\hline
\end{tabular}

Notes: ^ indicates that 2006 data is used for the 2004 column and ^^ indicates that 2007 data is used for the 2004 column because that is the first year of data availability. Each value represents the percentage of external borrowing for the sovereign or corporate sector that is in LC at the end of each year. 


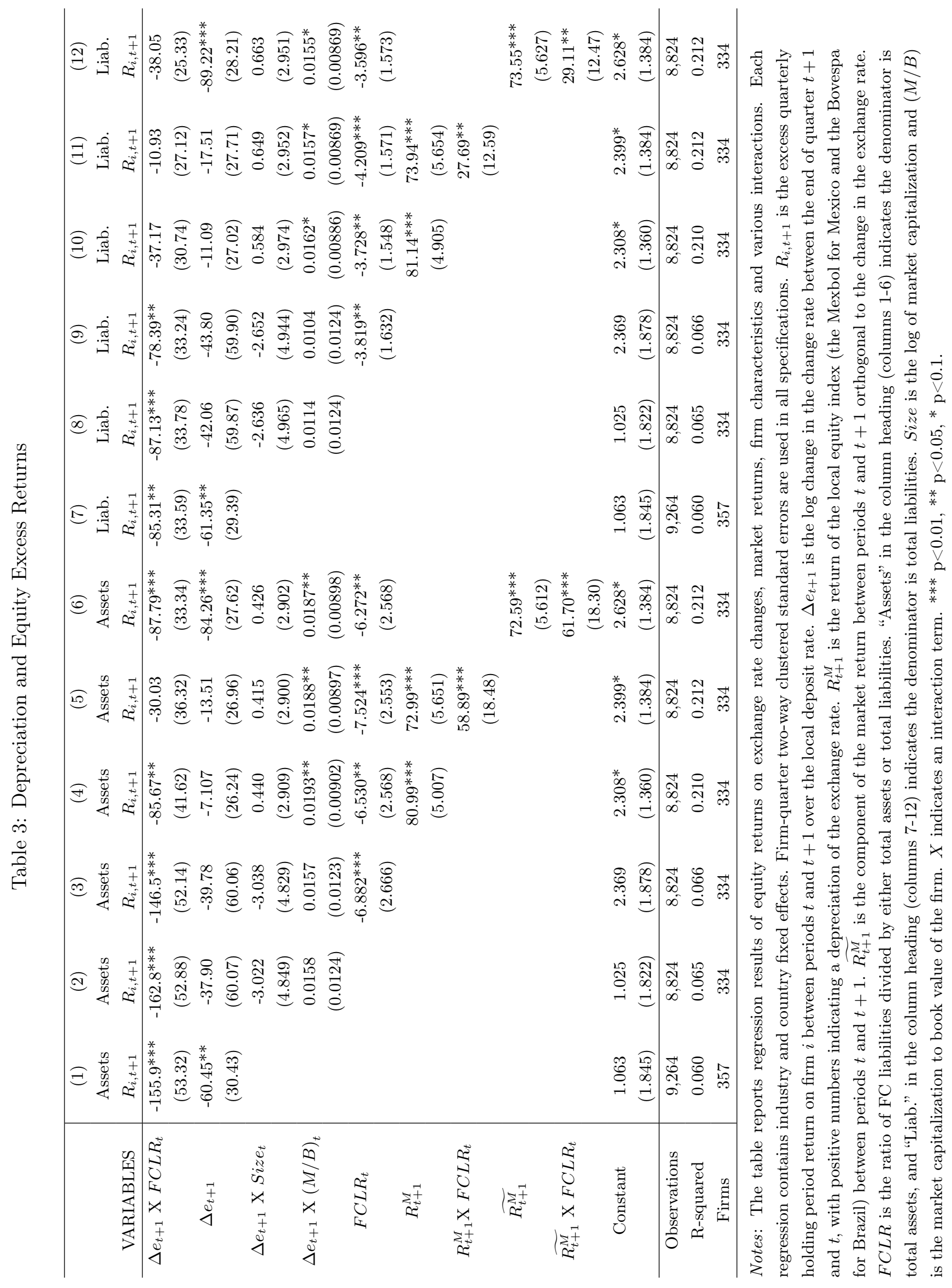




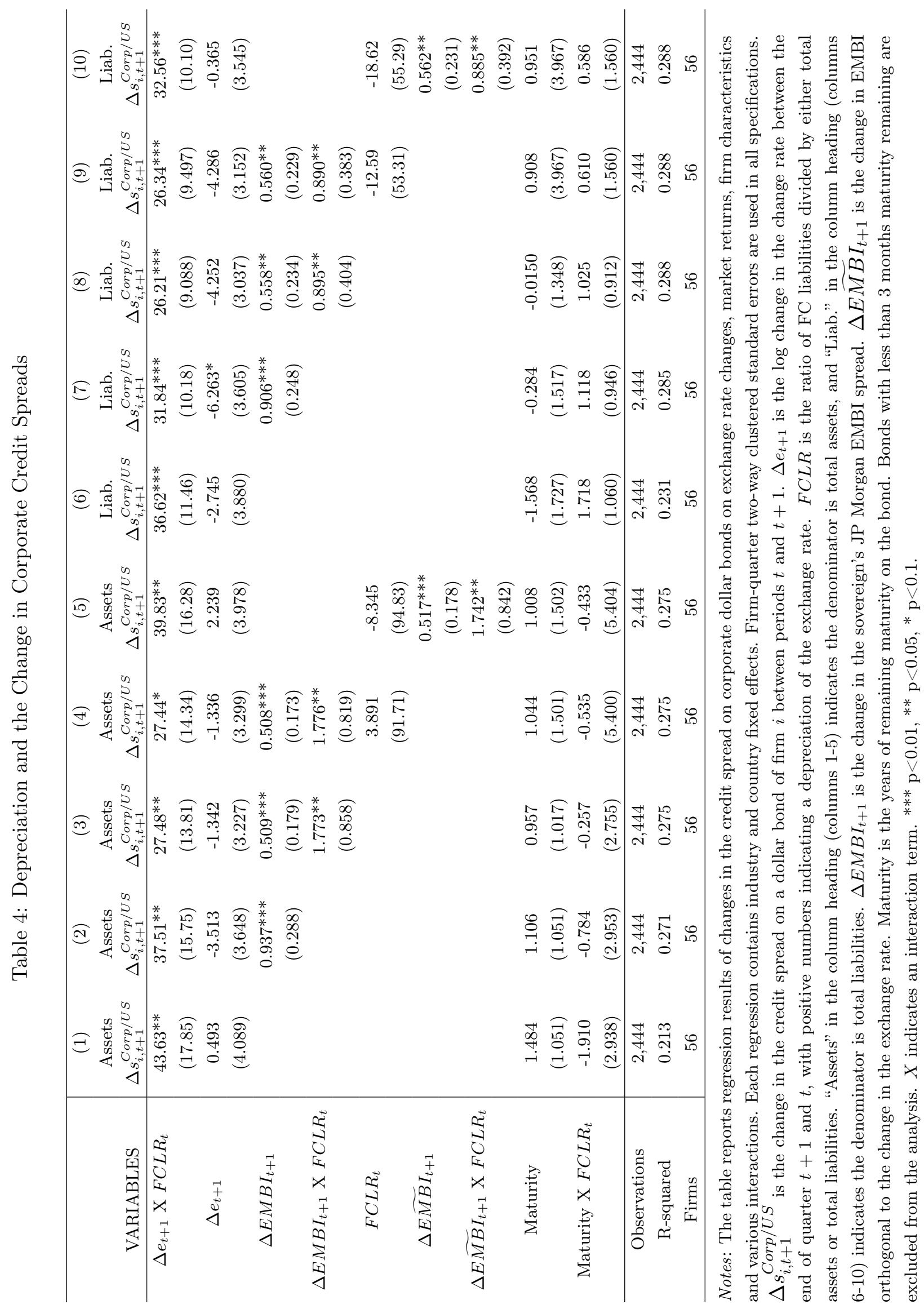




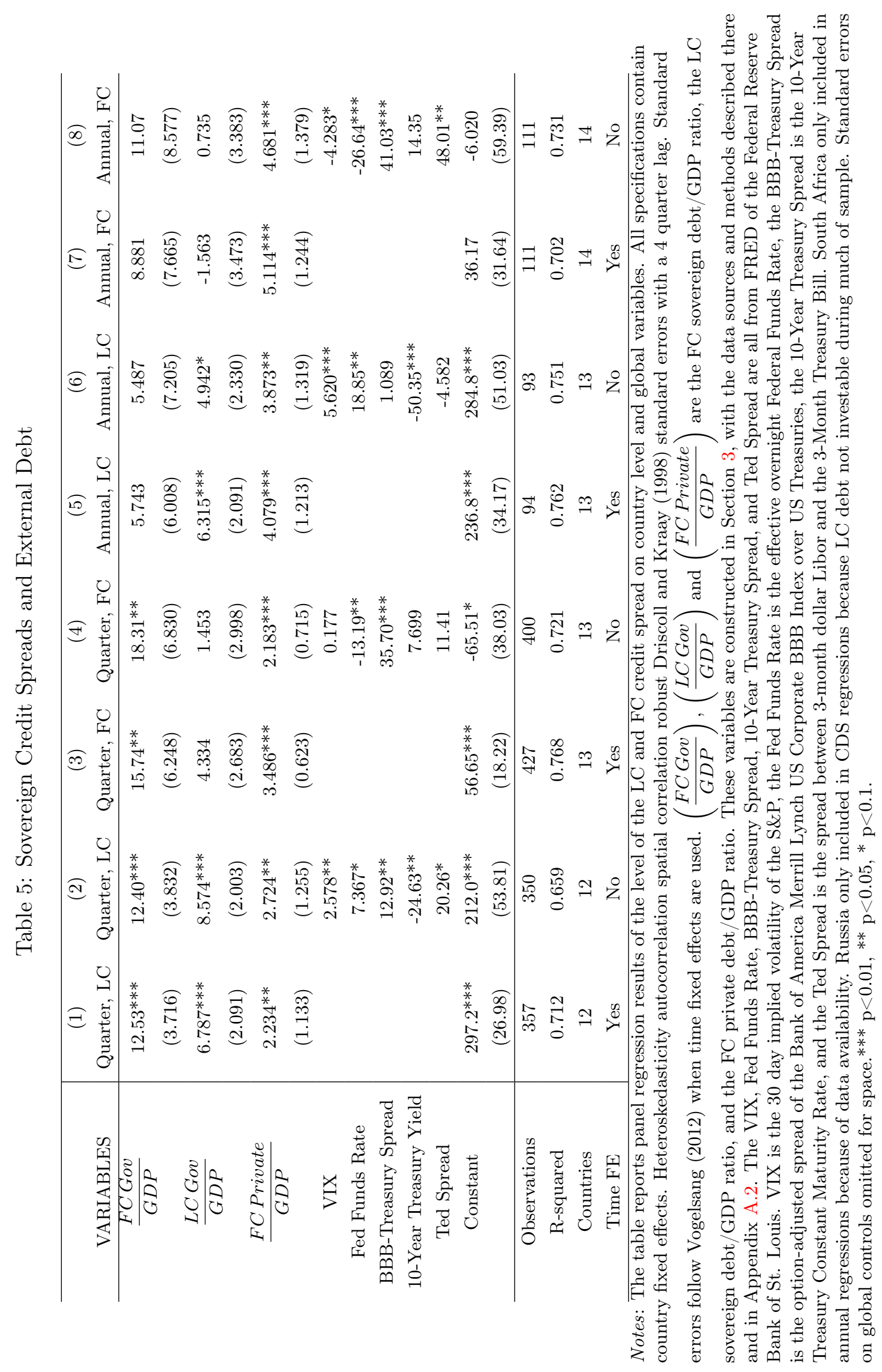


Table 6: Calibration (Quarterly)

\begin{tabular}{|c|c|c|}
\hline Parameter & Value & Description \\
\hline$\gamma$ & $1 / 3$ & Mean of Domestic/Total Corp. Financing in 2012Q4 \\
$\mathrm{Z}$ & .51 & External Corp/GDP of 17\% \\
$\omega$ & 1.5017 & $X=1$ if $\zeta=0$, inflation differential at 2000-2012 mean \\
$\xi$ & 3.025 & $X=1$ if $\zeta=0$, inflation differential at 2000-2012 mean \\
$\alpha_{P}$ & .1 & $\begin{array}{c}10 \% \text { of Corporate Debt in LC } \\
\delta\end{array}$ \\
$\beta$ & .9595 & Risk-Free Sovereign Duration of 5 years \\
$\mu$ & .95 & Discount Factor \\
$d_{0}, d_{1}$ & .75 & Share of fixed prices \\
$\sigma$ & $0.0174,0.0160]$ & Default costs: 3\% cost in bad state, 3.75\% in best state \\
$\rho$ & 2 & CRRA \\
$\sigma_{z}$ & .9 & AR(1) persistence (A\&G 2006) \\
$\lambda$ & .034 & S.D. of Log of Aggregate Productivity (A\&G 2006) \\
$r^{*}$ & $10 \%$ & Probability of redemption ((A\&G 2006)) \\
\hline
\end{tabular}

Notes: A\&G 2006 refers to Aguiar and Gopinath (2006).

Table 7: Key Moments

\begin{tabular}{|c|c|c|c|c|c|}
\hline & $\begin{array}{c}\text { Share LC Debt } \\
\alpha_{P}\end{array}$ & $\begin{array}{c}\text { Mean LCCS } \\
s^{L C C S}\end{array}$ & $\begin{array}{c}\text { Mean Nom. Spread } \\
s^{L C / U S}\end{array}$ & $\begin{array}{c}\text { Credit Share } \\
s^{L C / U S} / s^{L C C S}\end{array}$ & $\begin{array}{c}\text { Sov. Debt/GDP } \\
B / Y\end{array}$ \\
\hline Data & $10 \%$ & 1.28 & 4.77 & $26.8 \%$ & $9 \%$ \\
FC Debt & - & 2.0 & 2.0 & $100 \%$ & $9.8 \%$ \\
Model & $0 \%$ & 1.89 & 2.66 & $70.9 \%$ & $8.9 \%$ \\
Model & $5 \%$ & 1.67 & 2.98 & $55.9 \%$ & $8.8 \%$ \\
Model & $10 \%$ & 1.10 & 3.33 & $32.9 \%$ & $8.7 \%$ \\
Model & $15 \%$ & 0.88 & 3.73 & $23.6 \%$ & $8.5 \%$ \\
Model & $20 \%$ & 0.30 & 4.09 & $7.3 \%$ & $8.4 \%$ \\
Model & $25 \%$ & 0.05 & 4.28 & $1.2 \%$ & $8.2 \%$ \\
Model & $30 \%$ & 0.00 & 4.31 & $0.1 \%$ & $8.0 \%$ \\
Model & $50 \%$ & 0.00 & 4.34 & $0.0 \%$ & $7.1 \%$ \\
\hline
\end{tabular}

Notes: This table reports the empirical and model generated moments of currency and credit risk. The first row, Data, reports the mean local currency credit spread $s^{L C C S}$, nominal spread $s^{L C / U S}$, share of credit risk in the nominal spread $s^{L C / U S} / s^{L C C S}$ and external debt-to-GDP ratio $B / Y$ for the 13 countries in our dataset from 2005-2012. All subsequent rows report the mean model-generated parameters for different calibrations. The row labeled FC debt refers to a version of the model where the sovereign cannot choose to inflate, and so the LC share $\alpha_{P}$ is irrelevant. The next 8 columns refer to different calibrations of the model, with the share of corporate debt in LC $\alpha_{P}$ given by the first column. Our baseline results refer to the case when $\alpha_{P}=10 \%$. 


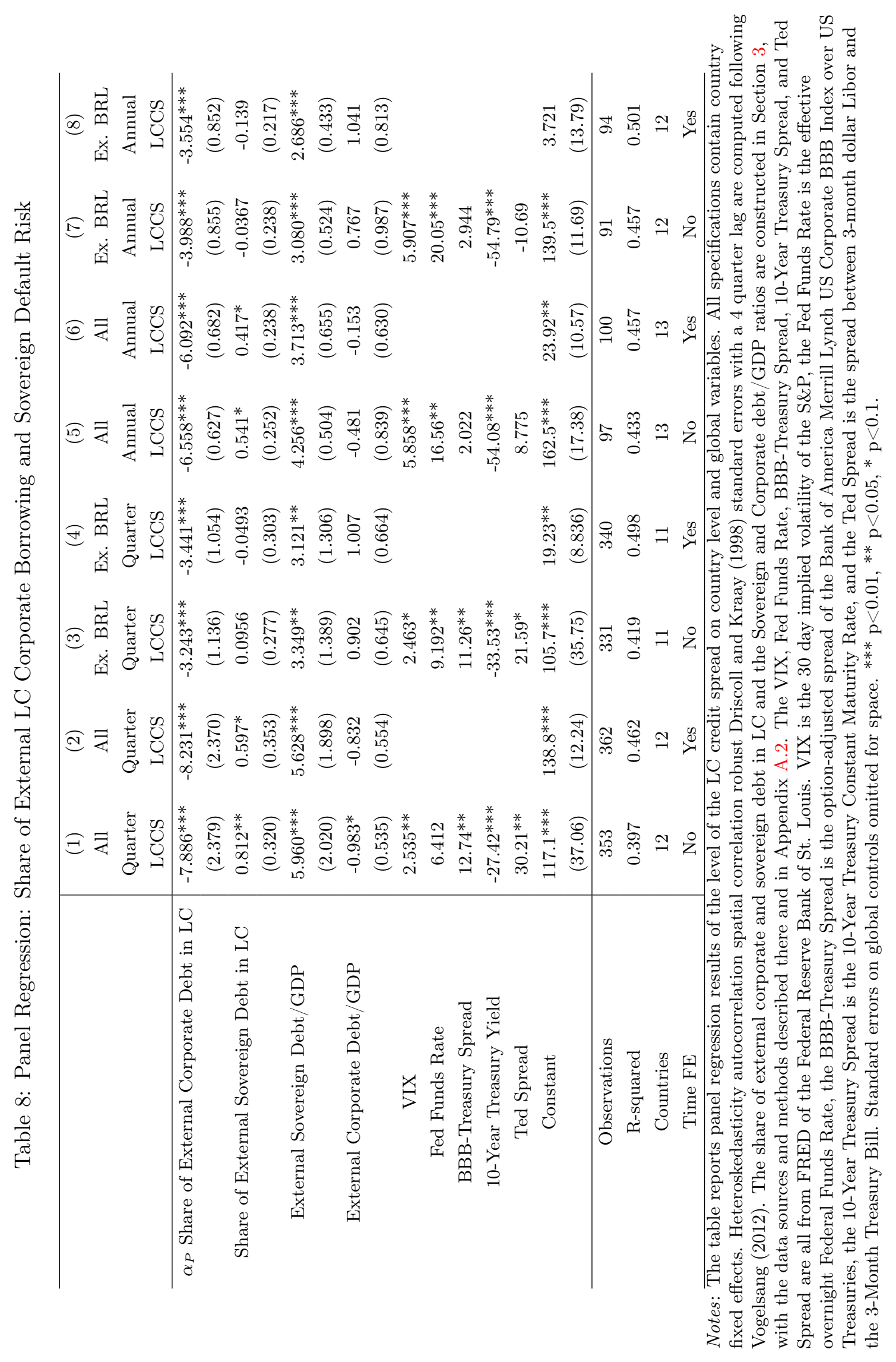




\section{Appendix}

\section{A Empirical Appendix}

\section{A.1 LC Sovereign Risk}

Table A1: Credit and Currency Risk in LC Sovereign Debt, 5-year bonds, 2005-2012

\begin{tabular}{|c|cccc|}
\hline Country & Start & $s^{\text {LC/US }}$ & $s^{L C C S}$ & $\rho$ \\
\hline Brazil & Feb 2007 & 10.36 & 3.57 & 6.79 \\
Colombia & Jun 2005 & 6.23 & 1.49 & 4.74 \\
Hungary & Oct 2006 & 5.97 & 2.43 & 3.53 \\
Indonesia & Jan 2005 & 7.10 & 1.30 & 5.80 \\
Israel & Feb 2006 & 2.38 & 0.99 & 1.39 \\
Korea & Jan 2005 & 2.06 & 1.65 & 0.42 \\
Malaysia & May 2005 & 1.26 & 1.12 & 0.15 \\
Mexico & Jan 2005 & 4.89 & 0.64 & 4.24 \\
Peru & Jul 2006 & 3.83 & 0.91 & 2.92 \\
Poland & Nov 2006 & 3.73 & 1.33 & 2.40 \\
South Africa & Jan 2005 & 5.53 & 0.52 & 5.01 \\
Thailand & Jan 2005 & 1.50 & 0.69 & 0.81 \\
Turkey & May 2005 & 10.14 & 1.84 & 8.30 \\
\hline
\end{tabular}

Notes: This table reports the country average nominal spread, $s^{L C / U S}$, LC credit spread $s^{L C C S}$, and cross currency swap rate $\rho$ for 13 emerging markets form 2005-2012. Start indicates the first month for which we were able to estimate a local currency sovereign yield curve and data on cross-currency swaps were available. Yield curve and cross currency swap data from Bloomberg.

\section{A.2 Currency Composition of External Portfolios}

\section{A.2.1 International Debt Securities}

We obtain country-level data on international sovereign debt outstanding from the BIS debt securities statistics. The BIS defines international debt as debt issued outside the market where the borrower resides (Table 11) or the nationality of the borrower (Table 12). For sovereigns, there is no difference between the residence and nationality definitions. Source: BIS. As discussed in the text, we collect data on international LC sovereign bonds from Bloomberg and international LC bonds from Thomson.

\section{A.2.2 Domestic Sovereign Debt}

In this section, we describe the data sources for foreign ownership of domestic sovereign debt.

- Brazil: Source: Brazilian Central Bank (direct contact). Ownership data are available at the security type level. Data on domestic debt outstanding by instruments are available. Includes foreign ownership of LFT (Financial Treasury Bills), LTN (National Treasury Bills), NTN (National Treasury Notes)

- Colombia: Source: Colombia Ministry of Finance (in Spanish). Only contains data only on Treasury Bonds. Ownership data are available at the security type level (i.e. fixed rate local currency and inflation-indexed). Data on domestic debt outstanding by instruments are 
available. Link to raw data: Source: Colombian Ministry of Finance (in Spanish)(last access: March 3, 2014).

- Hungary: Source: AKK - Hungarian Government Debt Management Agency. Quarterly data distinguishes between Treasury Bonds and Treasury Bills but the daily non-resident ownership data does not. Ownership data by interest rate types (i.e. fixed, floating, indexed) are not available. Links: to raw data: Data on domestic debt outstanding by instrument (last access: March 3, 2014). Non-resident ownership data (last access: March 3, 2014).

- Indonesia: Source: Asian Development Bank and Indonesian Central Bank. Treasury bills are not included. Ownership data by interest rate types are not available. Links to raw data: Ownership data source: Asian Development Bank Asian Bond Online (last access: March 3, 2014). Domestic debt outstanding by interest rate type from Bank of Indonesia (last access: March 3, 2014).

- Israel: Ownership data: Bank of Israel. Data prior to 2011 are obtained directly from central bank officials. Treasury bills are included. Ownership data by interest rate type are not available. Link to data after 2011: Bank of Israel (last access: March 3, 2014). Link to domestic debt outstanding by coupon type (excel files): 2007 data,2008 data,2009 data,2010 data,2011 data,2012 data,2013 data

- Korea: Source: Asian Development Bank. Treasury bills are not included. Domestic debt is close to 100 percent fixed coupon nominal debt but ownership data by interest rate types are not available. Link to raw data: Ownership data source: Asian Development Bank Asian Bond Online (last access: March 3, 2014).

- Malaysia: Source: Asian Development Bank. Treasury bills are not included. Only 3-20 year Malaysian bonds are included. Domestic debt is close to 100 percent fixed coupon nominal debt but ownership data by interest rate types are not available. Link to raw data: Ownership data source: Asian Development Bank Asian Bond Online (last access: March 3, 2014).

- Mexico: Source: Central Bank of Mexico. Treasury bills are included. Ownership data by interest rate types are available. Link to raw data: Central Bank of Mexico (last access: March 3, 2014).

- Peru: Source: Peruvian Ministry of Finance. Treasury Bonds only. Ownership data at the level of individual bond are available. Dataset created by digitizing the pie charts in the PDFs in link "Tenencia de Bonos Soberanos" (in Spanish)

- Poland: Source: Polish Ministry of Finance. Includes both Treasury Bonds and Treasury Bills, and foreign ownership data of bonds by interest rate type . Link to raw data: Polish Ministry of Finance( last access: March 3, 2014).

- Russia: Source: Russian Central Bank and Ministry of Finance. Treasury bills are included. Ownership data by interest rate types are not available. Debt outstanding by interest rate type are not available. Links to raw data: External debt of Russian Federation and Government debt outstanding from the Ministry of Finance (last access: March 3, 2014).

- South Africa: Source: South African Central Bank. The annual data are directly obtained from central bank officials. Ownership data by interest rate type are not available. Debt outstanding data by interest rate type are not available. 
- Thailand: Source: Asian Development Bank. Treasury bills are included. Domestic debt is close to 100 percent fixed coupon nominal debt but ownership data by interest rate types are not available. Link to raw data: Ownership data source: Asian Development Bank Asian Bond Online (last access: March 3, 2014).

- Turkey: Source: Ministry of Finance. Treasury bills are included. Link to raw data: Ownership data and debt outstanding by interest rate types (last access: March 3, 2014).

\section{A.2.3 Estimation of Non-resident Holdings of LC Corporate Debt Securities using TIC Data}

The Treasury International Capital (TIC) data publishes U.S. portfolio holdings of foreign securities at the annual frequency. Table A13 of the TIC data publishes the market value of U.S. holdings of foreign debt securities with maturities longer than one year, by country, sector of issuance and currency denomination. We use the updated Table 13 recently compiled by Carol Bertaut and Alexandra Tabova at the Federal Reserve Board. The updated dataset extended Table 13 back to 2003 and corrected a few errors in the public data published on the Treasury website (http://www.treasury.gov/resource-center/data-chart-center/tic/Pages/windex.aspx).

Given the total non-resident holdings of LC government securities $A_{T O T}^{G}$ and the U.S. holdings of LC government securities in TIC $A_{U S}^{G}$, we can estimate the share of the U.S. holdings in total non-resident holdings of government securities as

$$
S_{U S / T O T}^{G}=A_{U S}^{G} / A_{T O T}^{G}
$$

We estimate a time-invariant $S_{U S / T O T}^{G}$ using the 10-year full sample. Alternatively, we can also use a time-varying share each year, which yields similar final results for the currency composition of corporate external portfolios.

To estimate the U.S. holdings of LC corporate debt securities, we assume that the share of the U.S. holdings in total non-resident holdings of EM corporate debt securities $\left(S_{U S / T O T}^{C}\right)$ is the same as the share of the U.S. holdings in total non-resident holdings of EM sovereign debt securities $\left(S_{U S / T O T}^{G}\right)$. Given the level of U.S. holdings of corporate LC debt securities $A_{U S, t}^{C}$, we estimate the total non-resident holdings of LC EM corporate securities as

$$
\hat{A}_{T O T}^{L C}=\frac{A_{U S}^{C}}{S_{U S / T O T}^{C}}=\frac{A_{U S}^{C}}{\left(A_{U S}^{G} / A_{T O T}^{G}\right)} .
$$

\section{A.2.4 Estimation of the Currency Composition of Cross-Border Loans using BIS LBS Data}

The BIS Locational Banking Statistics (LBS) provides quarterly data on cross-border financial claims and liabilities of banks resident in the BIS reporting countries. There are currently 22 BIS reporting countries for LBS, including all the major countries and offshore financial centers, such as Bermuda and Cayman Islands. Total cross-border claims of BIS reporting countries vis-a-vis an emerging market $i$ represents the bulk of country $i$ 's external liabilities from foreign banks.

The level of cross-border loans and deposits vis-a-vis individual emerging markets are available in Table 7A published on the BIS website: http://www.bis.org/statistics/bankstats.htm. In terms of the currency composition of the loans and deposits, the publicly available data publishes the currency breakdown of reporting banks at the aggregate level. We use the restricted version the BIS LBS, which contains more detailed data of the currency breakdown of BIS reporting banks' 
claims for individual counterparty location country. In particular, the BIS LBS reports cross-border loans and deposits originated by BIS reporting country banks vis-a-vis an emerging market $i$ in five major currencies (the dollar, euro, yen, British pound, and Swiss franc) and a residual currency category. We treat the residual currency as the LC of the emerging market, and all the major currencies as FC. 


\section{A.2.5 Country-Level Currency Composition of External Debt}

Figure A1: Currency Compositions of External Debt by Country, percentage
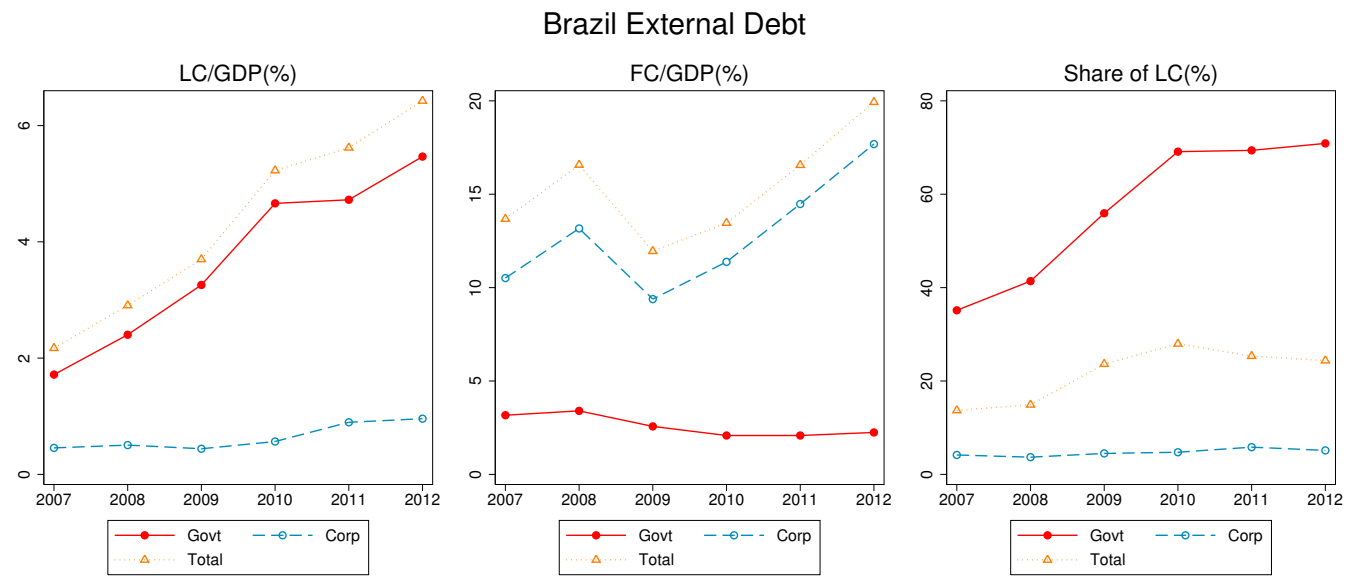

Colombia External Debt
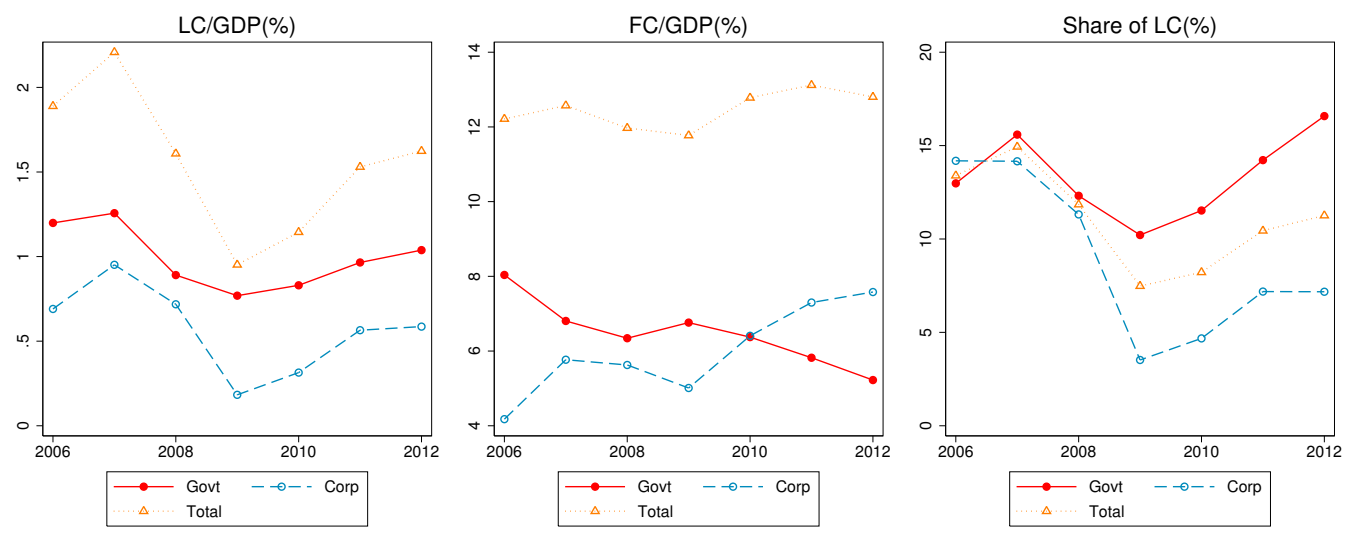

Hungary External Debt
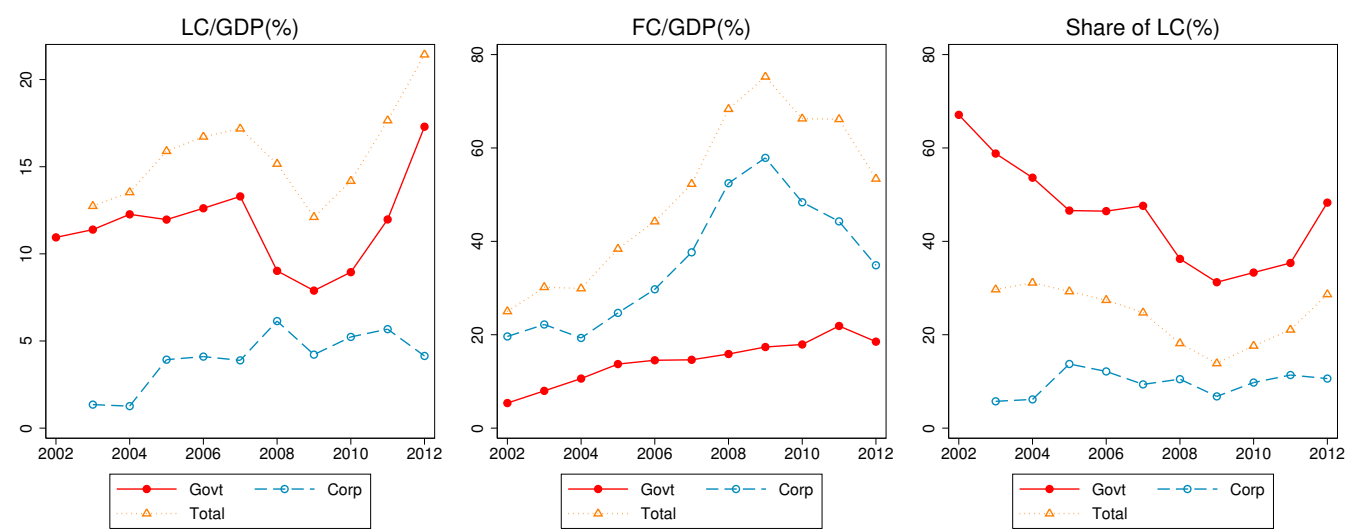
Figure A1: Sovereign debt structure by Country, percentage (continued) Indonesia External Debt
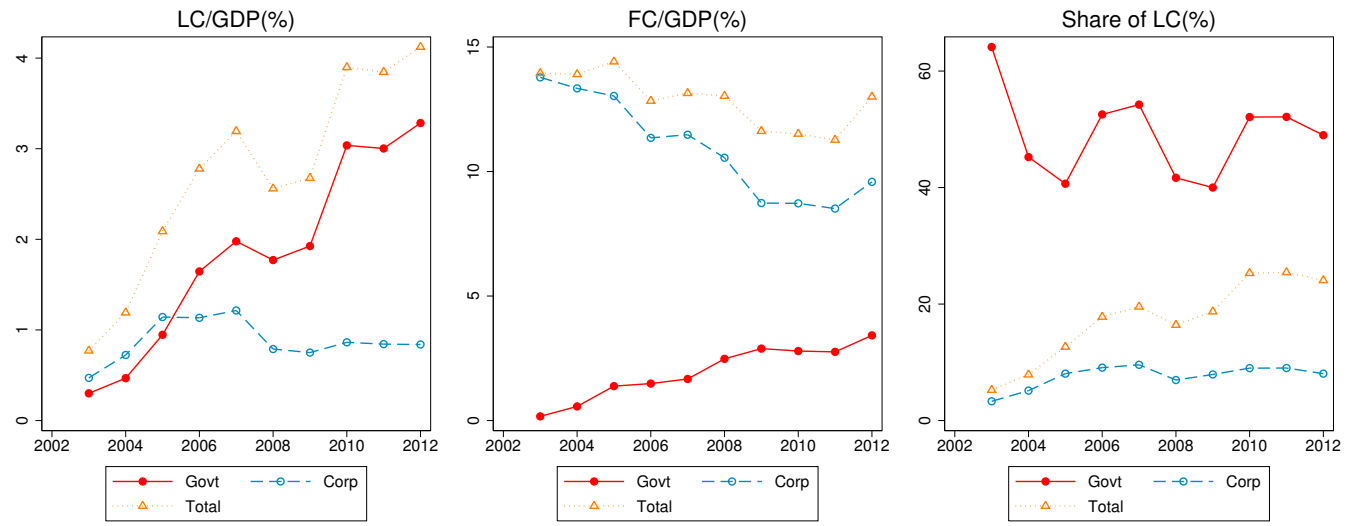

Israel External Debt
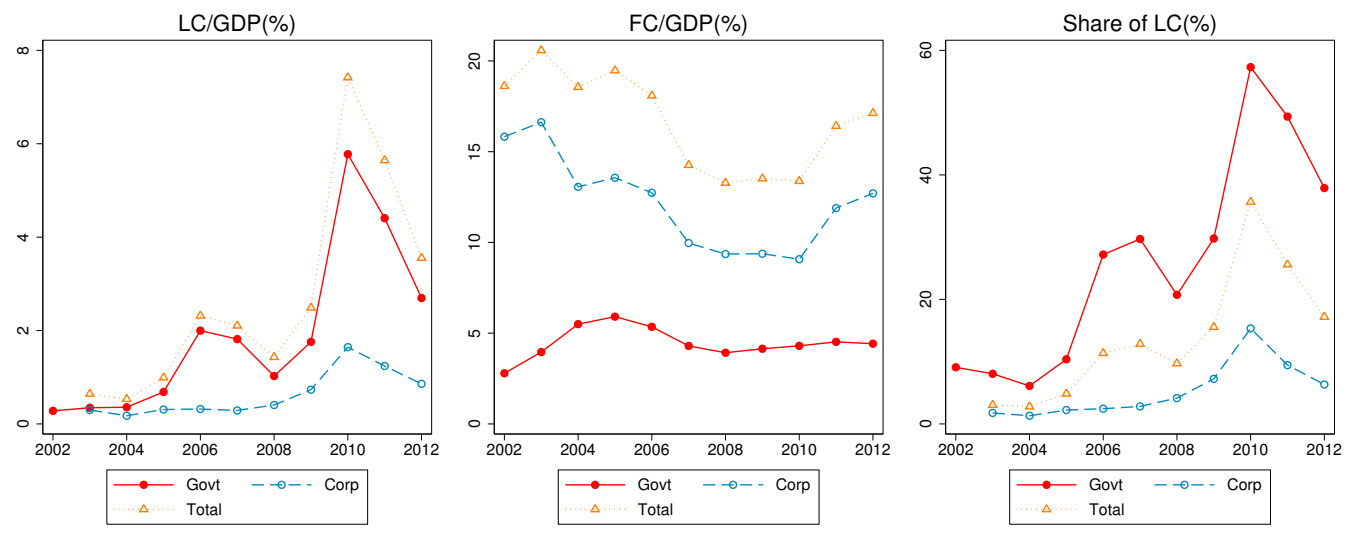

Korea External Debt
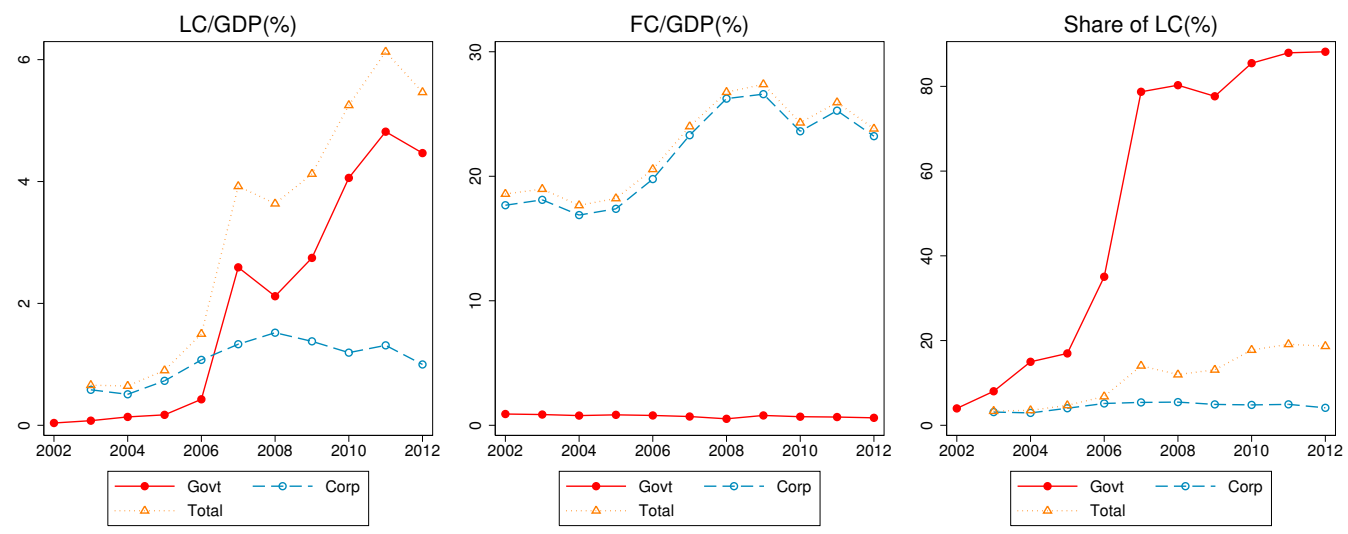
Figure A1: Sovereign debt structure by Country, percentage (continued) Malaysia External Debt
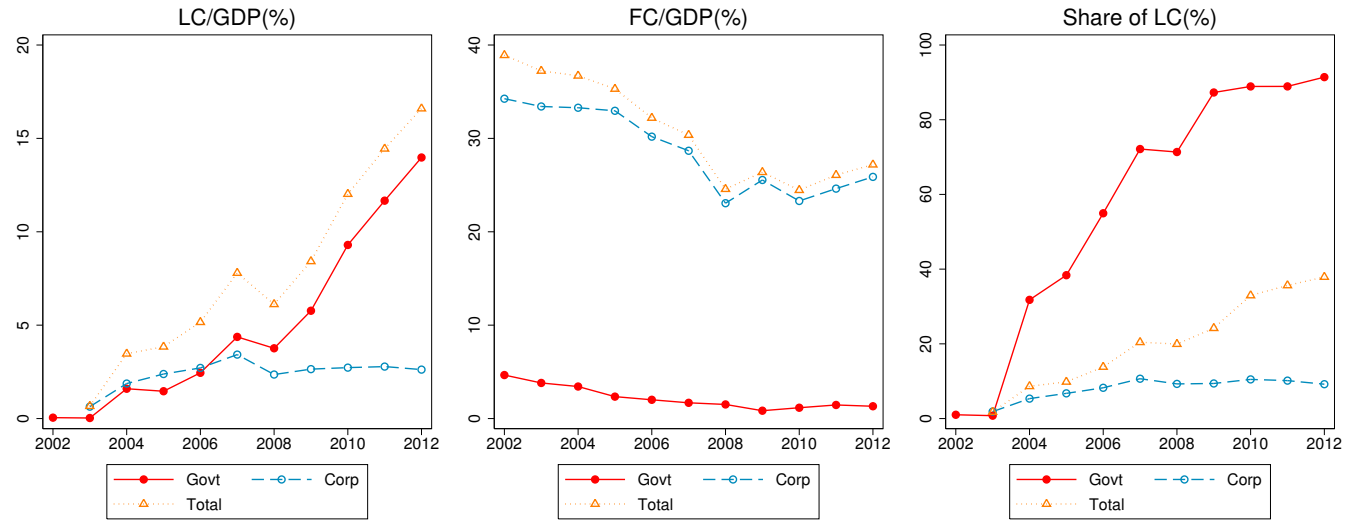

Mexico External Debt
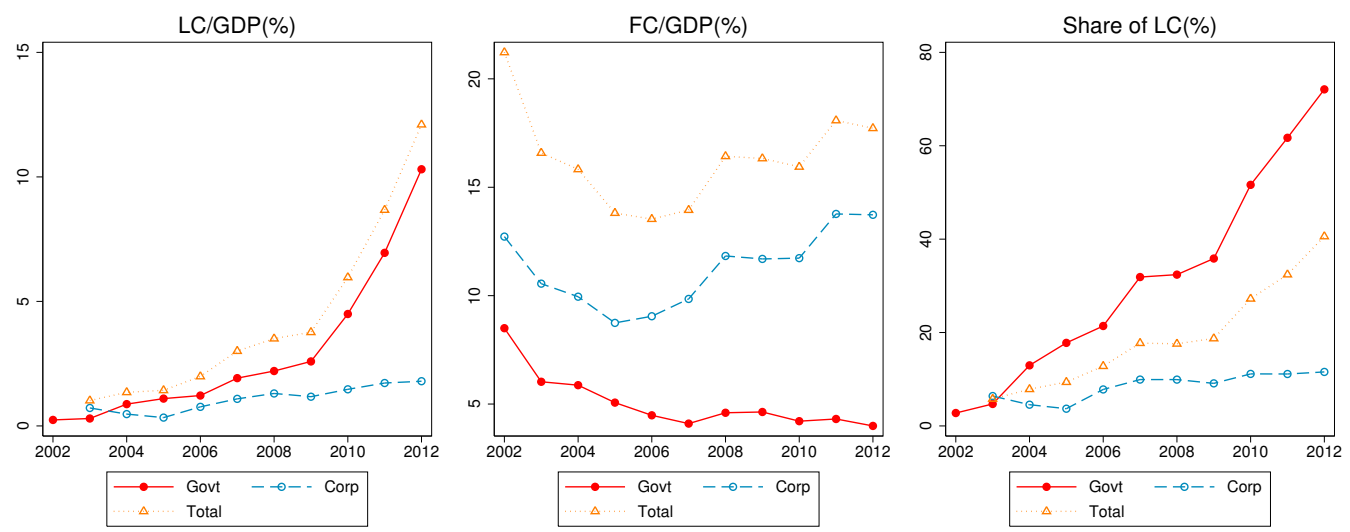

Peru External Debt
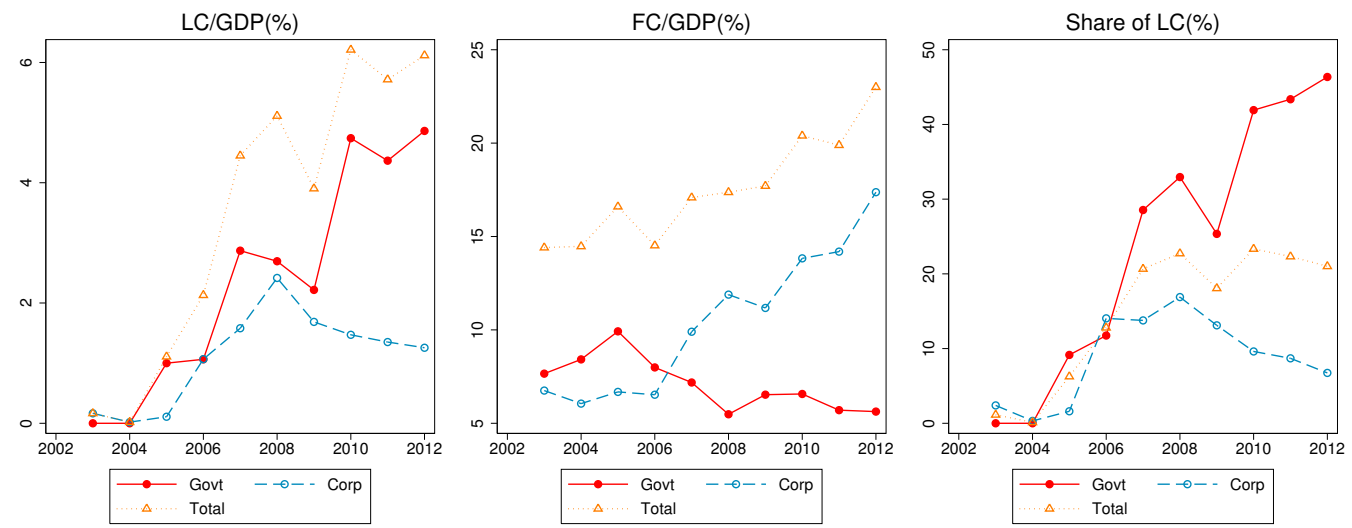
Figure A1: Sovereign debt structure by Country, percentage (continued)

Poland External Debt
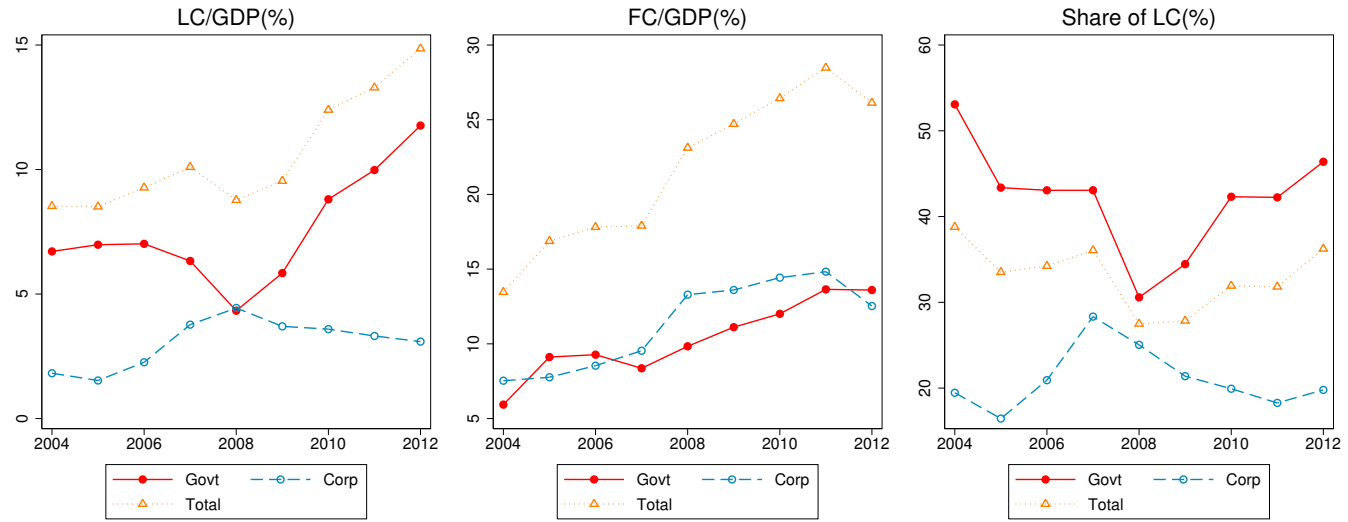

Russia External Debt
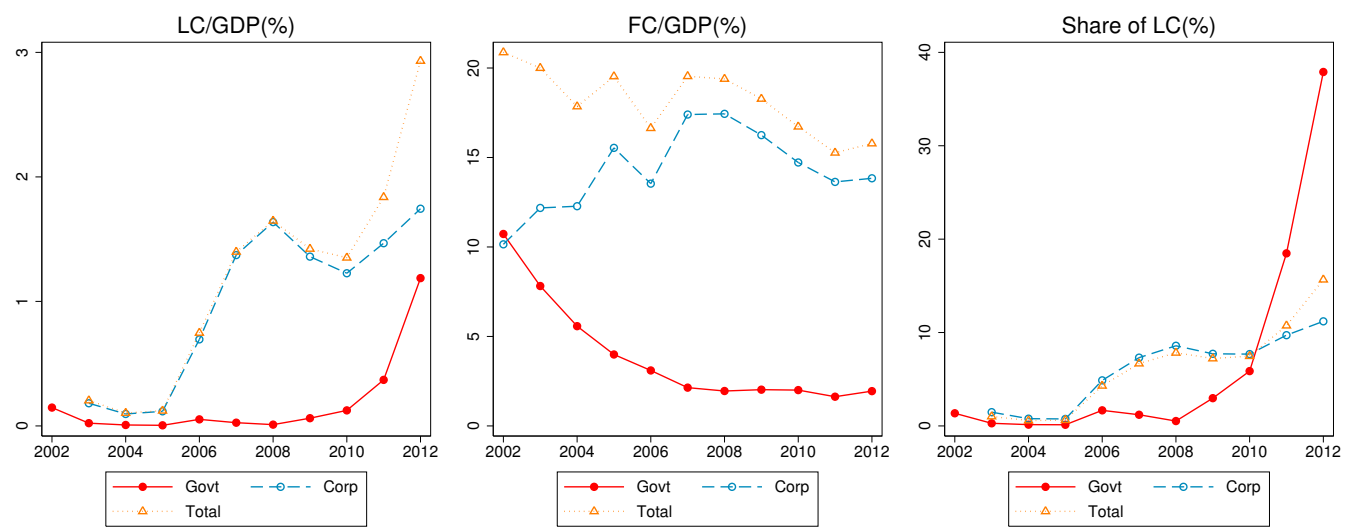

South_Africa External Debt
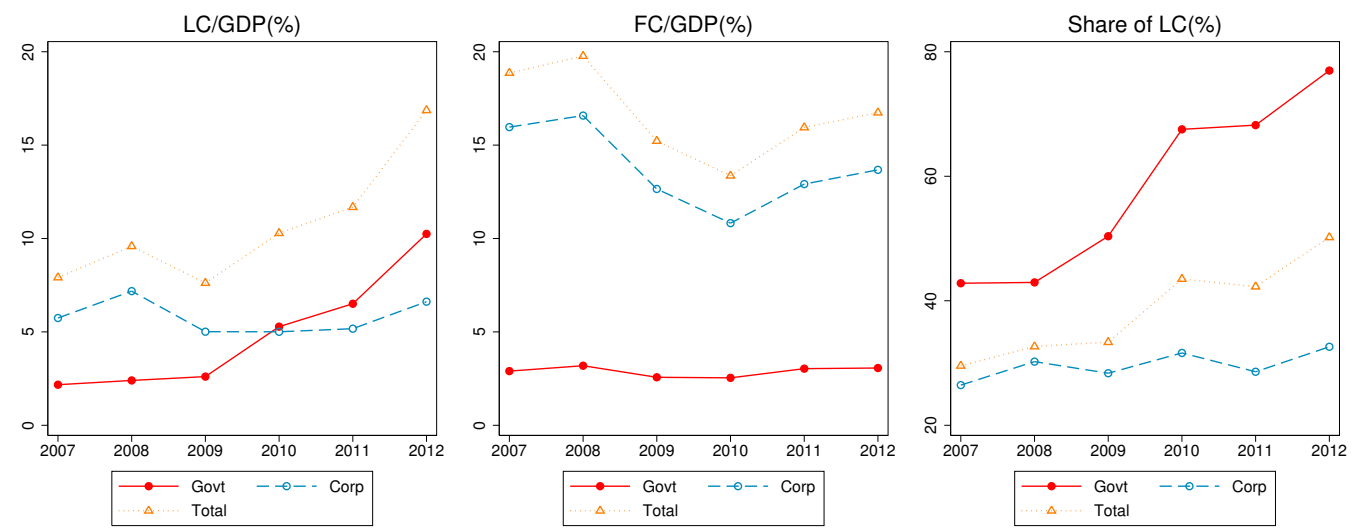
Figure A1: Sovereign debt structure by Country, percentage (continued)

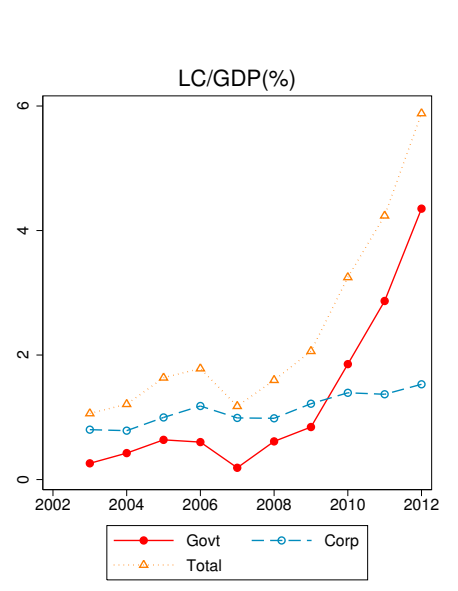

\section{Thailand External Debt}
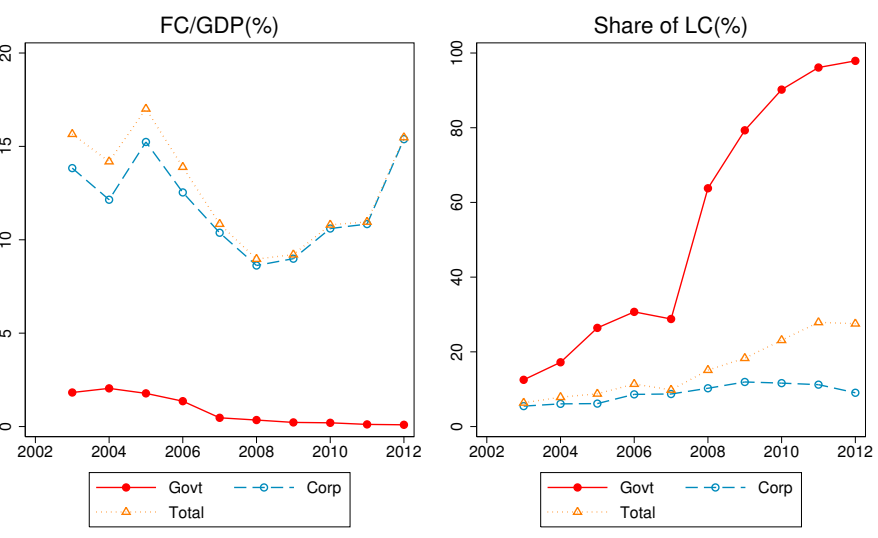

Turkey External Debt
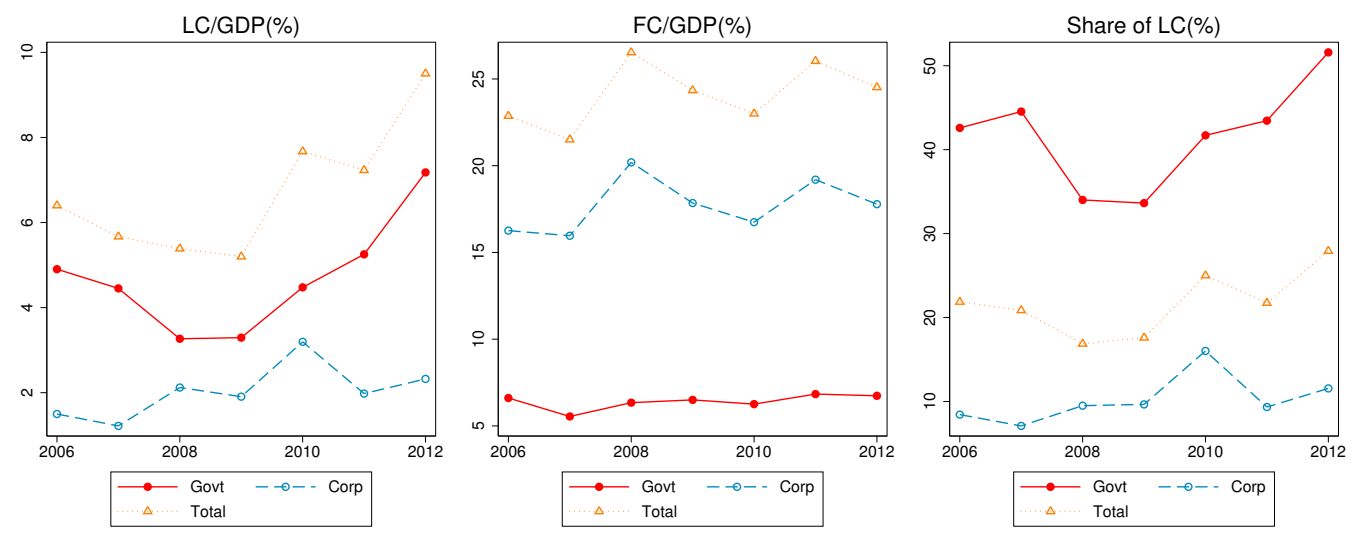

Notes: The first panel plots the amount of local currency external debt held by non-official lenders. The middle panel, FC/GDP (\%) is defined equivalently. The dotted orange line (Total) is the sum of corporate (Corp) and government (Govt) debt-to-GDP. Finally, the third panel is the share of each type of debt that is in local currency. The dotted orange line (Total) is the average of the share of corporate (Corp) and government (Govt) external debt in LC, weighted by the amount of each type of debt outstanding.

\section{A.3 Mexican and Brazilian Data}

The data on the currency composition of balance sheet data for Mexican firms come from Bloomberg. We began by running an equity search of all firms that list the country of risk as Brazil or Mexico. We then downloaded the balance sheet data for the every firm with an equity ticker. In particular, the key variables downloaded were "Debt in Foreign Currency" (Bloomberg Field BS_DEBT_INFOREIGN_CURR), "Total Liabilities" (Bloomberg Field BS_TOT_LIAB2") and "Total Assets" (Bloomberg Field BS_TOT_ASSET). Our key variable of interest, the Foreign Currency Liability Ratio ("FCLR") is then defined as the ratio of "Debt in Foreign Currency" to "Total Liabilities" or "Total Assets." Data for Brazil is consolidated but data for Mexico is unconsolidated.

For equity returns, we used the Bloomberg field "Total Return Index Gross of Dividends" (TOT_ RETURN_INDEX_GROSS_DVDS). We then compute quarterly returns by computing the change in the $\log$ of the total return index. We use the same definition for calculating the returns on the Brazilian and Mexican Equity Indices. Data on deposits rates are from Global Financial Data.

In order to look at changes in credit spreads, we have to go about matching firms to the debt that they issued. We begin by running a fixed income search ( $\mathrm{SRCH}<\mathrm{GO}>$ ) and find fixed coupon dollar 
denominated bonds issued by Brazilian and Mexican firms in Bloomberg. We can then download all available historical secondary market prices and yields for every bond. We use the mid yield to maturity on the bond for our analysis. Using Bloomberg's Excel Add-in, we can use the field BOND_TO_EQY_TICKER that provides the Bloomberg equity ticker for the firm that issued the fixed income instrument. This will be the firm identifier we use to match the bond prices to the balance sheet information of the issuing firm.

To compute the credit spread, we compute the remaining maturity on the bond at each point in time. We then use the Gurkaynak et al. (2007) coefficients to compute the yield to maturity on a US Treasury bond of the same maturity and define the spread as the difference between the two yields. We drop all bonds where the yield to maturity is negative, the spread is less than negative 50 basis points, the yield to maturity is over $1,000 \%$, or there is less than one quarter remaining until the bond matures.

We use the log of market capitalization for our measure of firm size (Bloomberg field HISTORICAL_MARKET_CAP). For the market to book ratio, we used the market to value to book value ratio per share (Bloomberg field PX_TO_BOOK_RATIO).

\section{A.4 Possibility of FX Derivative Hedging}

Comprehensive data on corporate FX derivative usage rarely exist, even for developed countries. ${ }^{33}$ It is even more challenging to estimate the degree of FX derivative hedging used by emerging market firms. We examine aggregate statistics on FX derivative and FC debt outstanding at the country level, and argue that the size of the derivative market in emerging markets is significantly smaller than total FC debt for most emerging markets. Therefore, firms do not fully hedge their FC liabilities using FX derivatives.

Cross currency swaps (CCS) provide a natural way for firms to hedge against FC fixed income liabilities. Depositary Trust \& Clearing Corporation (DTCC) started publishing global CCS derivative outstanding amounts by currency for the top 20 currencies very recently. Table A2 compares total CCS outstanding reported by DTCC and FC debt outstanding based on our estimation in 2012. Among 14 sample countries, 7 currencies are ranked as top 20 currencies in terms of CCS outstanding, so exact amounts are reported. The remaining 7 currencies by definition have a lower amount outstanding than the top 20 currencies, and so we can infer that they have CCS outstanding less than $\$ 25$ billion, the lowest reporting amount for the 20th ranked currency. We compare CCS outstanding amounts with FC liabilities by country. With exceptions of Turkey and South Africa, all the other 12 sample countries have total FC debt outstanding greater than total CCS outstanding.

Furthermore, we know that not all the CCS outstanding is used for corporate FX derivative hedging. According to the BIS Semiannual OTC Derivative Survey, about half of the currency swap outstanding is inter-dealer in nature. ${ }^{34}$ This inter-dealer exposure likely represents market making and proprietary trading related activities in LC rates markets. In addition, portfolio investors also use CCS to hedge their long-term currency exposure on LC denominated assets. Therefore, it is very plausible that total CCS outstanding amounts vastly overestimate the actual amount of FX hedging of $\mathrm{FC}$ corporate debt.

\footnotetext{
${ }^{33}$ Australia is the single exception, where comprehensive surveys are conducted regarding FX derivates used by firms.

${ }^{34}$ BIS surveys do not report FX derivative outstanding for individual emerging market currencies.
} 
Figure A2: CCS and FC Debt Outstanding in 2012 ( $\$$ billions)

\begin{tabular}{cccc}
\hline & $(1)$ & $(2)$ & $(3)$ \\
Currency & CCS Notional & Corp FC & Govt FC \\
\hline \multicolumn{4}{c}{ Reporting Currencies } \\
TRY & 320 & 136 & 58 \\
RUB & 83 & 288 & 41 \\
KRW & 76 & 272 & 10 \\
ZAR & 67 & 51 & 11 \\
MXN & 67 & 161 & 49 \\
HUF & 53 & 44 & 23 \\
PLN & 53 & 64 & 70 \\
\hline & Non-Reporting Currencies & \\
BRL & $<25$ & 370 & 58 \\
COP & $<25$ & 26 & 21 \\
IDR & $<25$ & 78 & 32 \\
ILS & $<25$ & 34 & 11 \\
MYR & $<25$ & 78 & 5 \\
PEN & $<25$ & 35 & 12 \\
THB & $<25$ & 57 & 0.3 \\
\hline
\end{tabular}

Notes: CCS notional outstanding from Table 3 in the DTCC Trade Information Warehouse: Link. Corporate FC and Government FC data from the dataset constructed in Section 3.

\section{A.5 Debt Duration}

Table A2: LC Debt Duration

\begin{tabular}{cccccccccccc}
\hline Year & 2002 & 2003 & 2004 & 2005 & 2006 & 2007 & 2008 & 2009 & 2010 & 2011 & 2012 \\
\hline Brazil & 1.95 & 2.17 & 2.01 & 2.02 & 2.23 & 2.69 & 2.80 & 2.85 & 2.85 & 2.96 & 3.13 \\
Colombia & & 3.42 & 3.47 & 3.25 & 3.25 & 3.54 & 3.63 & 4.41 & 4.44 & 4.49 & 4.60 \\
Hungary & 3.25 & 3.53 & 3.65 & 3.69 & 3.62 & 3.61 & 3.19 & 2.42 & 2.54 & 3.06 & 2.88 \\
Indonesia & & 5.03 & 5.85 & 4.95 & 5.35 & 5.86 & 5.59 & 5.45 & 6.25 & 7.11 & 7.56 \\
Malaysia & 3.79 & 4.58 & 4.59 & 4.62 & 4.78 & 4.89 & 4.90 & 4.83 & 4.15 & 4.75 & 5.04 \\
Mexico & 2.15 & 2.27 & 2.50 & 2.97 & 3.75 & 4.53 & 5.13 & 5.11 & 5.82 & 5.99 & 6.14 \\
Peru & & & & & 7.87 & 10.41 & 9.78 & 10.78 & 10.14 & 9.81 & 9.46 \\
Poland & 2.49 & 2.46 & 2.97 & 3.29 & 3.49 & 3.85 & 3.83 & 3.75 & 3.89 & 3.89 & 4.03 \\
Russia & & & & 5.96 & 6.60 & 6.82 & 6.46 & 5.74 & 4.66 & 5.07 & 5.26 \\
South Africa & 6.24 & 6.11 & 6.31 & 6.38 & 6.33 & 6.19 & 7.46 & 7.06 & 7.30 & 7.74 & 8.19 \\
Thailand & & 5.43 & 5.15 & 4.84 & 4.72 & 5.03 & 5.33 & 5.16 & 5.29 & 5.94 & 6.81 \\
Turkey & & & 1.37 & 1.57 & 1.51 & 1.05 & 1.54 & 1.70 & 2.27 & 2.22 & 2.38 \\
\hline Median & 3.25 & 4.05 & 3.65 & 4.15 & 4.72 & 4.96 & 5.02 & 5.14 & 4.98 & 5.51 & 5.69
\end{tabular}

Approximation of Macaulay duration of outstanding debt. Average maturity of the debt from BIS Securities Statistics and maturity weighted yield from JP Morgan EMBI. Assumption that coupons are paid annually.

\section{A.6 Panel Regression}




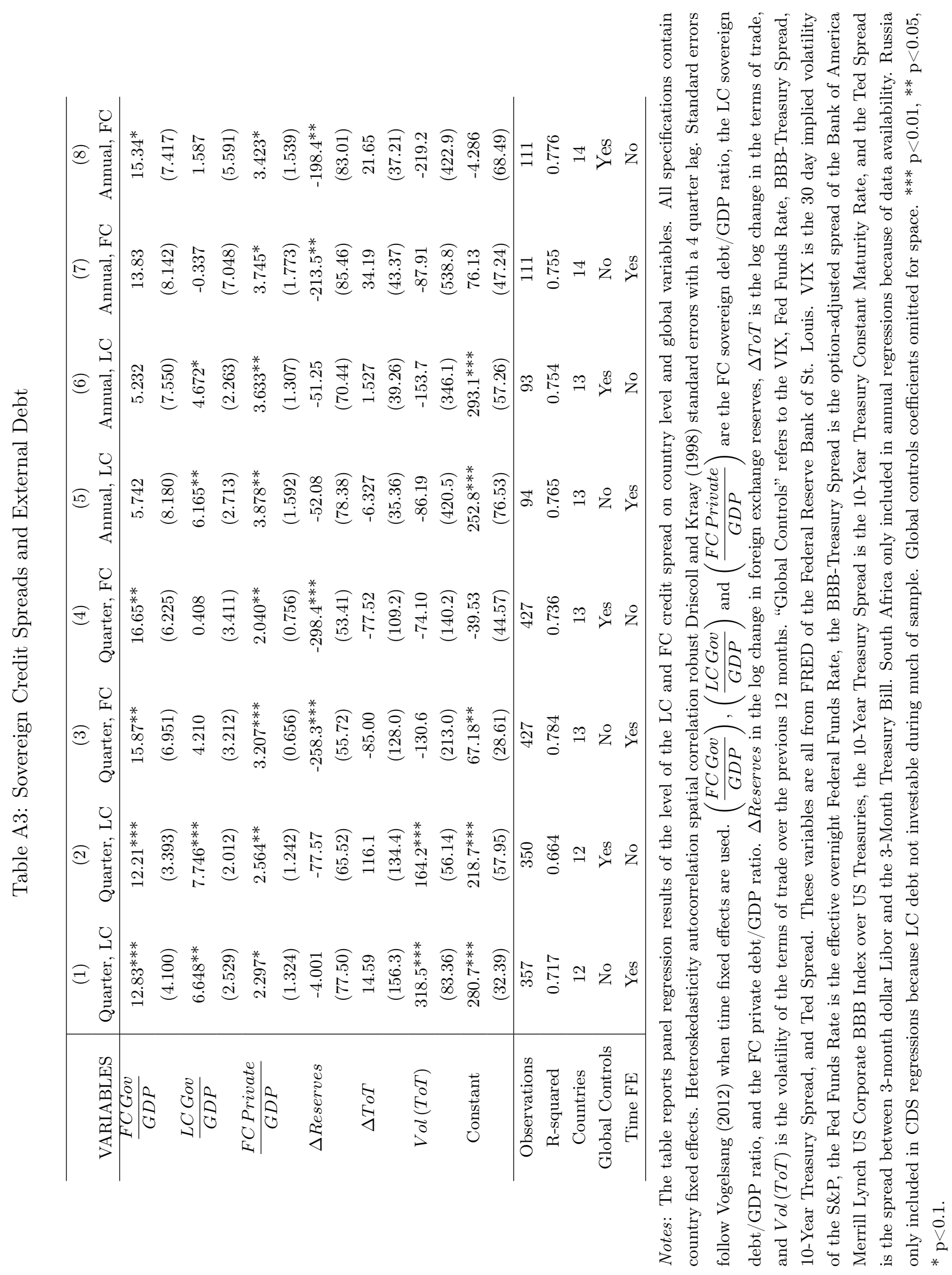




\section{B Theory Appendix}

\section{B.1 Bond Pricing}

In this section, we present the steps to price defaultable LC debt as in section 5.1 and default-free

LC debt as in section 5.2. As discussed in the text, the bond promises LC cash flows of

$$
P_{t} \kappa\left[1, \delta, \delta^{2}, \ldots\right]
$$

A foreign investor values these LC cash flows in FC by dividing through by the price level

$$
\kappa\left[\frac{P_{t}}{P_{t+1}}, \delta \frac{P_{t}}{P_{t+2}}, \delta^{2} \frac{P_{t}}{P_{t+3}}, \ldots\right] .
$$

To price the bond, the investors again calculates present value of the expectation of the cash flows

$$
\begin{aligned}
q_{t}^{L C} & =E_{t}\left[\frac{\kappa \cdot\left(1-D_{t+1}\right)\left(1-\zeta_{t+1}\right)}{1+r^{*}}+\frac{\delta \kappa \cdot\left(1-D_{t+1}\right)\left(1-D_{t+2}\right)\left(1-\zeta_{t+1}\right)\left(1-\zeta_{t+2}\right)}{\left(1+r^{*}\right)^{2}}+\ldots\right] \\
& =E_{t}\left[\frac{\kappa \cdot\left(1-D_{t+1}\right)\left(1-\zeta_{t+1}\right)}{1+r^{*}}+\frac{\delta \kappa \cdot \prod_{j=1}^{2}\left(1-D_{t+j}\right)\left(1-\zeta_{t+j}\right)}{\left(1+r^{*}\right)^{2}}+\frac{\delta^{2} \kappa \cdot \prod_{j=1}^{3}\left(1-D_{t+j}\right)\left(1-\zeta_{t+j}\right)}{\left(1+r^{*}\right)^{3}} \ldots\right] \\
& =E_{t}\left[\sum_{s=0}^{\infty}\left(\prod_{j=1}^{s+1}\left(1-D_{t+j}\right)\left(1-\zeta_{t+j}\right)\right) \frac{\kappa \delta^{s}}{\left(1+r^{*}\right)^{1+s}}\right] \\
& =E_{t}\left[\left(1-D_{t+1}\right)\left(1-\zeta_{t+1}\right) \frac{\kappa}{1+r^{*}}+\left(1-D_{t+1}\right)\left(1-\zeta_{t+1}\right) \sum_{s=1}^{\infty}\left(\prod_{j=2}^{s+1}\left(1-D_{t+j}\right)\left(1-\zeta_{t+j}\right)\right) \frac{\kappa \delta^{s}}{\left(1+r^{*}\right)^{1+s}}\right] \\
& =E_{t}\left[\frac{\left(1-D_{t+1}\right)\left(1-\zeta_{t+1}\right)}{1+r}\left(\kappa+\delta\left(\sum_{s=0}^{\infty}\left(\prod_{j=1}^{s+1}\left(1-D_{t+1+j}\right)\left(1-\zeta_{t+1+j}\right)\right) \frac{\kappa \delta^{s}}{\left(1+r^{*}\right)^{1+s}}\right)\right)\right] \\
& =\frac{E_{t}\left[\left(1-D_{t+1}\right)\left(1-\zeta_{t+1}\right)\left(\kappa+\delta q_{t+1}^{L C}\right)\right]}{1+r^{*}}
\end{aligned}
$$

where once again the last step uses the initial definition of $q_{t}^{L C}$. When we have $\delta=0$, and so we have one period debt, this becomes $q_{t}^{L C}=\kappa \frac{E_{t}\left[\left(1-D_{t+1}\right)\left(1-\zeta_{t+1}\right)\right]}{1+r^{*}}$.

Finally, we turn to pricing a default-free LC bond. While this bond has the same promised cash flows as the defaultable LC bond, the lender continues to receive the coupon payments in the event of a sovereign default. To price the bond, the lender calculates the discounted present value of the debt: 


$$
\begin{aligned}
& q_{t}^{* L C}=E_{t}\left[\frac{\kappa \cdot\left(1-\zeta_{t+1}\right)}{1+r^{*}}+\frac{\delta \kappa \cdot\left(1-\zeta_{t+1}\right)\left(1-\zeta_{t+2}\right)}{\left(1+r^{*}\right)^{2}}+\ldots\right] \\
& q_{t}^{* L C}=E_{t}\left[\frac{\kappa \cdot\left(1-\zeta_{t+1}\right)}{1+r^{*}}+\frac{\delta \kappa \cdot \prod_{j=1}^{2}\left(1-\zeta_{t+j}\right)}{\left(1+r^{*}\right)^{2}}+\frac{\delta^{2} \kappa \cdot \prod_{j=1}^{3}\left(1-\zeta_{t+j}\right)}{\left(1+r^{*}\right)^{3}} \ldots\right] \\
& q_{t}^{* L C}=E_{t}\left[\sum_{s=0}^{\infty}\left(\prod_{j=1}^{s+1}\left(1-\zeta_{t+j}\right)\right) \frac{\kappa \delta^{s}}{\left(1+r^{*}\right)^{1+s}}\right] \\
& q_{t}^{* L C}=E_{t}\left[\left(1-\zeta_{t+1}\right) \frac{\kappa}{1+r^{*}}+\left(1-\zeta_{t+1}\right) \sum_{s=1}^{\infty}\left(\prod_{j=2}^{s+1}\left(1-\zeta_{t+j}\right)\right) \frac{\kappa \delta^{s}}{\left(1+r^{*}\right)^{1+s}}\right] \\
& q_{t}^{* L C}=E_{t}\left[\left(1-\zeta_{t+1}\right) \frac{\kappa}{1+r^{*}}+\frac{\delta}{1+r}\left(1-\zeta_{t+1}\right)\left(\sum_{s=0}^{\infty}\left(\prod_{j=1}^{s+1}\left(1-\zeta_{t+1+j}\right)\right) \frac{\kappa \delta^{s}}{\left(1+r^{*}\right)^{1+s}}\right)\right] \\
& q_{t}^{* L C}=E_{t}\left[\frac{\left(1-\zeta_{t+1}\right)}{1+r}\left(\kappa+\delta\left(\sum_{s=0}^{\infty}\left(\prod_{j=1}^{s+1}\left(1-\zeta_{t+1+j}\right)\right) \frac{\kappa \delta^{s}}{\left(1+r^{*}\right)^{1+s}}\right)\right)\right] \\
& q_{t}^{* L C}=\frac{E_{t}\left[\left(1-\zeta_{t+1}\right)\left(\kappa+\delta q_{t+1}^{* L C}\right)\right]}{1+r^{*}}
\end{aligned}
$$

where once again the last step uses the initial definition of $q_{t}^{* L C}$. It is important to note that this bond price schedule does not affect the sovereign's decision in equilibrium and so, unlike the defaultable bond price schedule $q^{L C}$, this fixed point problem can be solved after the policy functions have been solved for. As discussed in the text, to calculate this expectation we need to price the default-free LC debt in states in which the sovereign has defaulted, accounting for stochastic re-entry into credit markets. Using the subscript $D$ to indicate default and $R$ to indicate repayment, we can write the expression for equation 10 .

$$
\begin{aligned}
q_{R}^{* L C}\left(A, b^{\prime}\right) & =\frac{E\left[(1-\zeta(\cdot))\left(\kappa+\delta\left(\left(1-D\left(A^{\prime}, b^{\prime}\right)\right)\left(q_{R}^{* L C}\left(A^{\prime}, b^{\prime \prime}\left(A^{\prime}, b^{\prime}\right)\right)\right)+D\left(A^{\prime}, b^{\prime}\right) q_{D}^{* L C}\left(A^{\prime}\right)\right)\right) \mid A, b^{\prime}\right]}{1+r^{*}} \\
q_{D}^{* L C}(A) & =\frac{\kappa+\delta E\left[\lambda q_{R}^{* L C}\left(A^{\prime}, 0\right)+(1-\lambda) q_{D}^{* L C}\left(A^{\prime}\right) \mid A, b^{\prime}\right]}{1+r^{*}}
\end{aligned}
$$

The expressions for the expectation of $q_{t+1}^{* L C}$ beginning from good and bad credit standing can be found in the text.

\section{B.1.1 Laffer Curves}

As discussed in the text, we focus our discussion on the stock Laffer curve, $q \cdot b^{\prime}$, rather than the issuance Laffer curve $q \cdot\left(b^{\prime}-(1-\zeta) \delta b\right)$, for intuition. Here, we briefly discuss why this is sufficient in practice. While the sovereign could potentially find it optimal to issue debt past the peak of the stock Laffer curve and up the peak of the issuance Laffer curve, this is the not the case for the policy functions from our calibration. In Figure A3, we plot the stock and issuance Laffer curves for the case that the sovereign issued $7.5 \%$ of debt-to-average-GDP last period, and productivity is at its mean level. Of course, the stock Laffer curve is independent of the amount of inherited debt. For the case when $\alpha_{P}=10 \%$ (first figure, top panel), we see the peak of the stock and issuance 
Laffer curves are very close together. This is because the bond price schedule is sufficiently steep that additional bond issuance at the peak of the stock Laffer curve fails to raise additional revenue. In the second figure of the first panel, we see that the credit share at the peak of the issuance Laffer curve is slightly higher than at the peak of the stock Laffer curve.

In the second set of figures, where $\alpha_{P}=50 \%$, we see in the top figure that there is now a fairly significant difference between the peak of the stock and issuance Laffer curves, with the issuance Laffer curve peaking after nearly $1.5 \%$ of GDP of additional borrowing. This is because the bond price schedule is less steep when the primary risk is inflation rather than default, and so there is a wide region where the debt dilution effects overwhelm the price fall. In the second figure, we can even see there is a small amount of credit risk at the peak of the issuance Laffer curve that is not present in the share Laffer curve. While the difference between these two curves makes it is potentially important to look at the issuance Laffer curve, in Figure A4, we see this is not the case for our calibration.

The first two panels of this figure plot debt issuance at the debt level that would cause the stock and issuance debt Laffer curves to peak, along with the equilibrium bond issuance policy function $\tilde{b}(\bar{A}, b)$ for average productivity. The 45 degree line is plotted to indicate when $\tilde{b}(\bar{A}, b)>b$. The left panel in the top row plots the case when $\alpha_{P}=10 \%$ and the right panel plots the case when $\alpha_{P}=50 \%$. The bond issuance that causes the stock Laffer curve to peak is the same regardless of $b$ and is therefore a horizontal line. The key result from the figure is that the sovereign does not choose to borrow past the peak of the stock Laffer curve when it begins on the increasing side of the stock Laffer curve. When we look at the right panel with $\alpha_{P}=50 \%$, we see that in equilibrium, the government's optimal policy keeps it below the peak of the stock Laffer curve and never comes close to approaching the peak of the issuance Laffer curve. In other words, the steepness of the bond price schedule as the sovereign approaches the peak of the stock Laffer curve makes the sovereign find it optimal to curtail its borrowing. 
Figure A3: Stock and Issuance Laffer Curves, $b=7.5 \% / \bar{Y}$
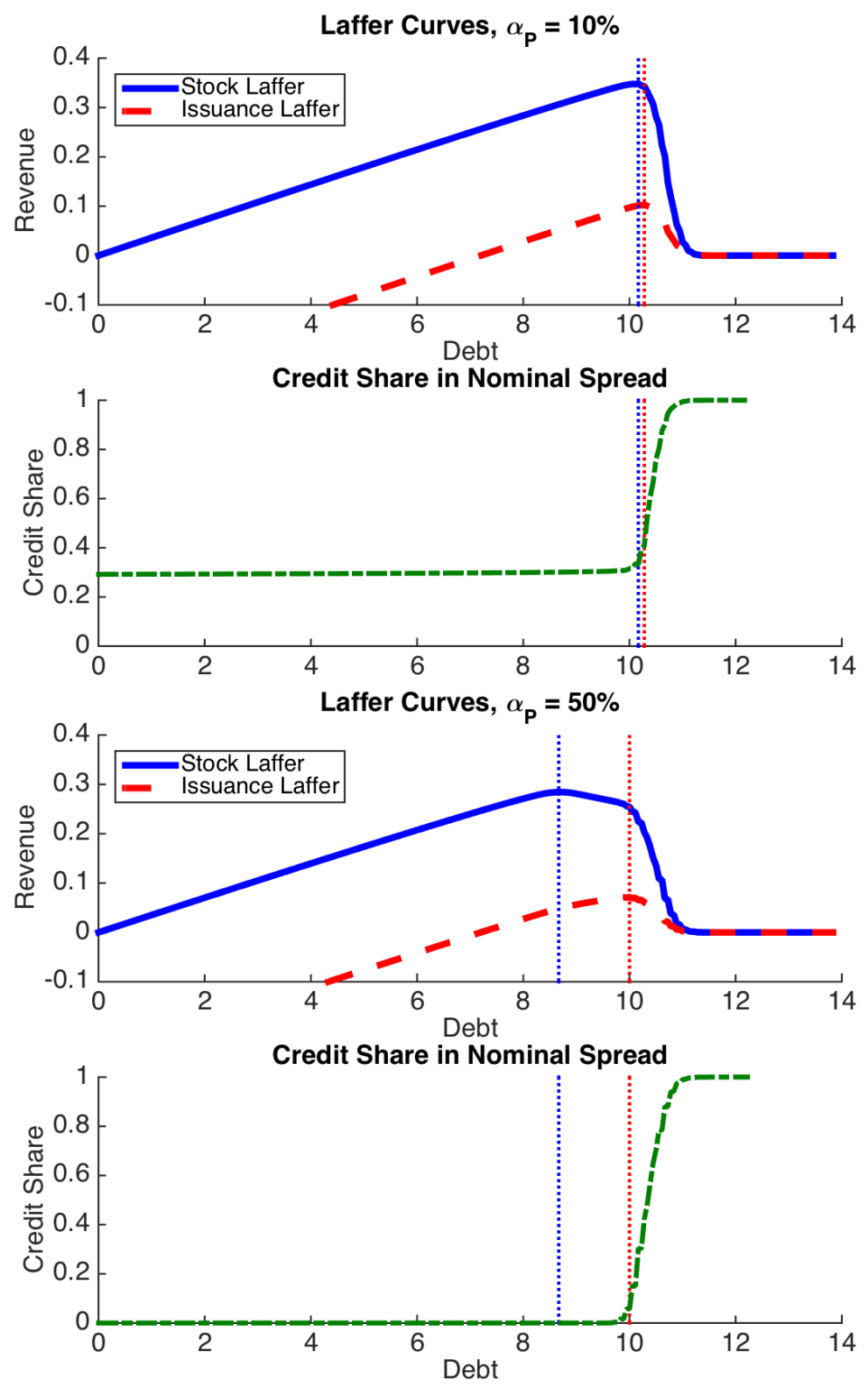

Notes: In both sets of plots, we consider the case when $A=\bar{A}$ and the sovereign issued $7.5 \%$ debt/GDP last period. The first pair of charts are for the case when $\alpha_{P}=10 \%$ and the second when $\alpha_{P}=50 \%$. The top figure in each of the two sets plots the stock and issuance Laffer curve, with the dashed vertical lines indicating the borrowing level at the peak of the two debt Laffer curves. The bottom figure in each set plots the credit share $s^{L C C S} / s^{L C / U S}$ for each set level of debt issuance, with the vertical lines denoting the borrowing level at the peak of both types of debt Laffer curve. 
Figure A4: Debt Levels and Credit Shares at Peak of Laffer Curve
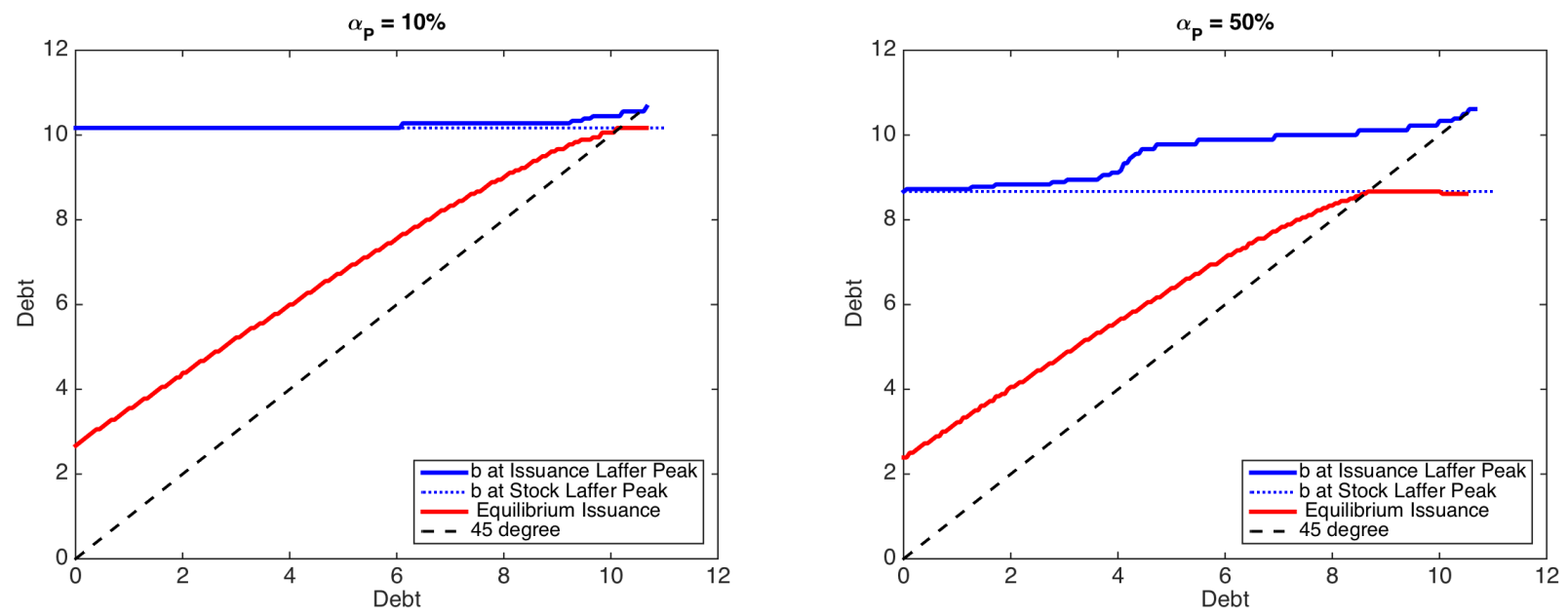

Notes: The first 2 panels of this figure plot debt issuance at the debt level that would cause the stock and issuance debt Laffer curves to peak, along with the equilibrium bond issuance policy function $\tilde{b}(\bar{A}, b)$ for average productivity. The 45 degree is plotted to indicate when $\tilde{b}(\bar{A}, b)>b$. The left panel in the top row plots the case when $\alpha_{P}=10 \%$ and the right panel plots the case when $\alpha_{P}=50 \%$. The bond issuance that causes the stock Laffer curve to peak is the same regardless of $b$ and is therefore a horizontal line. 